NIST Technical Note 2092

\title{
Estimating the Impact of 16 CFR Part 1633 on Bed Fire Outcomes
}

Stanley W. Gilbert

David T. Butry

Rick D. Davis

Richard G. Gann

This publication is available free of charge from:

https://doi.org/10.6028/NIST.TN.2092

National Institute of Standards and Technology

U.S. Department of Commerce 
This page was intentionally left blank. 


\title{
Estimating the Impact of 16 CFR Part 1633 on Bed Fire Outcomes
}

\author{
Stanley W. Gilbert \\ David T. Butry \\ Office of Applied Economics \\ Engineering Laboratory
}

Rick D. Davis

Richard G. Gann, Emeritus

Fire Research Division

Engineering Laboratory

This publication is available free of charge from:

https://doi.org/10.6028/NIST.TN.2092

April 2020

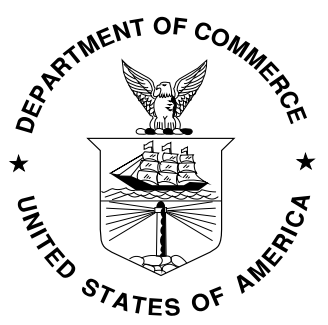

U.S. Department of Commerce Wilbur L. Ross, Jr., Secretary

National Institute of Standards and Technology Walter Copan, NIST Director and Undersecretary of Commerce for Standards and Technology 
Certain commercial entities, equipment, or materials may be identified in this document in order to describe an experimental procedure or concept adequately. Such identification is not intended to imply recommendation or endorsement by the National Institute of Standards and Technology, nor is it intended to imply that the entities, materials, or equipment are necessarily the best available for the purpose.

National Institute of Standards and Technology Technical Note 2092

Natl. Inst. Stand. Technol. Tech. Note 2092, 73 pages (April 2020) CODEN: NTNOEF

This publication is available free of charge from:

https://doi.org/10.6028/NIST.TN.2092 


\begin{abstract}
Effective July 1, 2007, the U.S. Consumer Product Safety Commission promulgated a Standard that would severely reduce the heat release rate and the early heat output from mattresses and foundations that had been ignited by a flaming ignition source. Mattresses complying with this Standard have now been sold for more than a decade. This study establishes a methodology for evaluating the effect of this Standard on the number of bed fires and the extent of their fire spread, fatalities, and injuries, and then estimates the Standard's success over its first decade. Because it is possible there were changes other than the Standard that affected the outcome of bed fires, the study normalized the changes to the numbers of residential upholstered furniture (RUF) fires, all residential fires, and all bed fires.

The Standard is accomplishing its purpose, resulting in considerable reductions in fatalities and injuries from bed fires ignited by flaming sources. Approximately 65 fatalities were prevented annually during the two-year period 2015-2016. Relative to RUF fires, flaming ignitions of beds led to decreases in the numbers of fires by $12 \%$, injuries by $34 \%$, and deaths by $82 \%$ between 2005-2006 and 2015-2016. Per bed fire, injuries decreased by $25 \%$ and fatalities decreased by $67 \%$. The decreases in injuries and, especially, fatalities are larger than the decrease in the number of fires, suggesting that the most severe fires are being prevented by the Standard.

There was no systematic evidence that the calculations were significantly affected by (1) the calculation method for calculating the replacement rate of pre-Standard mattresses, (2) variability in fire reporting among fire departments, (3) whether the initial combustible was reported as the mattress or bedding, or (4) whether the mattress or bedding was reported as the item most contributing to flame spread.
\end{abstract}

Key Words: bed fires; fires; fire data; fire deaths; fire injuries; fire standard effectiveness; fire standards; home fires; mattress fires; 16 CFR Part 1633 


\section{Executive Summary}

\section{Context and Methodology}

Effective July 1, 2007, the Consumer Product Safety Commission (CPSC) promulgated a standard for mattress flammability for flaming ignitions, 16 CFR Part 1633. This Technical Note documents a methodology for quantifying the effects of this standard on the number of reported bed fires in residential structures and the numbers of associated occupant deaths and injuries. We then use this methodology to calculate changes in the losses from bed fires between 2005-2006, the last two years before compliant mattresses were sold, and 20152016, the most recent two years when national fires losses were available. This methodology can be extended to future years as additional fire incidence data become available.

Beds have historically been one of the two most hazardous combustibles in fatal residential fires, residential upholstered furniture (RUF) being the other. A bed typically consists of a mattress, a foundation, and an assembly of covers and pillows collectively referred to as bedding. Typically, the bedding surrounds the mattress and is the initial site of an ignition.

A person in the bed at the time of ignition is at risk even when the fire is confined to the bed itself. Then, as the fire grows, it can ignite other furnishings and render the room untenable. The fire can also lead to room flashover, at which time the hot and toxic combustion products spew from the room and threaten people throughout the residence.

To mitigate these losses, the CPSC enforces two fire standards for mattresses. There are no standard tests or regulatory requirements for the flammability of bedclothes sets. The first standard, 16 CFR Part 1632, dates to 1972 and is directed at reducing the number of ignitions due to cigarettes. The test involves placing lit cigarettes on a mattress or mattress pad and noting whether it smolders away from the cigarette. Essentially all mattresses in use today have met this standard. The second standard, 16 CFR Part 1633, had an effective date of July 1,2007 . It is directed at limiting fire growth and the prevalence of room flashover from mattress fires, particularly those ignited by flaming sources. The test involves exposing a mattress and foundation to a burner replicating the flames from vigorously burning bedclothes. The Standard imposes severe limits on the rate of heat release and the total heat released early in the fire. In this Technical Note, "the Standard" refers to the 16 CFR 1633 standard.

Prior to the implementation of the Standard, mattresses and bedding were reported to be the first items to ignite in 11500 residential fires attended by the fire service annually. These fires resulted in 380 deaths, 1400 injuries and $\$ 360$ million in direct property loss. While only $3 \%$ of the home fires, mattress and bedding fires resulted in $13 \%$ of the fatalities, $10 \%$ of the injuries and $6 \%$ of the property loss. Mattress and bedding fires ignited by all flaming sources led to an estimated 95 fatalities and 570 injuries annually. $72 \%$ of the fatalities from bed fires started by lighters, candles, and matches and $86 \%$ of the fatalities from bed fires started by smoking materials were reported as occurring in the area of fire origin when fatally injured.

The 544 models analyzed in this study involved searching the National Fire Incident Reporting System (NFIRS) for incident-level information on reported fires and their outcomes. These analyses also used population data from the U.S. Census, estimates of the number of mattresses in residences by the CPSC, and annual mattress sales data from the 
International Sleep Products Association (ISPA). In each analysis, the figure of merit is the change between the ratio of bed fire outcomes after imposition of the Standard to bed fire outcomes before imposition of the Standard.

Ratios were used in this study as a means of canceling the influence of outside factors that might confound the attributed effect of the Standard on fire losses. We examined four approaches to indexing the bed fire severity results to limit the potential impact from these factors:

- The RUF-controlled Approach ratios the outcomes of bed fires to outcomes of residential upholstered furniture (RUF) fires. The assumption is that, except for the Standard, the same processes that affect the outcomes of bed fires affect the outcomes of RUF fires in a similar manner. In the absence of the Standard, the ratios of bed-to-RUF fires, fatalities, and injuries would remain constant over time.

- The All-fire-controlled Approach ratios bed fires to all residential structure fires. This assumes that exogenous factors that influence the occurrence of bed fires affect all other residential fires in the same way. The ratios of bed-to-all fires, fatalities, and injuries would remain constant over time in the absence of the Standard.

- The Variable-fire-department Approach is similar to the RUF-controlled Approach, but allows the ratio of bed fires to RUF fires to reflect the annual reports from each fire department. Within each fire department's jurisdiction, the ratios of bed-to-RUF fires, fatalities, and injuries would remain constant over time in the absence of the Standard.

- The Per-bed-fire Approach evaluates the numbers of injuries and fatalities per bed fire. It differs from the other three approaches in that it directly indicates changes in the severity of bed fires as a result of the Standard.

For each Approach, we used two analysis methods. A "before-and-after" analysis compared bed fire outcomes prior to implementation of the Standard vs. a decade later. The "mattress replacement" analysis used annual mattress sales data to enable summing over the annual fire losses weighted by the accumulated number of Standard-compliant mattresses in homes.

For each of the four Approaches, 16 residential fire scenarios were considered.

A. Four groupings of fire incidents:

1. All fires started by flaming ignition sources;

2. All fires started by smoking materials;

3. All fires that occurred at night, regardless of ignition source, and

4. All fires, regardless of ignition source and time of day.

B. For each of these groupings, we considered four roles of bed combustibles in the fire:

1. Bed fires in which a mattress was identified as the item first ignited;

2. Bed fires meeting Role 1 , but expanded to include bed fires in which bedding was identified as the item first ignited; 
3. Bed fires meeting Role 1, but expanded to include fires in which a mattress was identified as the item most contributing to flame spread; and

4. Bed fires meeting Role 3, but expanded to include bed fires in which bedding was identified as the item most contributing to flame spread.

There were two alternative models for the replacement of pre-Standard mattresses by postStandard mattresses. In the "first-in-first-out" (FIFO) model, the oldest mattresses are replaced first. In the random replacement or equal-probability (EP) model, each mattress in service is equally likely to be replaced regardless of age. Each case was evaluated for the upper or lower CPSC estimates of the initial number of mattresses in residences.

The impact of the Standard was evaluated across five fire outcomes: the numbers of bed fires, bed fires that spread beyond the object of origin, bed fires that spread beyond the room of origin, injuries resulting from bed fires, and fatalities resulting from bed fires.

There is a degree of uncertainty in each of the simulations, and the standard errors were calculated throughout. Many of the outcomes were identified as not statistically significant, generally due to the small number of fire incidents in those simulations.

\section{Findings}

The results of the simulations show that the Standard is accomplishing its purpose. The beds with new mattresses are far less likely to lead to a fatal fire upon ignition by flaming ignition sources. Relative to RUF fires, flaming ignitions of beds led to decreases in the numbers of fires by $12 \%$, injuries by $34 \%$, and deaths by $82 \%$ between 2005-2006 and 2015-2016. On a Per-all-fire basis, injuries decreased by $25 \%$ and fatalities decreased by $67 \%$.

The number of fatalities prevented by beds with Standard-compliant mattresses when ignited by flaming heat sources during the two-year period 2015 and 2016 are estimated to have been 170 (95\% CI: 63 to 352) using the before-and-after method and 214 (95\% CI: 94 to 396) using the mattress replacement method. Barring any other changes affecting the incidence of bed fires and their consequences, it is likely that the biennial number of prevented fatalities from flame-ignited bed fires will continue or exceed this level as more pre-Standard mattresses are replaced.

There are two additional strong indicators of the success of the Standard.

1. The reduction to date in casualties from flaming ignitions is comparable to the fraction of mattresses that have been replaced. The FIFO mattress replacement model estimates that approximately $65 \%$ to $90 \%$ of the pre-Standard mattresses should have been replaced by the end of 2016; using the ER model, $50 \%$ to $60 \%$ should have been replaced.

2. The most severe fires are being prevented by the Standard. The decreases in injuries and, especially, fatalities are larger than the decrease in the number of fires; and there are reductions in the number of injuries and deaths per bed fire. This finding is consistent with heat release rate (indicative of burning rate) being substantially limited under the Standard. 
The decrease in fatalities was unaffected significantly by the method used for calculating the introduction of post-Standard mattresses into residences. There was also no significant and systematic effect of whether the mattress or bedding was identified as the first item ignited or whether either was identified as the item most contributing to flame spread.

The reductions in casualties from these bed fires were not sensitive to whether they were normalized to RUF fires or to all fires. This gives credence to the premise that, in the aggregate, normalizing bed fires to either data set is indeed isolating the effect of the Standard. However, some subsets of the data indicate the presence of one or more additional, unidentified factors.

Regarding fires with smoking materials as ignition sources, there was no significant change in the bed-to-RUF ratio of reported fires over the decade covered in this document. Little to no change was expected since by 2005 essentially all in-use mattresses and furniture had been manufactured since the promulgation of their respective cigarette ignition tests. It also suggests that the ease of cigarette ignition of bedding items had not changed during the past decade.

There was a significant increase in injuries relative to RUF fires from these cigaretteinitiated fires. This also appeared as an increase in injuries per bed fire and no change in the number of fires that spread beyond the bed. We also found a decrease in fatalities from these fires. Combined, these suggest that many fires that resulted in fatalities prior to the implementation of the Standard resulted only in injuries post-Standard. This likely indicates that post-Standard mattresses experienced weaker flaming followed any transition from smoldering. There might also be contributions to this increase from an unknown change in the fire hazard of bedclothes, the use of weaker cigarettes to test for ignition susceptibility, pre-Standard mattresses having an additional degree of protection against smoldering ignition relative to post-Standard mattresses, and people being more likely to try to fight the smaller fires, increasing the potential for injury.

Relative to all fires, and independent of the type of ignition or time of day, there was evidence of decreases in the numbers of such fires, fires spreading beyond the bed, and casualties in the all-fires-controlled calculations; these were not found in the RUF-controlled calculations. "All Fires" includes ignition sources other than smoking materials and the flaming sources likely to ignite beds and RUF. Thus, for instance, reduced nighttime use of space heaters might have led to reductions in both RUF and bed fires, but not the more numerous kitchen fires.

Overall, we found no systematic evidence that the outcomes of the fires were significantly affected by (1) the method used for calculating the introduction of post-Standard mattresses into residences, (2) variability in fire reporting among fire departments, (3) reporting of the initial combustible as the mattress or bedding, or (4) whether the mattress or bedding was reported as the item most contributing to flame spread. However, many of the calculations of the sensitivity of the fire outcomes led to small numbers of fire incidents and thus generated results that were within the calculation uncertainty. 


\section{Contents}

Executive Summary ........................................................................................................................... ii

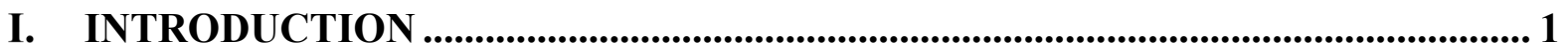

II. INPUT DATA ……......................................................................................................... 3

III. STRUCTURE OF THE ANALYSIS ........................................................................... 5

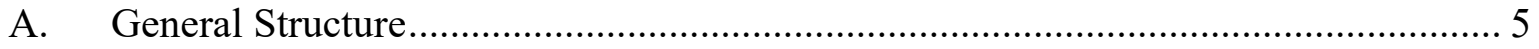

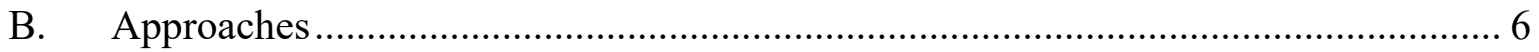

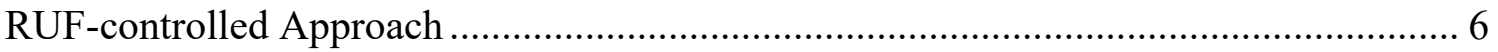

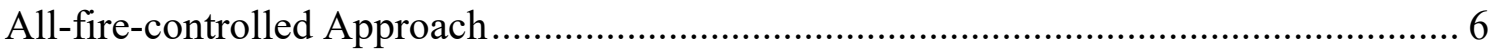

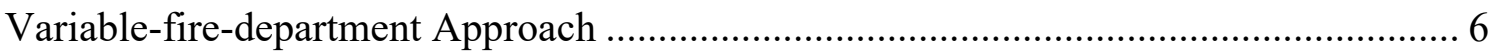

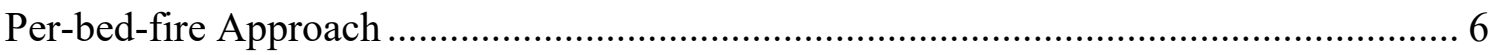

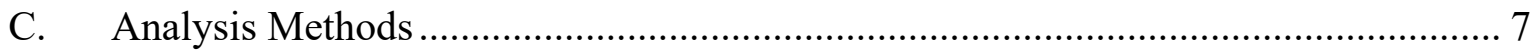

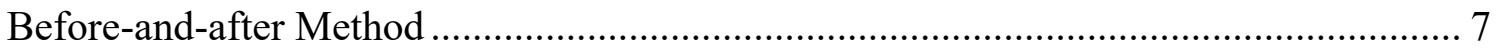

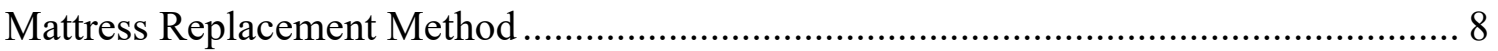

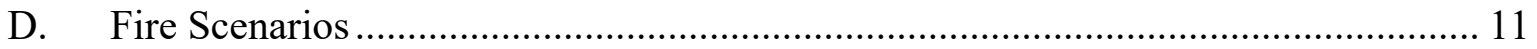

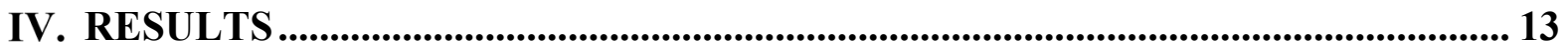

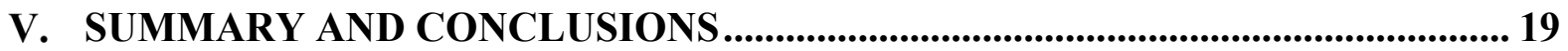

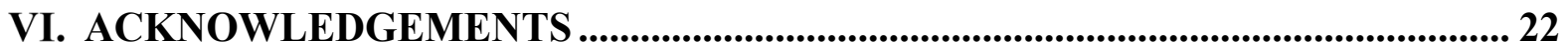

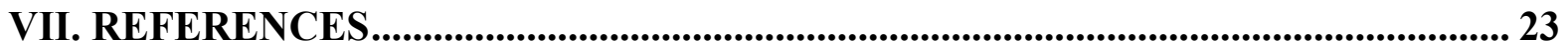

APPENDIX A: MATHEMATICAL DEVELOPMENT OF THE BEFORE-AND-

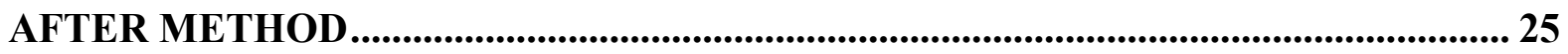

APPENDIX B: MATHEMATICAL DEVELOPMENT OF THE MATTRESS

REPLACEMENT METHOD ........................................................................................... 27

APPENDIX C: MATHEMATICAL DEVLOPMENT OF THE STANDARDCOMPLIANT MATTRESS REPLACEMENT PROCESS ............................................... 29

APPENDIX D: PARAMETRIC VARIATIONS WITHIN THE MODELING

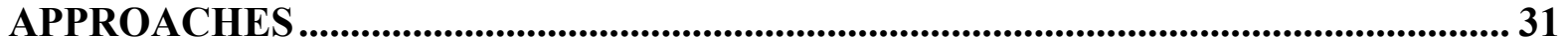

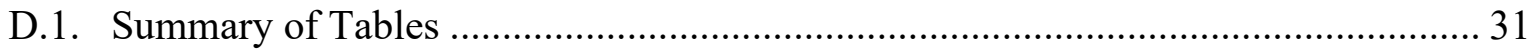

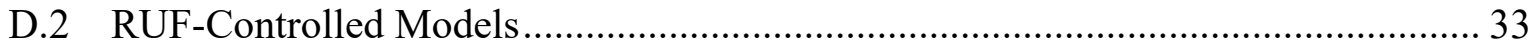

D.3 All-Fire-Controlled Models................................................................................... 41

D.4 Variable Fire Department Models ...................................................................... 49

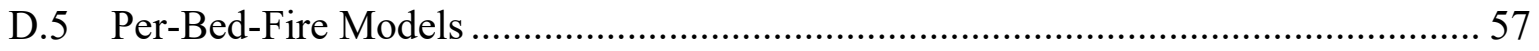




\section{List of Tables}

Table 1: Impact of the Standard on bed fires, injuries, and fatalities, estimated using the RUF-controlled approach with the before-and-after replacement method.

Table 2: Impact of the Standard on bed fire injuries, and fatalities using the Per-bed-fire approach with the before-and-after replacement method.

Table 3: Impact of the Standard on bed fires, injuries, and fatalities, estimated using the RUF-controlled approach with the FIFO mattress replacement method.

Table 4: Impact of the Standard on bed fire injuries and fatalities, estimated using the Perbed-fire Approach with the FIFO mattress replacement method.

Table 5: Table numbers for estimations of the effect of the Standard on various fire outcomes.

Table 6: Estimation Methods for Model Uncertainty.

Table 7: Effect of including bedding and the item contributing most to flame spread on the number of reported ignitions, estimated using the RUF-controlled approach and the beforeand-after method.

Table 8: Effect of including bedding and the item contributing most to flame spread on the number of fires that spread beyond the object of origin, estimated using the RUF-controlled approach and the before-and-after method.

Table 9: Effect of including bedding and the item contributing most to flame spread on the number of fires that spread beyond the room of origin, estimated using the RUF-controlled approach and the before-and-after method.

Table 10: Effect of including bedding and the item contributing most to flame spread on the number of injuries, estimated using the RUF-controlled approach and the before-and-after method.....

Table 11: Effect of including bedding and the item contributing most to flame spread on the number of fatalities, estimated using the RUF-controlled approach and the before-and-after method...

Table 12: Effect of varying the calculation method for the replacement rate of pre-Standard mattresses on the number of reported ignitions, estimated using the RUF-controlled approach.

Table 13: Effect of varying the calculation method for the replacement rate of pre-Standard mattresses on the fires that spread beyond the object of fire origin, estimated using the RUFcontrolled approach.

Table 14: Effect of varying the calculation method for the replacement rate of pre-Standard mattresses on the fires that spread beyond the room of fire origin, estimated using the RUFcontrolled approach.

Table 15: Effect of varying the calculation method for the replacement rate of pre-Standard mattresses on the number of injuries, estimated using the RUF-controlled approach...... 39 
Table 16: Effect of varying the calculation method for the replacement rate of pre-Standard mattresses on the number of fatalities, estimated using the RUF-controlled approach. 39

Table 17: Effect of including bedding and the item contributing most to flame spread on the number of reported ignitions, estimated using the all-fires-controlled approach and the before-and-after method.....

Table 18: Effect of including bedding and the item contributing most to flame spread on the number of fires that spread beyond the object of origin, estimated using the all-firescontrolled approach and the before-and-after method.

Table 19: Effect of including bedding and the item contributing most to flame spread on the number of fires that spread beyond the room of origin, estimated using the all-fires-controlled approach and the before-and-after method. 42

Table 20: Effect of including bedding and the item contributing most to flame spread on the number of injuries, estimated using the all-fires-controlled approach and the before-and-after method..

Table 21: Effect of including bedding and the item contributing most to flame spread on the number of fatalities, estimated using the all-fires-controlled approach and the before-andafter method.

Table 22: Effect of varying the calculation method for the replacement rate of pre-Standard mattresses on the number of reported ignitions, estimated using the all-fires-controlled approach.

Table 23: Effect of varying the calculation method for the replacement rate of pre-Standard mattresses on the fires that spread beyond the object of fire origin, estimated using the allfires-controlled approach.

Table 24: Effect of varying the calculation method for the replacement rate of pre-Standard mattresses on the fires that spread beyond the room of fire origin, estimated using the allfires-controlled approach.

Table 25: Effect of varying the calculation method for the replacement rate of pre-Standard mattresses on the number of injuries, estimated using the all-fires-controlled approach.

Table 26: Effect of varying the calculation method for the replacement rate of pre-Standard mattresses on the number of fatalities, estimated using the all-fires-controlled approach. .... 47

Table 27: Effect of including bedding and the item contributing most to flame spread on the number of reported ignitions, estimated using the variable fire department approach and the before-and-after method.

Table 28: Effect of including bedding and the item contributing most to flame spread on the number of fires that spread beyond the object of origin, estimated using the variable fire department approach and the before-and-after method.

Table 29: Effect of including bedding and the item contributing most to flame spread on the number of fires that spread beyond the room of origin, estimated using the variable fire department approach and the before-and-after method. 
Table 30: Effect of including bedding and the item contributing most to flame spread on the number of injuries, estimated using the variable fire department approach and the before-andafter method.

Table 31: Effect of including bedding and the item contributing most to flame spread on the number of fatalities, estimated using the variable fire department approach and the beforeand-after method.

Table 32: Effect of varying the calculation method for the replacement rate of pre-Standard mattresses on the number of reported ignitions, estimated using the variable-fire department approach.

Table 33: Effect of varying the calculation method for the replacement rate of pre-Standard mattresses on the number of fires that spread beyond the object of origin, estimated using the variable-fire-department approach.

Table 34: Effect of varying the calculation method for the replacement rate of pre-Standard mattresses on the number of fires that spread beyond the room of origin, estimated using the variable-fire-department approach.

Table 35: Effect of varying the calculation method for the replacement rate of pre-Standard mattresses on the number of injuries, estimated using the variable-fire-department approach.

Table 36: Effect of varying the calculation method for the replacement rate of pre-Standard mattresses on the number of fatalities, estimated using the variable-fire-department approach.

Table 37: Effect of including bedding and the item contributing most to flame spread on the numbers of injuries per bed fire, estimated using the before-and-after method.

Table 38: Effect of including bedding and the item contributing most to flame spread on the numbers of fatalities per bed fire, estimated using the before-and-after method.

Table 39: Effect of varying the calculation method for the replacement rate of pre-Standard mattresses on the number of injuries per bed fire, estimated using the per-bed-fire approach.

Table 40: Effect of varying the calculation method for the replacement rate of pre-Standard mattresses on the number of fatalities per bed fire, estimated using the per-bed-fire approach.

\section{List of Figures}

Figure 1: New Mattress Penetration from for the U.S. for the years 2005 to 2018 for the four different models. 


\section{INTRODUCTION}

Effective July 1, 2007, the Consumer Product Safety Commission (CPSC) promulgated a standard for mattress flammability for flaming ignitions, 16 CFR Part 1633. This Technical Note documents a methodology for quantifying the impacts of this standard on the number of reported bed fires in residential structures and the numbers of associated occupant deaths and injuries. We then use this methodology to calculate changes in the losses from bed fires to date.

Beds have historically been one of the two most prevalent combustibles in fatal residential fires (residential upholstered furniture, RUF, is the other) [1]. A bed typically consists of a mattress, a foundation, and an assembly of covers and pillows (collectively referred to as 'bedding'). A person who is in the bed at the time of ignition is at risk from the smoke and flames even when the fire is confined to the bed itself. As the fire grows, it can ignite nearby furniture or beds and raise the temperature in the room to untenable levels. The fire can also lead to room flashover, at which time all combustibles in the room are aflame and the hot and toxic combustion products flow rapidly into adjacent compartments. These combustion products threaten people throughout the residence.

There are two flammability standards enforced by the CPSC for mattresses. Both involve testing of full mattresses. There are no standard tests or regulatory requirements for the flammability of bedclothes sets.

The first standard, 16 CFR Part 1632 [2], was issued originally in 1972 by the U.S. Department of Commerce, with jurisdiction transferred to the CPSC in 1973 by Federal statute. This standard is intended to "protect the public from risks of death, personal injury, and property damage associated with fires which have resulted from ignition of mattresses by cigarettes" [2]. In the test method, lit cigarettes are placed at prescribed locations along the top surface of the bare mattress or mattress pad. A similar number of lit cigarettes are placed with sheeting between the cigarette and the mattress and on top of the cigarette. Ignition is determined by whether the mattress chars at least 2 inches away from a cigarette.

The second standard was promulgated by the CPSC in 2006, with an effective date of July 1 , 2007 [3]. It is intended to "reduce deaths and injuries related to mattress fires, particularly those initially ignited by open flame sources such as lighters, candles and matches." While the intention of the 1972 standard is to reduce the number of ignitions due to cigarettes, the intention of the 2006 standard is to limit the extent of fire growth, i.e., "minimize or delay flashover when a mattress is ignited in a typical bedroom fire" [4]. In what follows, "the Standard" refers to the open-flame mattress standard.

Typically, a mattress found in a home is surrounded by bedding, and thus these accessories are generally the initial site of an ignition. In the Standard's test method, a mattress (on a foundation such as a box spring) is subjected to the flames from a twin burner, which are directed at the top and side of the mattress. The intensity and duration of these flames were derived from the flaming behavior of various bedding sets [5]. The peak heat release rate (PHRR) of the test specimen in 16 CFR Part 1633 must not exceed $200 \mathrm{~kW}$ during the 30minute test. For reference, prior to the Standard the PHRR of a typical twin mattress set was approximately $2 \mathrm{MW}$, with king bed sets achieving approximately twice that rate. A PHRR of $1 \mathrm{MW}$ can result in flashover in a bedroom of modest size. In addition, the Standard 
requires that the total heat released (THR) during the first 10 minutes of the test must not exceed 15 MJ [3]. The PHRR criterion was deemed to provide substantial opportunity for able occupants to discover the fire and escape. The THR criterion further reduces the hazard in the early stages of a bed fire.

Prior to the implementation of the Standard, between 2002 and 2005, mattresses and bedding were reported to be the first items to ignite in 11,500 residential fires attended by the fire service annually [6]. These fires resulted in 380 deaths, 1400 injuries and \$360 million in direct property loss annually [1]. While only $3 \%$ of the home fires, mattress and bedding fires resulted in $13 \%$ of the fatalities, $10 \%$ of the injuries and $6 \%$ of the property loss. Mattress and bedding fires ignited by all flaming sources led to an estimated 95 fatalities and 570 injuries annually. $72 \%$ of the fatalities from bed fires started by lighters, candles, and matches and $86 \%$ of the fatalities from bed fires started by smoking materials that were in the area of fire origin when the fatal injury occurred.

The rest of the report is as follows: Section II provides an overview of the data sets used, Section III describes the methodology; Section IV presents the modeling results; and Section V provides further discussion, implications, and conclusions. 


\section{INPUT DATA}

Three sources of data were used in the analyses: The National Fire Incident Reporting System (NFIRS), the U.S. Census, and the International Sleep Products Association (ISPA), the trade association for the mattress industry.

The NFIRS data provide incident-level information of reported fires nationwide, as provided by fire department personnel [7]. Though fire department participation is voluntary, approximately $80 \%$ of the U.S. fire departments respond in any given year. The system is maintained by the U.S. Department of Homeland Security's Fire Administration.

The NFIRS system compiles records of the time, date and location of all reported incidents; the type of the incident (e.g., fire, EMS call, hazardous materials incident, service call); property use; equipment and personnel on the call; the number, type and severity of casualties; actions taken; and a host of other data. For fires specifically, NFIRS collects information on the extent of the fire, room of origin, heat source, item first ignited, human and other factors contributing to ignition, item principally contributing to fire growth, and presence and effectiveness of detection and automatic suppression equipment, among other data. While NFIRS has known reporting limitations, it is still the most comprehensive data set available for understanding the nature and extent of the urban fire problem in the United States.

This study includes residential (both single-family and multifamily) fires reported in NFIRS between 2005 and 2016. Since NFIRS is a voluntary system, sometimes new fire departments contribute to the system and participating departments drop out. To ensure that results are not an artifact of fire departments entering and leaving the system, only fires from departments that reported fires during both the periods 2005-2006 (the two full years prior to the effective date of the Standard) and 2015-2016 (the two most recent years in the NFIRS database) are included. We used two-year periods to mitigate the influence of any unusual one-year data, yet not obscure any trends that might still be evolving.

The population data are from the U.S. Census population projections (for the years from 2010 to the present), and intercensal estimates for the years before 2010. The population of the United States grew from approximately 299 million in 2005 to approximately 326 million in 2016.

The International Sleep Products Association (ISPA) supplied sales data, denominated in both dollars and units, at the four U.S. sales region (Northeast, West, Midwest, and South) for the period from 2000 to 2018. Typical national mattress sales are on the order of 10 million per year. Sales slowed during the recent recession but have now returned to prerecession levels. The CPSC estimated that there were between 237 million and 304 million mattresses in U.S. residences in 2005 [3].

On average, the original purchaser of a mattress replaces it roughly 10 to 12 years later. A used mattress may be reconditioned and resold, passed on to another user, or discarded. Thus, the total useful life of a mattress is difficult to estimate, but might well approach 20 years. 
This page was intentionally left blank. 


\section{STRUCTURE OF THE ANALYSIS}

\section{A. General Structure}

The main task is to capture the "big picture" results of the implementation of the Standard, i.e., the changes in the numbers of fires, injuries, and deaths from bed fires between the years before the compliant products entered use and today. The technique used to obtain these results can then be extended to future years as additional fire incidence data become available.

It is possible that external factors (e.g., a change in the prevalence of working smoke alarms) might confound the measured statistical effect of the Standard on these results, and the role of each of these factors in fire severity might be difficult to quantify. Thus, this report examines four different approaches to normalizing, or indexing, the bed fire severity results to limit the potential impact from these factors. The four approaches are termed "RUFcontrolled," "All-fire-controlled," "Variable-fire-department," and "Per-bed-fire." They are described further in Sections III.B and III.C and in Appendixes A, B, and C.

For each approach, two methods of analyses were performed. A "before-and-after" analysis was used to compare bed fire outcomes prior to implementation of the Standard vs. a decade later. The "mattress replacement" analysis used annual mattress sales data to model the rate of Standard-compliant mattress penetration into homes each year.

The impact of the Standard was evaluated across five fire outcomes that are entries in the NFIRS reports of fire incidents:

1. Number of bed fires,

2. Number of bed fires that spread beyond the object of origin,

3. Number of bed fires that spread beyond the room of origin,

4. Number of injuries resulting from bed fires, and

5. Number of fatalities resulting from bed fires

With regard to outcomes 2 and 3, the spread of a bed fire to other combustibles beyond the bed and to other spaces can only occur if the bed fire is flaming. A smoldering fire will not ignite a second item unless it is in intimate contact with the bed, and the heat release rate from a smoldering fire is far too low to initiate room flashover. However, under the right circumstances, the smoldering fire could transition into a flaming fire. If so, the Standard might reduce the intensity of the flaming and thus reduce the losses from, e.g., cigaretteinitiated fires as well as those fires started by flaming ignition sources.

Additionally, the effects of several variables on the changes in fire severity were examined. These included the nature of the ignition source, whether the bed was identified as the main combustible in the flame spread, the role of bedding, and different models for owners replacing their mattresses. 


\title{
B. Approaches
}

All Approaches assume that bed fires are independent events occurring at a constant rate within a given time interval, i.e., their rates each follow a Poisson distribution. The Poisson assumption enables treating mattress fires to be distributed as a Negative Binomial relative to RUF fires or all fires. (The Negative Binomial distribution is similar to the Poisson distribution, but unlike it, the Negative Binominal does not assume the expected mean number of occurrences to also equal its variance.) All approaches that use index fires in some form (whether that be RUF fires or all residential fires) make the same assumption about the index fires.

\section{RUF-controlled Approach}

The RUF-controlled Approach uses residential upholstered furniture (RUF) fires as a control group for bed fires. The assumption of the RUF-controlled Approach is that, except for the Standard, the same factors (such as usage of candles in homes or cigarette ignition strength) that affect the numbers of bed fires, deaths, and injuries affect the outcome of residential upholstered furniture (RUF) fires in a similar manner. This assumption implies the ratio of bed-to-RUF fires, fatalities, and injuries would remain constant over time in the absence of the Standard.

\begin{abstract}
All-fire-controlled Approach
Analogous to the RUF-controlled Approach, the All-fire-controlled Approach indexes bed fires to all residential structure fires. This assumption implies the ratio of bed-to-all fires, fatalities, and injuries would remain constant over time in the absence of the Standard. This approach assumes exogenous factors (such as a change in the sensitivity of residential smoke alarms) that influence the reported occurrence of bed fires affect all other residential fires in the same way.
\end{abstract}

\section{Variable-fire-department Approach}

The Variable-fire-department Approach is similar to the RUF-Controlled Approach, in that it indexes bed fires to RUF fires, but differs in allowing the initial ratio of bed fires to RUF fires to reflect the annual reports from each fire department. This assumption implies that within a fire department's jurisdiction, the ratios of bed-to-RUF fires, fatalities, and injuries would remain constant over time in the absence of the Standard. While the initial bed fires to RUF fires ratio is allowed to vary by department, the effect of the Standard is assumed to be constant for all departments across the U.S.

\section{Per-bed-fire Approach}

The Per-bed-fire Approach evaluates the number of outcomes (which are limited to injuries and fatalities) per bed fire. As such, it differs from the other three approaches in that it directly indicates any changes in the severity of bed fires as a result of the Standard. Two versions of this Approach were used: (1) allowing the initial ratio of bed fire outcomes to bed fires to vary by fire department and (2) assuming the initial ratio of bed fire outcomes to bed fires to be constant for all fire departments. 


\section{Analysis Methods \\ Before-and-after Method}

This method of analysis examined whether there has been a statistically significant change between the pre-Standard outcomes (2005-2006, the two full years prior to the effective date of the Standard) and the post-Standard outcomes (2015-2016, the two most recent years in the NFIRS database).

\section{Control Choice: Indexed to RUF Fires or All Fires}

For this analysis, using either the RUF-controlled Approach or the All-fire-controlled Approach, the expected number of bed fire outcomes can be expressed as:

$$
\mathrm{E}\left(m_{i j}\right)=\frac{c_{i j}+\alpha}{1+\beta} \eta \delta^{t_{i j}}
$$

where:

$\mathrm{E}$ is the expectation operator,

$m$ is the number of bed fires,

$c$ is the number of control fires (either RUF fires or all residential fires depending on the method,

$\eta$ is the ratio of bed fire outcomes to control outcomes before imposition of the standard,

$\delta$ measures the impact of the Standard, and is defined as the ratio:

$$
\delta=\frac{\frac{\text { bed fires after }}{\text { control fires after }}}{\frac{\text { bed fires before }}{\text { control fires before }}},
$$

$t$ indicates whether the Standard is in place and has a value of zero if the observation is before imposition of the standard and a value of one if the observation is after imposition of the standard,

$i$ indexes geographic mattress sales regions,

$j$ indexes time, and

$\alpha$ and $\beta$ are Bayesian priors on the frequency of control fires and are assigned the values $\alpha=\beta=0.001$. These values represent a commonly used, minimally informative prior in Bayesian analysis. They need to be non-zero because if they were zero then any cases where the number of control fires was zero would have to be deleted from the analysis.

The main variable of interest in this model is $\delta$, where we are interested in the case where $\delta<1$ or $\ln (\delta)<0$, which would indicate that the (undesirable) outcomes after the 
imposition of the Standard are fewer than before imposition of the Standard. $\operatorname{Ln}(\delta)$ is what is actually used for analysis and reporting because $\ln (\delta)$ is easier to estimate than $\delta$, and because it is easier to test for the statistical significance of $\ln (\delta)<0$ than of $\delta<1$. The mathematical development of the model is in Appendix A.

\section{Control Choice: Variable Fire Department}

Using the Variable-fire-department Approach, the expression above is modified slightly to:

$$
\mathrm{E}\left(m_{i j}\right)=\frac{c_{i j}+\alpha}{1+\beta} \eta_{i} \delta^{t_{i j}}
$$

where $i$ now indexes on fire departments. Otherwise all the variables are the same as above.

\section{Control Choice: Indexed to Bed Fires}

For the Per-bed-fire Approach using the before-and-after method, each outcome is modeled using a Poisson model and generalized linear model (GLM) techniques. The following model is analyzed:

$$
\mathrm{E}\left(y_{i j}\right)=g^{-1}\left(\ln \left(f_{i j}\right)+\ln \left(b_{i}\right)+t_{i j} \ln (\delta)\right)
$$

where:

$f_{i j}$ is the number of fires for department $i$ and time $j$;

$b_{j}$ is a parameter identifying the average rate at which the outcome occurred per fire before the imposition of the Standard for each fire department, $j$; and

$g$ is the natural logarithm.

Note that the model within the function $\left(g^{-1}\right)$ is linear in $\ln (\delta)$.

\section{Mattress Replacement Method}

Using the annual mattress sales data for the years in between the "before" and "after" fire data enables estimation of the penetration of new mattresses into homes. This, in turn, allows estimation of whether any changes in fires and fire outcomes follows the usage of the Standard-compliant mattresses. The mathematical development of the method is in Appendix B.

This approach inherently assumes that the placement of the compliant mattresses is constant over time across a variety of locations: children's room, guest room, single person adult room, two-person adult room, multiple occupant rooms, etc. As with the before-and-after method, it also assumes that the nature and flammability of the bedding have not changed over the period of these analyses.

The model requires values for standard-compliant mattress penetration by year and region, $\theta_{i}$. Unfortunately, we have no direct information on the values of $\theta_{i}$. Therefore, values of $\theta_{i}$ are estimated based on the initial number of mattresses in use, the U.S. population, and mattress sales data using the following equation: 


$$
\theta_{i}=\frac{P_{i-1}}{P_{i}}\left[\theta_{i-1}+\frac{P_{i}-P_{i-1}}{P_{i-1}}+\left(\frac{S_{i}}{\rho P_{i-1}}-\frac{P_{i}-P_{i-1}}{P_{i-1}}\right)\left(1-\kappa \theta_{i-1}\right)\right]
$$

where:

$P_{i}$ is the total U.S. population,

$S_{i}$ is the number of mattress sales, and

$\rho$ is the proportion of mattresses per person, and is assumed to be constant over the period of analysis.

The parameter $\kappa$ is a parameter with values between zero and one. A value of $\kappa=0$ indicates a 'first-in-first-out' (FIFO) model, where the oldest mattresses are replaced first. A value of $\kappa=1$ indicates a random replacement or equal-probability (EP) model, where each mattress in service is equally likely to be replaced regardless of age. Derivation of the estimates is found in Appendix C. Note that these are not the high and low extreme models for the rate of mattress replacement, but they are tractable and have some logical basis. Other types of models might include some households replacing the adult mattresses frequently, e.g., every five or seven years, and the children's mattresses less frequently, e.g., once after each child graduates from a crib or a different replacement profile for second-hand mattresses. There are no data that would allow these kinds of individual-choice-based concepts to be incorporated here.

Figure 1 shows the estimates of standard-compliant mattress penetration over time for the U.S. for the four different approaches. Holding the replacement method constant, the smaller initial number of mattresses produces the most aggressive replacement schedules for mattresses. For "long" periods of time, the FIFO models $(\kappa=0)$ produce the most aggressive replacement schedules. The EP $(\kappa=1)$ model represents a significantly slower replacement of pre-Standard mattresses.

The CPSC recognized [3] that some manufacturers were shipping/selling compliant mattresses before March 15, 2006, or 15 months before the effective date of the Standard. Figure 1 suggests that these sales represent an upper limit of about $10 \%$ of the mattresses in use on the effective date of the Standard. The before-and-after method neglected this fraction, but the replacement method accounted for it. 


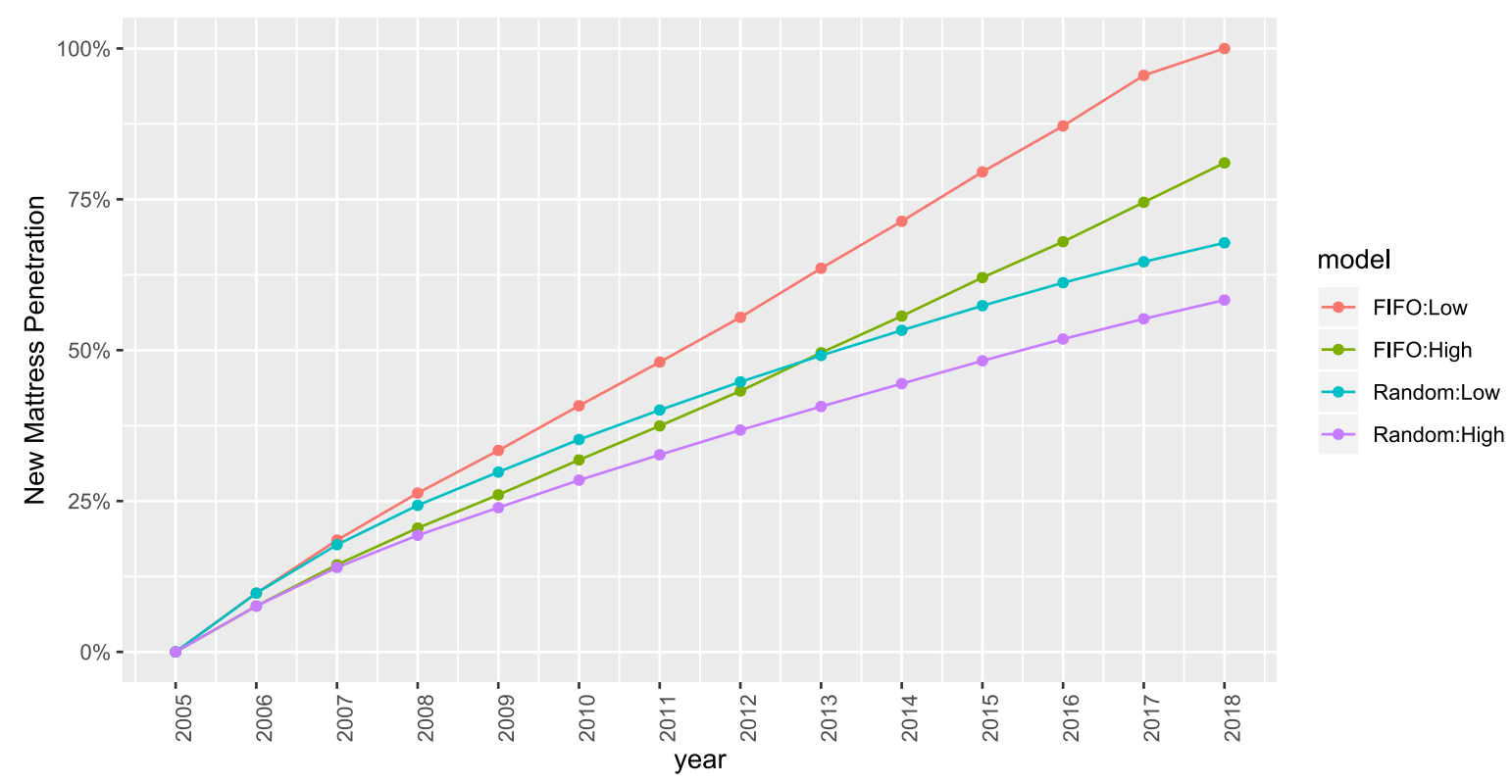

Figure 1: New Mattress Penetration in the U.S. during the years 2005 to 2018 for the four mattress models.

\section{Control Choice: Indexed to All Fires or to RUF Fires}

For the mattress replacement method, the All- and RUF-controlled Approaches are modified to:

$$
\mathrm{E}\left(m_{i j}\right)=\frac{\alpha+c_{i j}}{1+\beta} \eta\left(1+(\psi-1) \theta_{i j}\right)
$$

where:

$\theta_{i j}$ is the proportion of mattresses in service that are Standard-compliant, and

$\psi$ is interpreted as the ratio of outcomes for new mattresses compared to old mattresses. This differs from $\delta$ in that the value of $\delta$ is a characteristic of the time period analyzed (and thus would change if the time period used as the "after" period changed), while $\psi$ is a characteristic of the difference in the mattresses' change in fire contribution.

\section{Control Choice: Variable Fire Department}

Using the Variable Fire Department approach the model above is modified to:

$$
\mathrm{E}\left(m_{i j}\right)=\frac{\alpha+c_{i j}}{1+\beta} \eta_{i}\left(1+(\psi-1) \theta_{i j}\right)
$$

where, as before, the $i$ now indexes fire departments and all the other variables are as defined above. 


\section{Control Choice: Indexed to Bed Fires}

For the mattress replacement analysis, the Per-bed-fire model is modified to:

$$
\mathrm{E}\left(y_{i j}\right)=f_{i j} b\left(1+(\psi-1) \theta_{i j}\right)
$$

where $b$ now represents the proportion of non-Standard-compliant bed fires which have the outcome analyzed. All other variables have the same significance as before. Here, unlike with the before-and-after data, $b$ does not vary by fire department, but is constant across the country. While the Per-fire analysis is estimated using GLM techniques for the before-andafter method (as described above), it is estimated using maximum likelihood for the mattressreplacement method. The change in estimation techniques was necessary because the revised per-bed model was no longer linearizable.

\section{Fire Scenarios}

For each of the four approaches, there were 16 residential fire scenarios that were considered. Four groupings of fire incidents:

1. All fires started by flaming ignition sources;

2. All fires started by smoking materials;

3. All fires that occurred at night, regardless of ignition source, and

4. All fires, regardless of ignition source and time of day. ${ }^{1}$

For each of these groupings, we considered four roles of bed combustibles in the fire:

1. Bed (RUF) fires in which a mattress (RUF item) was identified as the item first ignited

2. Bed (RUF) fires meeting Definition 1, but expanded to include bed fires in which bedding was identified as the item first ignited.

3. Bed (RUF) fires meeting Definition 1, but expanded to include fires in which a mattress (RUF item) was identified as the item most contributing to flame spread.

4. Bed (RUF) fires meeting Definition 3, but expanded to include bed fires in which bedding was identified as the item most contributing to flame spread.

Outcomes for all four incident groupings were calculated using both the before-and-after method and the mattress-replacement method. The calculated outcomes for the Per-bed-fire Approach did not include the total number of fires, the fires spreading beyond the item first ignited, and the number of fires spreading beyond the room of origin. The number of fires on

\footnotetext{
1 "Flaming" Ignition type includes all NFIRS ignition sources that apply a flame to the combustible. "Smoking" ignition type includes smoking materials as the only NFIRS descriptor of non-flaming ignition sources. Thus, the number of reported fires included in the "All" ignition type is larger than the sum of the other two columns.
} 
a per-fire basis is by definition fixed at unity and therefore not meaningful. The other outcomes were not evaluated because they were not the core of this analysis.

The analyses involved four variations on the mode of mattress replacement. These involved using (a) the FIFO or EP model and (b) the high or low CPSC estimates of the initial number of mattresses, $\mathrm{N}_{0}=304$ million or 239 million, respectively[3]. 


\section{IV.RESULTS}

The results of a total of 544 cases were calculated. The four most prominent are presented in this section of the report. These include:

- Approaches: RUF-controlled, Per-bed-fire. The calculation referencing bed fires to all fires was not included, since it was expected that, e.g., kitchen fires are not controlled by the factors that control bed fires. The calculation in which the incident reporting was allowed to vary by fire department reporting was not included because the subsets were often too small for obtaining statistically significant results.

- Methods: Before-and-after; Mattress Replacement.

- Ignition Types: Flaming, Smoking Materials, All Ignitions.

- Outcomes: Number of bed fires; Number of Injuries; Number of Deaths.

The annotated output from the remaining cases can be found in Appendix D. Those cases examine the influence of possible variations in the coding and in the model assumptions.

In the following tables of selected estimation results (Tables 1 to 4 ), recall that the variable of interest is the ratio of bed fire outcomes after imposition of the Standard to bed fire outcomes before imposition of the Standard (reported here as $\ln (\delta)$ ). Large negative values of $\ln (\delta)$ indicate that the Standard has reduced the undesirable fire outcomes. Large positive values of $\ln (\delta)$ indicate that the (undesirable) fire outcomes increased after the imposition of the Standard. The other estimated variable shown in Tables 1 to 4 is the natural log of the ratio of bed fire outcomes to control outcomes before imposition of the Standard $(\eta)$. Positive estimates indicate more bed fire outcomes than the control, while negative estimates indicate fewer than the control.

It is important to recognize that there is a degree of uncertainty in each of the simulations. The second and fourth rows in each table are the standard errors for the values in the first and third rows. As the models become more complex, and especially as the fire incidence data are divided into smaller groupings, the standard errors can become comparable to the mean values for $\ln (\delta)$. In these cases, it may not be possible to determine whether the Standard had a beneficial effect, a negative effect, or no effect. The values of $\ln (\delta)$ and the values of $\ln (\eta)$ that are statistically significant at the $95 \%$ confidence level (two-sided) are in boldface italics in the tables.

Table 1 presents the estimated impact of the Standard on bed fires, fatalities, and injuries using the RUF-controlled Approach with the Before-and-after Method. "Flaming" Ignition type includes all NFIRS ignition sources that apply a flame to the combustible. "Smoking" ignition type includes smoking materials as the only NFIRS descriptor of non-flaming ignition sources. Thus, the number of reported fires included in the "All" ignition type is larger than the sum of the other two columns. Before imposition of the Standard, positive values of $\ln (\eta)$ indicate that there were more reported bed fires and injuries than from 
upholstered furniture. A negative value of $\ln (\eta)$ indicates there were fewer reported deaths from bed fires than furniture fires.

Table 1: Impact of the Standard on bed fires, injuries, and fatalities, estimated using the RUF-controlled approach with the before-and-after replacement method.

\begin{tabular}{|c|c|c|c|c|c|c|c|c|c|}
\hline \multirow[b]{2}{*}{ Type: } & \multicolumn{3}{|c|}{ Fires } & \multicolumn{3}{|c|}{ Injuries } & \multicolumn{3}{|c|}{ Fatalities } \\
\hline & Flaming & Smoking & All & Flaming & Smoking & All & Flaming & Smoking & All \\
\hline $\ln (\eta)$ & 0.78 & 0.23 & 0.38 & 0.65 & -0.10 & 0.18 & 0.06 & -0.36 & -0.26 \\
\hline standard error & 0.03 & 0.03 & 0.02 & 0.08 & 0.07 & 0.04 & 0.24 & 0.15 & 0.10 \\
\hline $\ln (\delta)$ & -0.12 & 0.01 & 0.01 & -0.41 & 0.12 & -0.07 & -1.73 & -0.002 & -0.15 \\
\hline standard error & 0.05 & 0.06 & 0.03 & 0.13 & 0.12 & 0.06 & 0.51 & 0.24 & 0.15 \\
\hline Change in $\delta(\%)$ & -12 & 1 & 1 & -34 & 13 & -7 & -82 & -0.2 & -14 \\
\hline $\mathrm{Cl}^{*}$ & $-19:-3$ & $-10: 13$ & $-4: 6$ & $-49:-15$ & $-11: 44$ & $-18: 5$ & $-93:-52$ & $-37: 58$ & $-35: 15$ \\
\hline
\end{tabular}

* Confidence Interval

Looking at the estimated $\ln (\delta)$ values, the Standard is correlated with a reduction in the number of bed fires from flaming ignitions and the associated fatalities and injuries. Between 2005-2006 and 2015-2016, flaming ignitions led to decreases in fires by $12 \%$ (95\% CI: $3 \%$ to $19 \%$ ), injuries by $34 \%$ (95\% CI: $15 \%$ to $48 \%$ ) and deaths by $82 \%$ (95\% CI: $52 \%$ to $93 \%)$.

There are two strong indicators of the success of the Standard.

1. The consistency of the fraction of mattresses that have been replaced and the reduction to date in casualties from flaming ignitions. Figure 1 shows that, using the FIFO mattress replacement model, $65 \%$ to $90 \%$ of mattresses in the U.S. should have been replaced by 2015; using the EP model, $50 \%$ to $60 \%$ should have been replaced.

2. The decreases in injuries and, especially, fatalities are larger than the decrease in the number of fires. From this, we can infer that it is the most severe fires that are being prevented by the Standard. This is consistent with the metric (heat release rate) in the test method that is significantly curtailed by the Standard.

With regard to smoking materials as ignition sources, there was no statistically significant change in the number of reported fires over the decade covered in this document relative to RUF fires, nor was there when considering all ignition sources in aggregate. This is not a surprise, since it is probable that essentially all in-use mattresses had been manufactured in the more than 30 years between the promulgation of the cigarette ignition test in 1972 and 2005. It also suggests that the ease of cigarette ignition of bedding items had not changed during the decade covered by this study relative to the ease of ignition of RUF items.

The lack of significant reduction in fatalities from smoking material ignitions presents additional insight into the effectiveness of the Standard. As just noted, Table 1 shows no significant change in the number of reported bed fires started by smoking materials. Table 8 (Appendix D) shows no significant change in the number of smoking-initiated bed fires that spread beyond the bed in the ensuing decade $(\operatorname{small} \ln (\delta)$ values $)$. Similarly, Table 9 shows 
no significant change in fire spread beyond the fire room. Therefore, it is likely that there was no significant change in the fraction of smoking material ignited fires that transitioned from smoldering to flaming. The NFPA data analysis indicated that in 2002-2005, prior to the Standard, $86 \%$ of the fatalities from bed fires initiated by smoking materials were reported as occurring in the fire room [6], i.e., in or near to the bed.

The Per-bed-fire calculations shown in Table 2 allowed the value of $\eta$ to vary from fire department to fire department. The values shown in Table 2 for $\eta$ are the average of the $\eta$ values for all fire departments, and the associated standard errors are the standard errors of

Table 2: Impact of the Standard on bed fire injuries, and fatalities using the Per-bedfire approach with the before-and-after replacement method.

\begin{tabular}{|c|c|c|c|c|c|c|}
\hline \multirow[b]{2}{*}{ Ignition Type } & \multicolumn{3}{|c|}{ Injuries } & \multicolumn{3}{|c|}{ Fatalities } \\
\hline & Flaming & Smoking & All & Flaming & Smoking & All \\
\hline $\ln (n)$ & -2.80 & -2.01 & -2.56 & -4.77 & -4.34 & -6.32 \\
\hline standard error & 0.11 & 0.09 & 0.06 & 0.19 & 0.29 & 0.48 \\
\hline $\ln (\delta)$ & -0.29 & 0.16 & 0.02 & -1.12 & 0.21 & 0.16 \\
\hline standard error & 0.09 & 0.10 & 0.05 & 0.45 & 0.20 & 0.13 \\
\hline Change in $\delta(\%)$ & -25 & 17 & 2 & -67 & 23 & 17 \\
\hline $\mathrm{Cl}^{*}$ & $-37:-10$ & $-3: 41$ & $-7: 12$ & $-86:-22$ & $-17: 82$ & $-9: 50$ \\
\hline
\end{tabular}

* Confidence Interval

those averages.

On a per-bed-fire basis, with flaming materials as the ignition sources, injuries decreased by $25 \%$ and fatalities decreased by $67 \%$. These reductions are consistent with the equivalent reductions in Table 1 . The changes in casualties from smoking-initiated fires and all fires are within their respective calculation uncertainties, consistent with the results shown in Table 1.

The consistencies of these two tables indicates that the casualties from bed fires were not sensitive to whether they were normalized to RUF fires or to the number of bed fires. This gives credence to the premise that, in the aggregate, normalizing bed fires to either data set is indeed isolating the effect of the Standard. (As can be seen in Appendix D, there are some subsets of the data that indicate the presence of one or more additional factors.)

Note that the results presented in Tables 1 and 2 are a snapshot. They will change over time as old mattresses are retired and new mattresses are put in service. The mattress-replacement analysis is intended to directly compare the impact of standard-compliant mattresses to nonstandard compliant ones, and therefore be less time-dependent.

Table 3 presents the results for the RUF-controlled approach in Table 1, but with the FIFO mattress replacement assumption and the lower bound (237 million) for the initial number of mattresses in use. Alternately worded, these results are different from those in Table 1 in that they factor in the rate at which Standard-compliant mattresses replaced pre-Standard ones. 
Table 3: Impact of the Standard on bed fires, injuries, and fatalities, estimated using the RUF-controlled approach with the FIFO mattress replacement method.

\begin{tabular}{|c|c|c|c|c|c|c|c|c|c|}
\hline \multirow[b]{2}{*}{ Ignition Type: } & \multicolumn{3}{|c|}{ Fires } & \multicolumn{3}{|c|}{ Injuries } & \multicolumn{3}{|c|}{ Fatalities } \\
\hline & Flaming & Smoking & All & Flaming & Smoking & All & Flaming & Smoking & All \\
\hline $\ln (\eta)$ & 0.80 & 0.19 & 0.38 & 0.76 & -0.08 & 0.22 & 0.25 & -0.40 & -0.36 \\
\hline standard error & 0.02 & 0.03 & 0.01 & 0.06 & 0.07 & 0.03 & 0.17 & 0.13 & 0.08 \\
\hline $\ln (\psi)$ & -0.08 & 0.08 & 0.02 & -0.26 & 0.32 & 0.03 & -1.74 & 0.15 & -0.06 \\
\hline standard error & 0.05 & 0.06 & 0.03 & 0.15 & 0.12 & 0.07 & 0.77 & 0.25 & 0.15 \\
\hline Change in $\psi(\%)$ & -8 & 9 & 3 & -23 & 38 & 3 & -83 & 16 & -6 \\
\hline $\mathrm{Cl}^{*}$ & $-16: 2$ & $-4: 22$ & $-4: 8$ & $-43: 3$ & 9:74 & $-10: 18$ & $-96:-21$ & $-29: 90$ & $-30: 26$ \\
\hline
\end{tabular}

These results support the finding in Table 1 that the new mattresses result in beds that are far less likely to lead to a fatal fire upon ignition by flaming ignition sources.

By contrast, bed fires ignited by smoking materials had become significantly more likely to result in injuries. Since there was no significant increase in the number of fires that spread beyond the bed, this likely indicates that post-Standard mattresses experienced weaker flaming following any transition from smoldering. There are four other possible contributors to this result, realizing that both the pre- and post-Standard mattresses met the requirements of the pass/fail cigarette ignition test (16 CFR Part 1632). ${ }^{2}$

- As the new mattresses were replacing the old ones, the fire hazard of the bedclothes might have been increasing; and/or

- The cigarette used in the test for ignition resistance of mattresses might have been a weaker ignition source ${ }^{3}$; and/or

- The pre-Standard mattresses might have provided an additional degree of protection from the consequences of cigarette ignition beyond that observed in the pass/fail test method.

- People might be more likely to fight the smaller fires, increasing their potential for injury.

Table 4 presents results similar to those in Table 3, but with the bed fire outcomes evaluated per reported bed fire.

\footnotetext{
${ }^{2}$ During the decade of interest in this report, requirements for less fire-prone cigarettes were being adopted by an increasing number of U.S. states. These regulations were shown to have decreased the deaths from cigarette-initiated fires [8].

${ }^{3}$ The original test cigarette in 16 CFR Part 1632 was a commercial cigarette identified in 1972 as the most severe ignition source for testing mattresses and mattress pads. In 2008, the manufacturer of that cigarette announced that it would be stopping production of that cigarette. Starting then, testing might have been performed using the available commercial cigarettes, which were, by law, less likely to ignite upholstered furniture and mattresses. Effective October 23, 2012, the CPSC required the use of SRM 1196 cigarettes, which became available in 2010 and were designed to replicate the ignition strength of the original commercial cigarette [9]. Thus, for as much as half of the period under consideration in this report, the test cigarette used in 16 CFR Part 1632 might have been weaker than in the years preceding the effective date of the Standard.
} 
Table 4: Impact of the Standard on bed fire injuries and fatalities, estimated using the Per-bed-fire Approach with the FIFO mattress replacement method.

\begin{tabular}{|c|c|c|c|c|c|c|}
\hline \multirow[b]{2}{*}{ Ignition Type: } & \multicolumn{3}{|c|}{ Injuries } & \multicolumn{3}{|c|}{ Fatalities } \\
\hline & Flaming & Smoking & All & Flaming & Smoking & All \\
\hline $\ln (n)$ & -1.86 & -1.65 & -1.93 & -4.54 & -3.24 & -3.99 \\
\hline standard error & 0.04 & 0.05 & 0.02 & 0.13 & 0.10 & 0.06 \\
\hline $\ln (\psi)$ & -0.27 & 0.18 & -0.05 & -0.63 & 0.16 & 0.04 \\
\hline standard error & 0.08 & 0.09 & 0.05 & 0.38 & 0.19 & 0.12 \\
\hline Change in $\psi(\%)$ & -24 & 19 & -5 & -46 & 18 & 4 \\
\hline $\mathrm{Cl}^{*}$ & $-35:-11$ & $0: 43$ & $-14: 5$ & $-75: 12$ & $-19: 70$ & $-18: 32$ \\
\hline
\end{tabular}

These results re-affirm:

- The finding in Tables 1 and 2 that the new mattresses result in beds that are far less likely to lead to a death or injury upon ignition by flaming ignition sources.

- The finding in Table 3 that bed fires from smoking materials had become significantly more likely to result in injuries.

- The finding from Tables 1 and 2 that normalizing bed fire outcomes to either RUF fires or to the number of bed fires is indeed isolating the effect of the Standard.

The results of cases with variations on these inputs are contained in Appendix D, along with assessment of the findings. 
This page was intentionally left blank. 


\section{SUMMARY AND CONCLUSIONS}

\section{Context and Methodology}

Effective July 1, 2007, the CPSC promulgated a Standard that would severely reduce the heat release rate (burning rate) and the early heat output from mattresses and foundations that had been ignited by a flaming ignition source. The design and intensity of this ignition source replicated the flames from a vigorously burning set of bedclothes. Mattresses complying with this Standard have been entering residences for more than a decade.

The purposes of this study are to (1) establish a methodology for evaluating the impact of this Standard and (2) estimate the extent to which the Standard was achieving its intent. The sources of data for the computer simulations were the National Fire Incident Reporting System (NFIRS), the U.S. Census, and mattress sales data from the International Sleep Products Association (ISPA).

The study consisted of compiling the number of bed fires, the numbers of resulting injuries and fatalities, and the number of fires that spread beyond the initially burning bed and that spread beyond the room in which the bed was located.

Over the course of a decade, it is possible that there were changes in factors other than the Standard that affected the outcome of bed fires. Thus, the study calculated the ratios of bed fire outcomes to each of three references:

- The number of residential upholstered furniture (RUF) fires. These combustibles are similar to beds in their component materials and their historic burning rates. The premise for using this ratio was that the only significant fire-related change occurring in the past decade that would have affected bed fires and not RUF fires was the promulgation of the Standard.

- The number of all residential fires. The premise was that the ratios of outcomes from bed fires to all fires would have remained constant in the absence of the Standard.

- The number of bed fires in residences. This provided an indication of any change in the severity of bed fires.

We applied two methods for analyzing for any changes in fire outcomes:

- A before-and-after method. The prevalence of the fire outcomes was determined for 2005-2006, the last two years prior to the introduction of the Standard, and 20152016, the two latest years for which NFIRS has compiled fire reports. The results reflect any changes in fire outcomes over that time period that affected bed fires without impacting RUF fires. The only such change that we are aware of is the implementation of the Standard, although it is possible other changes occurred. Since we are unaware of any other such changes, we believe the Standard to be the most likely cause of the changes measured by this method.

- A mattress-replacement-based method. For 2005 through 2016, the annual fire incidence data were combined with the corresponding mattress sales data to estimate the number of Standard-compliant mattresses in service each year and the effect of replacing a non-Standard-compliant mattress with a Standard-compliant one. 
Within these computations, we varied whether fire departments all experienced and reported fires uniformly or whether there was a diversity of fire department experience, whether fires reported as bedding fires differed from fires reported as mattress fires, whether identifying the mattress or bedding as the item most contributing to flame spread affected the fire outcome profile, whether we assumed that the oldest mattresses were replaced first or whether mattresses were replaced randomly, whether we input the high or low end of the estimated range of mattresses in use, and whether the fire occurred at night.

We also estimated the standard error in each of the calculations. This enabled us to flag those changes in fire outcome that were meaningful. Not unexpectedly, in many cases, subdividing the reported fires to investigate the effect of the modeling alternatives resulted in a very small number of incidents per subgroup. As a result, the standard error often became comparable to the mean value, and this masked any differentiation among the subgroups.

\section{General Findings}

Our general conclusion is that the Standard is accomplishing its purpose. The Standard led to considerable reductions in fatalities and injuries from bed fires ignited by flaming sources, relative to the casualties from RUF fires, all fires, and all bed fires. There was also no evidence of an increase in the spread of the bed fires beyond the bed itself.

For fires that were ignited by smoking materials (smoldering ignition), there were no significant changes in the numbers of reported fires, fires that spread beyond the bed or the fire room, and fatalities compared to RUF fires. There was a significant increase in the number of injuries, probably resulting from some beds burning less intensely if the fire transitioned from smoldering to flaming.

There was evidence that the number and consequences of nighttime fires had decreased relative to the consequences for all fires. This was not found in the calculations relative to RUF fires, i.e., there were factors involved in the decrease in both bed and RUF fires that occurred at night.

There are subsets of the bed fire incident data that show no effect of the Standard when referenced to RUF fires but show substantive reductions in losses when referenced to all fires. This further indicates that there are some factors that affected both bed fires and RUF fires differently from other types of fires.

Noting that many of the calculations of the sensitivity of the fire outcomes led to small numbers of fire incidents and thus generated results that were within the calculation uncertainty, we found no systematic evidence that the outcomes of the fires were significantly affected by (1) the method used for calculating the introduction of post-Standard mattresses into residences, (2) variability in fire reporting among fire departments, (3) reporting of the initial combustible was the mattress or bedding, or (4) whether the mattress or bedding was reported as the item most contributing to flame spread.

The following sections expand on these findings and summarize the effects of the modeling parameter variations on them. 


\section{Fires Ignited by Flaming Sources}

Fatalities from fires ignited by flaming ignition sources declined by approximately $80 \%$ relative to RUF fires or all fires. This decrease is comparable to the fraction of mattresses that had been replaced during this time period, supporting the finding that the decline is attributable to the Standard. Injuries from these fires declined by about one-third relative to RUF fires, and the number of bed fires decreased by about $12 \%$. That the decreases in fatalities and injuries are larger than the decrease in the number of bed fires indicates that the Standard is reducing the harm from what had been the most hazardous fires.

Implementation of the Standard reduced the numbers of fires that spread beyond the bed and beyond the room, relative to RUF-referenced fires, all fires, and per-bed-fires. This supports the finding in the prior paragraph that the Standard has diminished the harm from the most hazardous fires.

The decrease in fatalities was unaffected significantly by the method used for calculating the introduction of post-Standard mattresses into residences. There was no significant effect of whether the mattress or bedding was identified as the first item ignited or whether either was identified as the item most contributing to flame spread. There was a good degree of NFIRS reporting consistency among the fire departments, i.e., there was no more than a modest effect of whether fire departments were treated individually or in the aggregate.

The number of fatalities prevented by beds with Standard-compliant mattresses when ignited by flaming heat sources during the two-year period 2015 and 2016 are estimated to have been 59 (95\% CI: 22 - 122) using the before-and-after method and 75 (95\% CI: 33 - 138) using the mattress replacement method. (For reference, NFPA estimated that during 2002 through 2005, i.e., prior to the Standard, fires started by flaming ignition sources resulted in an annual average of 115 fatalities and fires started by smoking materials resulted in an annual average of 165 fatalities[6].) Barring any other changes affecting the incidence of bed fires and their consequences, it is likely that the number of prevented fatalities from flameignited bed fires will continue or exceed this level as more pre-Standard mattresses are replaced.

\section{Fires Ignited by Smoking Materials}

As discussed in Appendix D, there were no significant changes in the numbers of reported fires, fires that spread beyond the bed or the fire room, and fatalities compared to RUF fires. This was expected since the Standard focused on reducing casualties due to flaming ignitions and not smoking ignitions.

However, there were indications of a significant increase in injuries from these fires.

Combined with not finding any increase in fire spread beyond the bed, this increase might be explained by weaker flaming following a transition from smoldering. There might also be contributions from an unknown change in the fire hazard of bedclothes, the use of weaker cigarettes to test for ignition susceptibility, pre-Standard mattresses having an additional degree of protection against smoldering ignition relative to post-Standard mattresses, and/or people being more likely to try to fight the smaller fires, increasing the potential of injury. 


\section{Nighttime Fires}

There was a significant decrease in the numbers of reported nighttime fires, fires spreading beyond the bed, and casualties in the all-fires-controlled calculations; this was not found in the RUF-controlled calculations. The calculated decreases were larger in cases where the sales rate was included in the calculation. Note that this category includes ignitions by both flaming and non-flaming sources, including those other than smoking materials. Thus, for instance, more nighttime care in the separation of space heaters from combustibles might have led to reductions in both RUF and bed fires, but not the more numerous kitchen fires.

Only one of the calculations showed a significant increase in nighttime injuries. This was not seen in either the fires ignited by smoking materials or by flaming sources and is thus unexplained.

\section{ACKNOWLEDGEMENTS}

This project was supported fully by Federal funding. The authors thank the International Sleep Products Association (ISPA) and Ryan Trainer, the ISPA President, for providing the annual mattress sales data. 


\section{REFERENCES}

1. Ahrens, M., (2018). Home Structure Fires and Supporting Tables. National Fire Protection Association, Quincy, MA.

2. 16 Code of Federal Regulations Part 1632. (FF 4-72 amended). Consumer Product Safety Commission. (1984). Standard for the flammability of mattresses (and mattress pads); final rule. Federal Register, 49, 39653. Retrieved from https:/www.loc.gov/item/fr049197/.

3. 16 Code of Federal Regulations Part 1633. Consumer Product Safety Commission. (2006). Final rule: Standard for the flammability (open flame) of mattress sets. Federal Register, 71(50), 13472. Retrieved from https://www.federalregister.gov/documents/2006/03/15/062206/final-rule-standard-for-the-flammability-open-flame-of-mattress-sets.

4. Ohlemiller, T.J., and Gann, R.G. (2002). Estimating Reduced Fire Risk Resulting from an Improved Mattress Flammability Standard. NIST Technical Note 1446. National Institute of Standards and Technology, Gaithersburg, MD.

5. Ohlemiller, T.J., Shields, J.R., McLane, R.A., and Gann, R.G. (2000). Flammability Assessment Methodology for Mattresses. NISTIR 6497. National Institute of Standards and Technology, Gaithersburg, MD, 20899.

6. Ahrens, M. (2008) Home Fires that Began with Mattresses and Bedding, National Fire Protection Association, Quincy, MA.

7. U.S. Fire Administration. (2015). National Fire Incident Reporting System Complete Reference Guide 2015. U.S. Fire Administration. Emmitsburg, MD.

8. Hall, Jr., J.R. (2013). The Smoking Material Fire Problem. National Fire Protection Association. Quincy, MA.

9. Gann, R.G., and Hnetkovsky E.J. (2009). Modification of ASTM E 2187 for Measuring the Ignition Propensity of Conventional Cigarettes, Technical Note 1627. National Institute of Standards and Technology. Gaithersburg, MD. https://doi.org/10.6028/NIST.TN.1627. 
This page was intentionally left blank. 


\section{APPENDIX A: MATHEMATICAL DEVELOPMENT OF THE BEFORE-AND- AFTER METHOD}

The following definitions apply:

$Y_{i}$ is a composite random variable determining the number of fires in location $\times$ time $i \times j$. Specifically, we define $Y_{i}=\left\{c_{i j}, m_{i j}, t_{i j}\right\}$, where:

$c_{i}$ is a random variable representing the number of control fires in location $\times$ time $i \times j$.

$m_{i}$ is a random variable representing the number of treatment fires in location $\times$ time $i \times j$.

$t_{i}$ is a non-random variable indicating whether the Standard is in place at location $\times$ time $i \times j$. In particular, $t_{i j}=0$ indicates that this observation is prior to the imposition of the Standard and $t_{i j}=1$ indicates that this observation is after the imposition of the Standard.

We assume that both $c_{i j}$ and $m_{i j}$ are distributed Poisson, where:

$$
c_{i j} \sim \operatorname{Pois}\left(\lambda_{i j}\right)
$$

and

$$
m_{i j} \sim \operatorname{Pois}\left(\lambda_{i j} \eta \delta^{t_{i j}}\right)
$$

Assume that our prior belief on $\lambda_{i j}$ is distributed $\operatorname{Gamma}\left(\alpha_{i j}, \beta_{i j}\right)$, then the posterior distribution on $\lambda_{i j}$ conditional on $c_{i j}$ is:

$$
\left(\lambda_{i j} \mid \alpha_{i j}, \beta_{i j}, c_{i j}\right) \sim \operatorname{Gamma}\left(\alpha_{i j}+c_{i j}, \beta_{i j}+1\right)
$$

Then we have

$$
P\left\{m_{i j}=n \mid \lambda_{i j}, \eta, \delta, t_{i j}\right\}=\frac{\left(\lambda_{i j} \eta \delta^{t_{i j}}\right)^{n}}{n !} e^{-\lambda_{i j} \eta \delta^{t_{i j}}}
$$

Integrate over the posterior for $\lambda_{i j}$ :

$$
P\left\{m_{i j}=n \mid \eta, \delta, t\right\}=\int_{0}^{\infty} \frac{\left(\lambda \eta \delta^{t}\right)^{n}}{n !} e^{-\lambda \eta \delta^{t}} \gamma\left(\lambda \mid \alpha_{i j}+c_{i j}, \beta_{i j}+1\right) d \lambda,
$$

where $\gamma$ is the probability density function for the gamma distribution. Note that, since for the gamma distribution if $x \sim \operatorname{Gamma}(\alpha, \beta)$ then $c x \sim \operatorname{Gamma}(\alpha, \beta / c)$, we can rewrite this as:

$$
P\left\{m_{i j}=n \mid \eta, \delta, t\right\}=\int_{0}^{\infty} \frac{u^{n}}{n !} e^{-u} \gamma\left(u \mid \alpha_{i j}+c_{i j}, \frac{\beta_{i j}+1}{\eta \delta^{t}}\right) d u .
$$

This is a standard Gamma-Poisson distribution, which is equivalent to the Negative Binomial Distribution.

A standard Gamma-Poisson distribution, defined as: 


$$
P\{x=n \mid \alpha, \beta\}=\int_{0}^{\infty} \frac{u^{n}}{n !} e^{-u} \gamma\left(u \mid \alpha, \frac{1-p}{p}\right) d u,
$$

is equivalent to a Negative Binomial distribution:

$$
x \sim N B(\sigma, p) .
$$

That means that

$$
\left(m_{i j} \mid \delta, t_{i j}, \alpha_{i}, \beta_{i}, c_{i}\right) \sim N B\left(\alpha_{i j}+c_{i j}, \frac{\eta \delta^{t}}{1+\beta_{i j}+\eta \delta^{t}}\right) .
$$

In particular, we can consider the case where $\left(\alpha_{i j}, \beta_{i j}\right) \rightarrow 0$, which serves as an uninformative prior on $\lambda_{i j}$. In that case, we have:

$$
\left(m_{i j} \mid \delta, t_{i j}, c_{i j}\right) \sim N B\left(c_{i}, \frac{\eta \delta^{t}}{1+\eta \delta^{t_{i j}}}\right) .
$$

Expressing this in terms of mean $(\mu)$ and $\sigma$ (which turns out to be a convenient parameterization), we have:

$$
\left(m_{i j} \mid \delta, t_{i j}, \alpha_{i j}, \beta_{i j}, c_{i j}\right) \sim N B\left(r_{i j}, \mu_{i j}\right)=N B\left(\alpha_{i j}+c_{i j}, \frac{\alpha_{i j}+c_{i j}}{1+\beta_{i j}} \eta \delta^{t}\right) .
$$

and

$$
\left(m_{i j} \mid \delta, t_{i j}, c_{i j}\right) \sim N B\left(r_{i j}, \mu_{i j}\right)=N B\left(c_{i j}, c_{i j} \eta \delta^{t_{i j}}\right) .
$$




\section{APPENDIX B: MATHEMATICAL DEVELOPMENT OF THE MATTRESS REPLACEMENT METHOD}

Consider the cases where there are multiple time periods with information about the proportion of mattress types. The following revised definitions apply:

$Y_{i}$ is composite random variable determining the number of fires in location $\times$ time $i \times j$.

Specifically, we define $Y_{i j}=\left\{c_{i j}, m_{i j}, m_{i j}^{1}, m_{i j}^{2}, \theta_{i j}\right\}$, where:

$c_{i j}$ is a random variable representing the number of control fires in location $\times$ time $i \times j$.

$m_{i j}^{1}$ is a random variable representing the number of treatment fires in location $\times$ time $i \times j$ for non-standard-compliant mattresses. $m_{i j}^{2}$ is a random variable representing the number of treatment fires in location $\times$ time $i \times j$ for standard-compliant mattresses. Note that both $m_{i j}^{1}$ and $m_{i j}^{2}$ are latent variables and are not known.

$m_{i j}=m_{i j}^{1}+m_{i j}^{2}$ is a random variable representing the total number of treatment fires and is known.

$\theta_{i j}$ is a non-random variable indicating the proportion of standard-compliant mattresses as a total of all mattresses at location $\times$ time $i \times j$. (See Appendix $\mathrm{C}$ for this calculation.)

As before, we assume that $c_{i j}, m_{i j}^{1}$ and $m_{i j}^{2}$ are distributed Poisson, where:

$$
\begin{gathered}
c_{i j} \sim \operatorname{Pois}\left(\lambda_{i j}\right), \\
m_{i j}^{1} \sim \operatorname{Pois}\left(\lambda_{i j} \eta\left(1-\theta_{i j}\right)\right),
\end{gathered}
$$

and

$$
m_{i j}^{2} \sim \operatorname{Pois}\left(\lambda_{i j} \eta \psi \theta_{i j}\right)
$$

As before, we assume that our prior belief on $\lambda_{i j}$ is distributed $\operatorname{Gamma}\left(\alpha_{i j}, \beta_{i j}\right)$.

Since $m_{i j}=m_{i j}^{1}+m_{i j}^{2}$ and both $m_{i j}^{1}$ and $m_{i j}^{2}$ are distributed Poisson, then $m_{i j}$ is also distributed Poisson with distribution:

$$
m_{i j} \sim \operatorname{Pois}\left(\lambda_{i j} \eta\left(\left(1-\theta_{i j}\right)+\psi \theta_{i j}\right)\right) .
$$

This can alternatively be expressed as:

$$
m_{i j} \sim \operatorname{Pois}\left(\lambda_{i j} \eta\left(1+(\psi-1) \theta_{i j}\right)\right) \text {. }
$$

Note that this is the same expression as in the equivalent equation above with $\left(1+(\psi-1) \theta_{i j}\right)$ substituted for $\delta^{t_{i j}}$. So, based on the derivation above we have that: 


$$
\left(m_{i j} \mid \delta, t_{i j}, \alpha_{i j}, \beta_{i j}, c_{i j}\right) \sim N B\left(\alpha_{i j}+c_{i j}, \eta \frac{1+(\psi-1) \theta_{i j}}{1+\beta_{i j}+\eta\left(1+(\psi-1) \theta_{i j}\right)}\right) .
$$

And in the case of our uninformative prior where $\left(\alpha_{i}, \beta_{i}\right) \rightarrow 0$, we have:

$$
\left(m_{i j} \mid \delta, t_{i j}, c_{i j}\right) \sim N B\left(c_{i j}, \frac{\eta\left(1+(\psi-1) \theta_{i j}\right)}{1+\eta\left(1+(\psi-1) \theta_{i j}\right)}\right) .
$$

Again, expressing this in terms of mean $(\mu)$ and , we have:

$$
\left(m_{i j} \mid \delta, t_{i j}, \alpha_{i j}, \beta_{i j}, c_{i j}\right) \sim N B\left(r_{i j}, \mu_{i j}\right)=N B\left(\alpha_{i j}+c_{i j}, \frac{\alpha_{i j}+c_{i j}}{1+\beta_{i j}} \eta\left(1+(\psi-1) \theta_{i j}\right)\right) .
$$

and

$$
\left(m_{i j} \mid \delta, t_{i j}, c_{i j}\right) \sim N B\left(r_{i j}, \mu_{i j}\right)=N B\left(c_{i j}, c_{i j} \eta\left(1+(\psi-1) \theta_{i j}\right)\right) .
$$




\section{APPENDIX C: MATHEMATICAL DEVLOPMENT OF THE STANDARD- COMPLIANT MATTRESS REPLACEMENT PROCESS}

The following definitions apply:

$N_{i}^{S}$ is the number of standard-compliant mattresses at time $i$.

$N_{i}^{n}$ is the number of non-standard-compliant mattresses at time $i$.

$N_{i}$ is the total number of mattresses at time $i$, where $N_{i}=N_{i}^{S}+N_{i}^{n}$.

$\theta_{i}$ is the proportion of Standard-compliant mattresses in service at time $i$ and is $\theta_{i}=$ $\frac{N_{i}^{s}}{N_{i}}$.

$S_{i}$ is the number of mattress sales between time periods $i-1$ and $i$. It is assumed that all mattress sales for $i>0$ are Standard-compliant.

$P_{i}$ is the total population at time $i$.

It is assumed that the proportion of mattresses per person is constant. That is, for all $i, \rho=\frac{N_{i}}{P_{i}}$ is constant.

$R_{i}^{S}$ is the number of Standard-compliant mattresses retired from service between time periods $i-1$ and $i$.

$R_{i}^{n}$ is the number of non-Standard-compliant mattresses retired from service between time periods $i-1$ and $i$.

$R_{i}$ is the total number of mattresses retired from service between time periods $i-1$ and $i$, where $R_{i}=R_{i}^{S}+R_{i}^{n}$.

Then:

$$
N_{i}=N_{i-1}+S_{i}-R_{i}
$$

or

$$
N_{i}=\rho P_{i}=\rho P_{i-1}+S_{i}-R_{i}
$$

Then

$$
R_{i}=S_{i}-\rho\left(P_{i}-P_{i-1}\right) .
$$

Similarly,

$$
N_{i}^{S}=N_{i-1}^{S}+S_{i}-R_{i}^{S},
$$

since all new mattresses are Standard-compliant.

The value of $R_{i}^{S}$ depends on what model we use for retirement of the pre-Standard mattresses. There are two end-member models that are considered here. A first-in-first-out (FIFO) model, and an equal-probability (EP) model. In the FIFO model, so long as there are 
non-Standard-compliant mattresses in circulation (that is, so long as $\theta_{i}<1$ ), then $R_{i}^{S}=0$. In the EP model, each mattress in service is equally likely to be retired, so:

$$
R_{i}^{S}=\frac{N_{i-1}^{S}}{N_{i-1}} R_{i}=\theta_{i-1} R_{i}
$$

We combine the two models by writing:

$$
R_{i}^{S}=\kappa \theta_{i-1} R_{i},
$$

where $\kappa \in[0,1]$. Here $\kappa=0$ corresponds to the FIFO model and $\kappa=1$ corresponds to the equal-probability model.

Then:

$$
\begin{gathered}
N_{i}^{S}=\theta_{i} N_{i}=N_{i-1}^{s}+S_{i}-R_{i}^{S} \\
\theta_{i} N_{i}=\theta_{i-1} N_{i-1}+S_{i}-\kappa \theta_{i-1} R_{i} \\
\theta_{i} N_{i}=\theta_{i-1} N_{i-1}+S_{i}-\kappa \theta_{i-1}\left[S_{i}-\rho\left(P_{i}-P_{i-1}\right)\right] .
\end{gathered}
$$

Now, we add and subtract $\rho\left(P_{i}-P_{i-1}\right)$ from the right side and collect terms to give:

$$
\begin{gathered}
\theta_{i} N_{i}=\theta_{i-1} N_{i-1}+S_{i}+\rho\left(P_{i}-P_{i-1}\right)-\rho\left(P_{i}-P_{i-1}\right)-\kappa \theta_{i-1}\left[S_{i}-\rho\left(P_{i}-P_{i-1}\right)\right] \\
\theta_{i} N_{i}=\theta_{i-1} N_{i-1}+\rho\left(P_{i}-P_{i-1}\right)+\left(S_{i}-\rho\left(P_{i}-P_{i-1}\right)\right)\left(1-\kappa \theta_{i-1}\right) .
\end{gathered}
$$

Factor $N_{i-1}$ from the right-hand side and divide by $N_{i}$ gives:

$$
\theta_{i}=\frac{N_{i-1}}{N_{i}}\left[\theta_{i-1}+\rho \frac{P_{i}-P_{i-1}}{N_{i-1}}+\left(\frac{S_{i}}{N_{i-1}}-\rho \frac{P_{i}-P_{i-1}}{N_{i-1}}\right)\left(1-\kappa \theta_{i-1}\right)\right] \text {. }
$$

Replace the remaining $N_{i}$ terms with the population-based value and simplifying gives:

$$
\theta_{i}=\frac{P_{i-1}}{P_{i}}\left[\theta_{i-1}+\frac{P_{i}-P_{i-1}}{P_{i-1}}+\left(\frac{S_{i}}{\rho P_{i-1}}-\frac{P_{i}-P_{i-1}}{P_{i-1}}\right)\left(1-\kappa \theta_{i-1}\right)\right] .
$$




\section{APPENDIX D: PARAMETRIC VARIATIONS WITHIN THE MODELING APPROACHES}

\section{D.1. Summary of Tables}

Table 5 summarizes the data tables in this Appendix.

Table 5: Table numbers for estimations of the effect of the Standard on various fire outcomes.

\begin{tabular}{|c|c|c|c|c|c|c|}
\hline \multirow{2}{*}{} & & \multicolumn{5}{|c|}{ Outcome Estimated } \\
\hline Approach & Method & $\begin{array}{c}\text { Reported } \\
\text { Fires }\end{array}$ & $\begin{array}{c}\text { Fires } \\
\text { Beyond } \\
\text { Object }\end{array}$ & $\begin{array}{c}\text { Fires } \\
\text { Beyond } \\
\text { Room }\end{array}$ & Injuries & Fatalities \\
\hline RUF & B/A & Table 7 & Table 8 & Table 9 & Table 10 & Table 11 \\
\hline RUF & Sales & Table 12 & Table 13 & Table 14 & Table 15 & Table 16 \\
\hline All & B/A & Table 17 & Table 18 & Table 19 & Table 20 & Table 21 \\
\hline All & Sales & Table 22 & Table 23 & Table 24 & Table 25 & Table 26 \\
\hline VFD & B/A & Table 27 & Table 28 & Table 29 & Table 30 & Table 31 \\
\hline VFD & Sales & Table 31 & Table 33 & Table 34 & Table 35 & Table 36 \\
\hline PBF & B/A & n/a & n/a & n/a & Table 37 & Table 38 \\
\hline PBF & Sales & n/a & n/a & n/a & Table 39 & Table 40 \\
\hline
\end{tabular}

RUF: RUF-controlled approach, FD: variable fire department approach, All: per-all-fires approach, B/A: beforeand-after method, Sales: mattress replacement method; PBF: per-bed-fire approach.

In each of the following tables, the first data row contains the calculated values of $\ln (\eta)$, the natural $\log$ of the ratio of bed fire outcomes to control outcomes before imposition of the standard $(\eta)$. The second row contains the standard errors in these calculations. The third and fourth rows contain the calculated values and standard errors of $\ln (\delta$ or $\psi)$, where $\delta$ is the ratio of bed fire outcomes post-Standard to bed fire outcomes pre-Standard for the before-and-after model calculations. $\psi$ is the analog of $\delta$ for the time-dependent mattress replacement calculations using the annual mattress sales data.

Positive values of $\eta$ indicate more bed fire outcomes than the control, while negative estimates indicate fewer than the control. Large negative values of $\ln (\delta$ or $\psi)$ indicate that the Standard has reduced the undesirable fire outcomes. Large positive values of $\ln (\delta$ or $\psi)$ indicate that the (undesirable) fire outcomes increased after the imposition of the Standard. The other estimated variable shown in Tables 1 to 4 is the natural log of the ratio of bed fire outcomes to control outcomes before imposition of the standard $(\eta)$. Positive estimates indicate more bed fire outcomes than the control, while negative estimates indicate fewer than the control. The values of $\ln (\delta)$ and the values of $\ln (\eta)$ that are statistically significant at the $95 \%$ (two-sided) confidence level are in italics and boldface in the tables. 
In some of the tables, there are values of $\ln (\delta$ or $\psi)$ that are smaller than -12 . Since there are fewer than 400,000 NFIRS incidents per year, these indicate there was no more than one or two fires involving a post-Standard mattress with that outcome. In addition, there are blanks in some cells of standard errors. In those cases, the standard errors were so large they were not estimable. Any result with missing standard error is not statistically significant. Similarly, there are entries with very large standard errors in the tables (some indicating decreases of $100 \%$ ) that are not in boldface and italics, indicating these are not statistically significant. Both groups occur because there are not enough different outcomes to effectively estimate the model outcome for those cases.

Within each set of five tables (same model, different outcome being tabulated), the value of $\ln (\eta)$ for All Ignitions should be statistically the same, subject to a small error in data sampling. This is because, prior to the Standard, the numbers of RUF fires and/or all fires are the same and the numbers of fire outcomes are the same.

Standard errors are determined in different ways depending on the estimation methodology used. For any model estimated using maximum likelihood or as a generalized linear model, the standard errors are determined in the usual way for those estimation methods. For models estimated using Bayesian Markov-Chain Monte Carlo (MCMC) methods, 15000 iterations (after warmup) were run and the standard error was the standard deviation of the results over those iterations. Which models were estimated using each technique is shown in Table 6.

Table 6: Estimation Methods for Model Uncertainty.

\begin{tabular}{|l|l|l|}
\hline \multicolumn{1}{|c|}{ Index } & \multicolumn{1}{c|}{ Before and After } & \multicolumn{1}{c|}{ Mattress Replacement } \\
\hline RUF Fires & Maximum Likelihood & Maximum Likelihood \\
\hline All Fires & Maximum Likelihood & Maximum Likelihood \\
\hline $\begin{array}{l}\text { Variable Fire } \\
\text { Department }\end{array}$ & Bayesian MCMC & Bayesian MCMC \\
\hline Per-bed-fire & GLM & Maximum Likelihood \\
\hline
\end{tabular}




\section{D.2 RUF-Controlled Models}

Tables 7 through 11 present the results of calculations of changes in fire outcome which result from including fire reports in which (a) the bed was identified as the item contributing most to fire spread (IC) and (b) whether or not bedding was identified as the item first ignited (IFI) and/or the item most contributing to fire spread. Nighttime fires (all ignitions) are also singled out, since this is when people are more likely to be in an ignited bed and thus are more at risk of injury or death.

Table 7: Effect of including bedding and the item contributing most to flame spread on the number of reported ignitions, estimated using the RUF-controlled approach and the before-and-after method.

\begin{tabular}{|c|c|c|c|c|c|c|c|c|c|}
\hline \multicolumn{2}{|c|}{ Model Includes: } & \multicolumn{4}{|c|}{ Flaming Ignitions } & \multicolumn{4}{|c|}{ Smoking Material Ignitions } \\
\hline Mode & $\begin{array}{l}\text { Ides: } \\
\text { Mattress/RUF } \\
\text { Bedding }\end{array}$ & IFI & IFI, IC & $\begin{array}{l}\text { IFI } \\
\text { IFI }\end{array}$ & $\begin{array}{l}\text { IFI, IC } \\
\text { IFI, IC }\end{array}$ & IFI & IFI, IC & $\begin{array}{l}\mathrm{IFI} \\
\mathrm{IFI}\end{array}$ & $\begin{array}{l}\text { IFI, IC } \\
\text { IFI, IC }\end{array}$ \\
\hline \multirow{2}{*}{$\ln (n)$} & value & 0.03 & 0.01 & 0.89 & 0.78 & -0.32 & -0.31 & 0.27 & 0.23 \\
\hline & standard error & 0.04 & 0.04 & 0.03 & 0.03 & 0.041 & 0.040 & 0.035 & 0.034 \\
\hline $\ln (\delta)$ & value & 0.00 & -0.02 & -0.11 & -0.12 & -0.04 & -0.03 & 0.01 & 0.01 \\
\hline
\end{tabular}

\begin{tabular}{|c|c|c|c|c|c|c|c|c|c|}
\hline & & \multicolumn{4}{|c|}{ Ignitions at Night } & \multicolumn{4}{|c|}{ All Ignitions } \\
\hline \multicolumn{10}{|c|}{ Model Includes: } \\
\hline & Mattress/RUF & IFI & IFI, IC & IFI & IFI, IC & IFI & IFI, IC & IFI & IFI, IC \\
\hline & Bedding & & & IFI & IFI, IC & & & IFI & IFI, IC \\
\hline \multirow{2}{*}{$\ln (\eta)$} & value & -0.46 & -0.47 & 0.32 & 0.25 & -0.30 & -0.32 & 0.47 & 0.38 \\
\hline & standard error & 0.04 & 0.03 & 0.03 & 0.03 & 0.02 & 0.02 & 0.02 & 0.012 \\
\hline $\ln (\delta)$ & value & 0.13 & 0.15 & 0.05 & 0.06 & 0.07 & 0.08 & 0.00 & 0.01 \\
\hline \multicolumn{2}{|c|}{ Change in $\delta(\%)$} & $13 \%$ & $16 \%$ & $5 \%$ & $6 \%$ & $8 \%$ & $8 \%$ & $0 \%$ & $0 \%$ \\
\hline
\end{tabular}


Table 8: Effect of including bedding and the item contributing most to flame spread on the number of fires that spread beyond the object of origin, estimated using the RUFcontrolled approach and the before-and-after method.

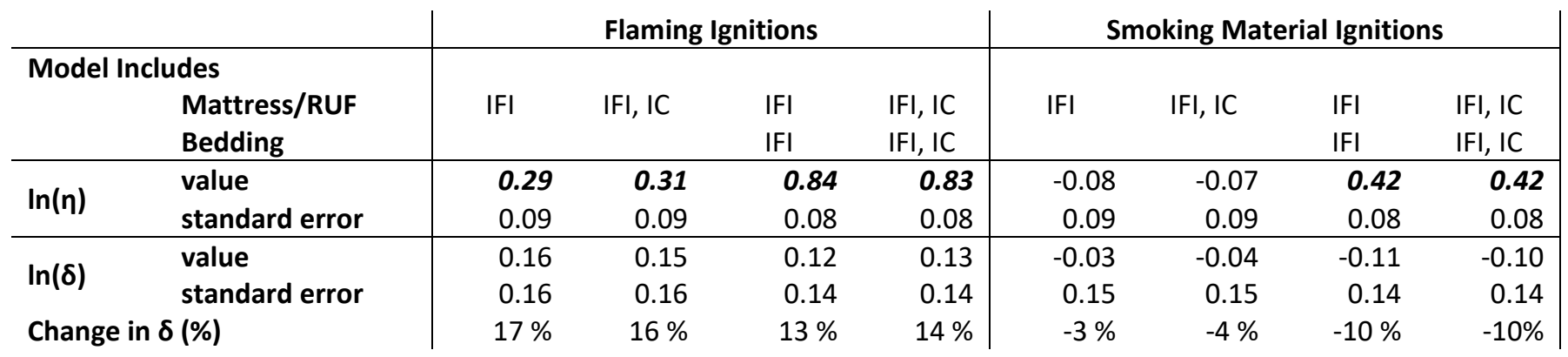

\begin{tabular}{|c|c|c|c|c|c|c|c|c|c|}
\hline \multirow{2}{*}{\multicolumn{2}{|c|}{ Model Includes }} & \multicolumn{4}{|c|}{ Night Ignitions } & \multicolumn{4}{|c|}{ All Ignitions } \\
\hline & & & & & & & & & \\
\hline & Mattress/RUF & IFI & IFI, IC & IFI & IFI, IC & IFI & IFI, IC & IFI & IFI, IC \\
\hline & Bedding & & & IFI & IFI, IC & & & $\mathrm{IFI}$ & $\mathrm{IFI}, \mathrm{IC}$ \\
\hline \multirow{2}{*}{$\ln (n)$} & value & -0.19 & -0.19 & 0.38 & 0.37 & -0.01 & 0.00 & 0.56 & 0.56 \\
\hline & standard error & 0.08 & 0.08 & 0.07 & 0.07 & 0.05 & 0.05 & 0.04 & 0.04 \\
\hline \multirow{2}{*}{$\ln (\delta)$} & value & 0.15 & 0.15 & 0.05 & 0.07 & 0.05 & 0.04 & 0.01 & 0.01 \\
\hline & standard error & 0.14 & 0.14 & 0.13 & 0.13 & 0.08 & 0.08 & 0.07 & 0.07 \\
\hline \multicolumn{2}{|c|}{ Change in $\delta(\%)$} & $16 \%$ & $16 \%$ & $6 \%$ & $7 \%$ & $5 \%$ & $4 \%$ & $1 \%$ & $1 \%$ \\
\hline
\end{tabular}

Table 9: Effect of including bedding and the item contributing most to flame spread on the number of fires that spread beyond the room of origin, estimated using the RUF-controlled approach and the before-and-after method.

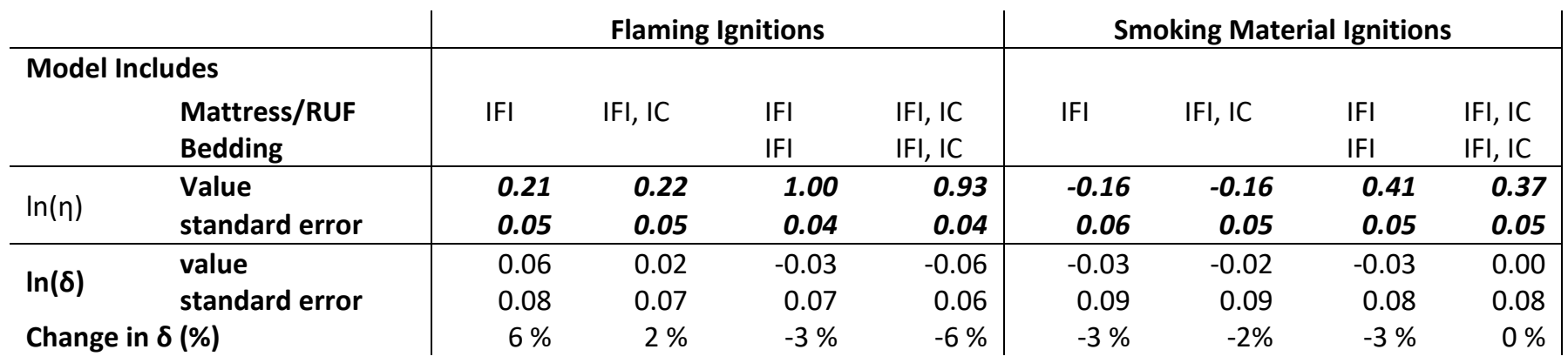

\begin{tabular}{|c|c|c|c|c|c|c|c|c|c|}
\hline \multirow{2}{*}{\multicolumn{2}{|c|}{ Model Includes }} & \multicolumn{4}{|c|}{ Night Ignitions } & \multicolumn{4}{|c|}{ All Ignitions } \\
\hline & & & & & & & & & \\
\hline & Mattress/RUF & IFI & IFI, IC & IFI & IFI, IC & IFI & IFI, IC & IFI & IFI, IC \\
\hline & Bedding & & & IFI & $\mathrm{IFI}, \mathrm{IC}$ & & & IFI & $\mathrm{IFI}, \mathrm{IC}$ \\
\hline \multirow{2}{*}{$\ln (n)$} & value & -0.28 & -0.26 & 0.45 & 0.41 & -0.11 & -0.11 & 0.61 & 0.55 \\
\hline & standard error & 0.05 & 0.05 & 0.04 & 0.04 & 0.03 & 0.03 & 0.02 & 0.02 \\
\hline \multirow{2}{*}{$\ln (\delta)$} & value & 0.12 & 0.12 & 0.05 & 0.06 & 0.08 & 0.09 & 0.03 & 0.04 \\
\hline & standard error & 0.08 & 0.07 & 0.07 & 0.06 & 0.04 & 0.04 & 0.04 & 0.03 \\
\hline \multicolumn{2}{|c|}{ Change in $\delta(\%)$} & $12 \%$ & $13 \%$ & $5 \%$ & $6 \%$ & $9 \%$ & $10 \%$ & $3 \%$ & $4 \%$ \\
\hline
\end{tabular}


Table 10: Effect of including bedding and the item contributing most to flame spread on the number of injuries, estimated using the RUF-controlled approach and the before-andafter method.

\begin{tabular}{|c|c|c|c|c|c|c|c|c|c|}
\hline & & \multicolumn{4}{|c|}{ Flaming Ignitions } & \multicolumn{4}{|c|}{ Smoking Material Ignitions } \\
\hline \multirow{2}{*}{$\ln (n)$} & value & -0.15 & -0.14 & 0.69 & 0.65 & -0.92 & -0.88 & -0.09 & -0.10 \\
\hline & Standard error & 0.10 & 0.09 & 0.08 & 0.08 & 0.10 & 0.10 & 0.08 & 0.07 \\
\hline $\ln (\delta)$ & value & -0.28 & -0.47 & -0.20 & -0.41 & 0.08 & 0.12 & 0.16 & 0.12 \\
\hline
\end{tabular}

\begin{tabular}{|c|c|c|c|c|c|c|c|c|c|}
\hline \multirow{2}{*}{\multicolumn{2}{|c|}{ Model Includes: }} & \multicolumn{4}{|c|}{ Night Ignitions } & \multicolumn{4}{|c|}{ All Ignitions } \\
\hline & & & & & & & & & \\
\hline & Mattress/RUF & IFI & IFI, IC & IFI & IFI, IC & IFI & IFI, IC & IFI & IFI, IC \\
\hline & Bedding & & & IFI & IFI, IC & & & $\mathrm{IFI}$ & IFI, IC \\
\hline \multirow{2}{*}{$\ln (n)$} & value & -0.96 & -0.96 & 0.03 & -0.06 & -0.62 & -0.62 & 0.27 & 0.18 \\
\hline & standard error & 0.09 & 0.08 & 0.07 & 0.06 & 0.06 & 0.05 & 0.05 & 0.04 \\
\hline \multirow{2}{*}{$\ln (\delta)$} & value & 0.21 & 0.39 & -0.08 & 0.08 & 0.06 & 0.01 & -0.03 & -0.07 \\
\hline & standard error & 0.15 & 0.13 & 0.12 & 0.10 & 0.09 & 0.08 & 0.07 & 0.06 \\
\hline \multicolumn{2}{|c|}{ Change in $\delta(\%)$} & $24 \%$ & $48 \%$ & $-8 \%$ & $8 \%$ & $6 \%$ & $1 \%$ & $-3 \%$ & $-7 \%$ \\
\hline
\end{tabular}

Table 11: Effect of including bedding and the item contributing most to flame spread on the number of fatalities, estimated using the RUF-controlled approach and the before-andafter method.

\begin{tabular}{|c|c|c|c|c|c|c|c|c|c|}
\hline \multicolumn{2}{|c|}{ Model Includes: } & \multicolumn{4}{|c|}{ Flaming Ignitions } & \multicolumn{4}{|c|}{ Smoking Material Ignitions } \\
\hline & Bedding & IFI & IFI, IC & $\begin{array}{l}\text { IFI } \\
\text { IFI }\end{array}$ & $\begin{array}{l}\text { IFI, IC } \\
\text { IFI, IC }\end{array}$ & IFI & $\mathrm{IFI}, \mathrm{IC}$ & IFI & $\begin{array}{l}\text { IFI, IC } \\
\text { IFI, IC }\end{array}$ \\
\hline $\ln (n)$ & standard error & 0.37 & 0.35 & 0.26 & 0.24 & 0.20 & 0.18 & 0.15 & 0.15 \\
\hline $\ln (\delta)$ & value & -1.93 & -2.37 & -1.68 & -1.73 & -0.84 & -0.64 & 0.00 & 0.00 \\
\hline
\end{tabular}

\begin{tabular}{|c|c|c|c|c|c|c|c|c|c|}
\hline \multirow{2}{*}{\multicolumn{2}{|c|}{ Model Includes: }} & \multicolumn{4}{|c|}{ Night Ignitions } & \multicolumn{4}{|c|}{ All Ignitions } \\
\hline & & & & & & & & & \\
\hline & Mattress/RUF & IFI & IFI, IC & $\mathrm{IFI}$ & IFI, IC & IFI & IFI, IC & IFI & IFI, IC \\
\hline & Bedding & & & $\mathrm{IFI}$ & $\mathrm{IFI}, \mathrm{IC}$ & & & IFI & IFI, IC \\
\hline \multirow{2}{*}{$\ln (n)$} & value & -1.15 & -1.24 & -0.30 & -0.40 & -1.11 & -1.13 & -0.16 & -0.26 \\
\hline & standard error & 0.20 & 0.19 & 0.15 & 0.14 & 0.14 & 0.13 & 0.10 & 0.10 \\
\hline \multirow{2}{*}{$\ln (\delta)$} & value & -0.08 & 0.42 & -0.05 & 0.23 & -0.31 & -0.15 & -0.17 & -0.15 \\
\hline & standard error & 0.33 & 0.28 & 0.24 & 0.22 & 0.23 & 0.20 & 0.16 & 0.15 \\
\hline \multicolumn{2}{|c|}{ Change in $\delta(\%)$} & $-8 \%$ & $52 \%$ & $-5 \%$ & $26 \%$ & $-26 \%$ & $-14 \%$ & $-16 \%$ & $-14 \%$ \\
\hline
\end{tabular}


Once a mattress, RUF item, or bedding was identified as being the item first ignited, also tagging it as the item most contributing to flame spread had no significant effect on the $\ln (\eta)$ results (Columns 1 and 2 and Columns 3 and 4) in any of the five tables. This suggests that the incident reports generally equated the two roles.

Including the bedding as the item first ignited (Column 3 vs. Column 1 in all five tables) led to substantial increases in $\ln (\eta)$. By including bedding, we are increasing the number of fires included in the category of bed fires without increasing the number of fires included in the category of RUF fires, which alters the ratio of bed to RUF fires.

The differences in increase percentages among the five sets of data inputs were mostly small (less than or about $15 \%$ ) or not statistically significant. There were three notable exceptions in which the Standard led to:

- A large decrease in the number of injuries for fires in which the mattress was ignited by a flaming source and was identified as the item contributing most to fire spread. (Table 10) For beds with pre-Standard mattresses, this was the type of fire that would reach a lethal level quickly. Table 11 indicates an even greater decrease in the number of fatalities from these fires.

- A large increase in the number of injuries from these same fires when they occurred at night (Table 10). Table 10 indicates an even greater decrease in the number of fatalities from these fires.

- A large decrease in the number of fatalities for fires in which mattresses were ignited by smoking materials. (Table 11) These fires are generally slow to develop lethal conditions compared to flaming fires. Moreover, bed fires with post-Standard mattresses are far less likely to transition to flaming fires with their high life-threatening levels of toxic gases and elevated temperatures. 
Tables 12 through 16 present the results of calculations of changes in fire outcome for four different ways of including the rate at which post-Standard mattresses replaced pre-Standard mattresses. In all cases, $\mathrm{H}$ is the upper estimate of the total number of mattresses in use at the time of the implementation of the Standard, 304 million; L is the lower estimate, 237 million; FIFO is the first-in-first-out mattress replacement model; and EP is the random mattress replacement model.

Table 12: Effect of varying the calculation method for the replacement rate of preStandard mattresses on the number of reported ignitions, estimated using the RUFcontrolled approach.

\begin{tabular}{|c|c|c|c|c|c|c|c|c|c|}
\hline \multicolumn{2}{|c|}{ Mattress Model: } & \multicolumn{4}{|c|}{ Flaming Ignitions } & \multicolumn{4}{|c|}{ Smoking Materials Ignitions } \\
\hline \multirow{2}{*}{$\ln (n)$} & Value & 0.80 & 0.80 & 0.80 & 0.80 & 0.19 & 0.20 & 0.19 & 0.19 \\
\hline & Standard error & 0.02 & 0.03 & 0.02 & 0.03 & 0.03 & 0.03 & 0.03 & 0.03 \\
\hline $\ln (\Psi)$ & Value & -0.08 & -0.11 & -0.11 & -0.13 & 0.08 & 0.10 & 0.11 & 0.12 \\
\hline \multicolumn{2}{|c|}{ Change in $\Psi(\%)$} & $-8 \%$ & $-10 \%$ & $-10 \%$ & $-12 \%$ & $9 \%$ & $11 \%$ & $11 \%$ & $13 \%$ \\
\hline
\end{tabular}

\begin{tabular}{|c|c|c|c|c|c|c|c|c|c|}
\hline & & \multicolumn{4}{|c|}{ Night Ignitions } & \multicolumn{4}{|c|}{ All Ignitions } \\
\hline \multicolumn{10}{|c|}{ Mattress Model: } \\
\hline & Initial No. & $\mathrm{L}$ & $\mathrm{H}$ & $\mathrm{L}$ & $\mathrm{H}$ & $\mathrm{L}$ & $\mathrm{H}$ & $\mathrm{L}$ & $\mathrm{H}$ \\
\hline & Replacement & FIFO & FIFO & EP & EP & FIFO & FIFO & EP & EP \\
\hline \multirow{2}{*}{$\ln (\eta)$} & value & 0.22 & 0.22 & 0.22 & 0.22 & 0.38 & 0.38 & 0.38 & 0.38 \\
\hline & standard error & 0.02 & 0.03 & 0.02 & 0.03 & 0.01 & 0.01 & 0.01 & 0.01 \\
\hline $\ln (\psi)$ & value & 0.09 & 0.12 & 0.12 & 0.14 & 0.02 & 0.04 & 0.03 & 0.04 \\
\hline
\end{tabular}


Table 13: Effect of varying the calculation method for the replacement rate of pre-Standard mattresses on the fires that spread beyond the object of fire origin, estimated using the RUF-controlled approach.

\begin{tabular}{|c|c|c|c|c|c|c|c|c|c|}
\hline \multicolumn{2}{|c|}{ Mattress Model: } & \multicolumn{4}{|c|}{ Flaming Ignitions } & \multicolumn{4}{|c|}{ Smoking Materials Ignitions } \\
\hline \multirow{2}{*}{$\ln (\eta)$} & Value & 0.94 & 0.93 & 0.94 & 0.93 & 0.36 & 0.37 & 0.36 & 0.37 \\
\hline & Standard error & 0.07 & 0.08 & 0.07 & 0.07 & 0.06 & 0.07 & 0.06 & 0.06 \\
\hline $\ln (\Psi)$ & Value & 0.08 & 0.14 & 0.10 & 0.15 & -0.12 & -0.21 & -0.16 & -0.24 \\
\hline \multicolumn{2}{|c|}{ Change in $\Psi(\%)$} & $9 \%$ & $15 \%$ & $11 \%$ & $17 \%$ & $-12 \%$ & $-19 \%$ & $-14 \%$ & $-21 \%$ \\
\hline
\end{tabular}

\begin{tabular}{|c|c|c|c|c|c|c|c|c|c|}
\hline \multirow{2}{*}{\multicolumn{2}{|c|}{$\begin{array}{l}\text { Mattress Model: } \\
\text { Initial No. } \\
\text { Replacement }\end{array}$}} & \multicolumn{4}{|c|}{ Night Ignitions } & \multicolumn{4}{|c|}{ All Ignitions } \\
\hline & & $\begin{array}{c}\mathrm{L} \\
\text { FIFO }\end{array}$ & $\begin{array}{c}\mathrm{H} \\
\text { FIFO }\end{array}$ & $\begin{array}{c}\mathrm{L} \\
\mathrm{EP}\end{array}$ & $\begin{array}{l}\mathrm{H} \\
\mathrm{EP}\end{array}$ & $\begin{array}{c}\mathrm{L} \\
\text { FIFO }\end{array}$ & $\begin{array}{c}\mathrm{H} \\
\text { FIFO }\end{array}$ & $\begin{array}{c}\mathrm{L} \\
\mathrm{EP}\end{array}$ & $\begin{array}{l}\mathrm{H} \\
\mathrm{EP}\end{array}$ \\
\hline \multirow{2}{*}{$\ln (n)$} & value & 0.37 & 0.37 & 0.37 & 0.37 & 0.60 & 0.59 & 0.60 & 0.59 \\
\hline & standard error & 0.06 & 0.06 & 0.06 & 0.06 & 0.03 & 0.04 & 0.03 & 0.04 \\
\hline \multirow{2}{*}{$\ln (\psi)$} & value & 0.05 & 0.05 & 0.06 & 0.07 & -0.02 & -0.02 & -0.03 & -0.03 \\
\hline & standard error & 0.12 & 0.17 & 0.15 & 0.20 & 0.07 & 0.10 & 0.09 & 0.12 \\
\hline \multicolumn{2}{|c|}{ Change in $\psi(\%)$} & $5 \%$ & $5 \%$ & $7 \%$ & $7 \%$ & $-2 \%$ & $-2 \%$ & $-3 \%$ & $-3 \%$ \\
\hline
\end{tabular}

Table 14: Effect of varying the calculation method for the replacement rate of pre-Standard mattresses on the fires that spread beyond the room of fire origin, estimated using the RUF-controlled approach.

\begin{tabular}{|c|c|c|c|c|c|c|c|c|c|}
\hline \multicolumn{2}{|c|}{ Mattress Model: } & \multicolumn{4}{|c|}{ Flaming Ignitions } & \multicolumn{4}{|c|}{ Smoking Materials Ignitions } \\
\hline Mattr & $\begin{array}{l}\text { Aodel: } \\
\text { Initial No. } \\
\text { Replacement }\end{array}$ & $\begin{array}{c}\mathrm{L} \\
\text { FIFO }\end{array}$ & $\begin{array}{c}\mathrm{H} \\
\text { FIFO }\end{array}$ & $\begin{array}{c}\mathrm{L} \\
\mathrm{EP}\end{array}$ & $\begin{array}{l}\mathrm{H} \\
\mathrm{EP}\end{array}$ & $\begin{array}{c}\mathrm{L} \\
\text { FIFO }\end{array}$ & $\begin{array}{c}\mathrm{H} \\
\text { FIFO }\end{array}$ & $\begin{array}{c}\mathrm{L} \\
\mathrm{EP}\end{array}$ & $\begin{array}{l}\mathrm{H} \\
\mathrm{EP}\end{array}$ \\
\hline \multirow{2}{*}{$\ln (\eta)$} & value & 0.98 & 0.98 & 0.98 & 0.98 & 0.33 & 0.33 & 0.33 & 0.33 \\
\hline & standard error & 0.03 & 0.04 & 0.03 & 0.04 & 0.04 & 0.04 & 0.04 & 0.04 \\
\hline $\ln (\Psi)$ & value & -0.05 & -0.05 & -0.07 & -0.07 & 0.04 & 0.04 & 0.05 & 0.05 \\
\hline
\end{tabular}

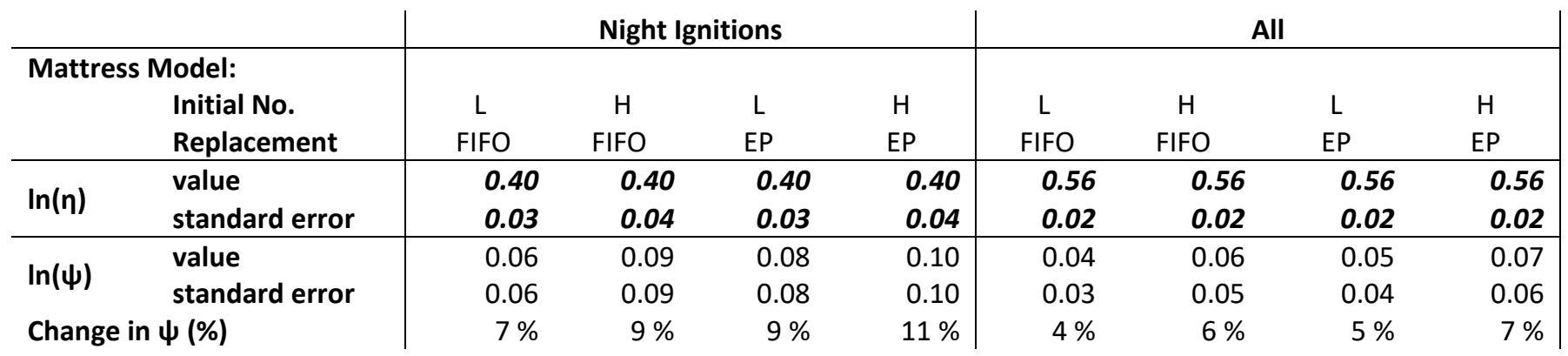


Table 15: Effect of varying the calculation method for the replacement rate of pre-Standard mattresses on the number of injuries, estimated using the RUF-controlled approach.

\begin{tabular}{|c|c|c|c|c|c|c|c|c|c|}
\hline \multicolumn{2}{|c|}{ Mattress Model } & \multicolumn{4}{|c|}{ Flaming ignitions } & \multicolumn{4}{|c|}{ Smoking Materials Ignitions } \\
\hline \multirow{2}{*}{$\ln (n)$} & value & 0.76 & 0.75 & 0.76 & 0.76 & -0.08 & -0.10 & -0.08 & -0.10 \\
\hline & standard error & 0.06 & 0.07 & 0.06 & 0.07 & 0.07 & 0.07 & 0.07 & 0.07 \\
\hline $\ln (\Psi)$ & value & -0.26 & -0.30 & -0.35 & -0.40 & 0.32 & 0.45 & 0.40 & 0.52 \\
\hline \multicolumn{2}{|c|}{ Change in $\Psi(\%)$} & $-23 \%$ & $-26 \%$ & $-30 \%$ & $33 \%$ & $38 \%$ & $57 \%$ & $49 \%$ & $68 \%$ \\
\hline
\end{tabular}

\begin{tabular}{|c|c|c|c|c|c|c|c|c|c|}
\hline \multirow{2}{*}{\multicolumn{2}{|c|}{ Mattress Model }} & \multicolumn{4}{|c|}{ Night Ignitions } & \multicolumn{4}{|c|}{ All Ignitions } \\
\hline & & & & & & & & & \\
\hline & Initial No. & L & $\mathrm{H}$ & $\mathrm{L}$ & $\mathrm{H}$ & $\mathrm{L}$ & $\mathrm{H}$ & L & $\mathrm{H}$ \\
\hline & Replacement & FIFO & FIFO & EP & EP & FIFO & FIFO & EP & EP \\
\hline \multirow{2}{*}{$\ln (n)$} & value & 0.04 & 0.02 & 0.04 & 0.02 & 0.22 & 0.20 & 0.22 & 0.21 \\
\hline & standard error & 0.05 & 0.06 & 0.05 & 0.06 & 0.03 & 0.04 & 0.03 & 0.04 \\
\hline \multirow{2}{*}{$\ln (\psi)$} & value & 0.10 & 0.19 & 0.13 & 0.21 & 0.03 & 0.07 & 0.03 & 0.08 \\
\hline & standard error & 0.11 & 0.15 & 0.14 & 0.17 & 0.07 & 0.09 & 0.09 & 0.11 \\
\hline \multicolumn{2}{|c|}{ Change in $\Psi(\%)$} & $11 \%$ & $21 \%$ & $14 \%$ & $23 \%$ & $3 \%$ & $7 \%$ & $3 \%$ & $8 \%$ \\
\hline
\end{tabular}

Table 16: Effect of varying the calculation method for the replacement rate of pre-Standard mattresses on the number of fatalities, estimated using the RUF-controlled approach.

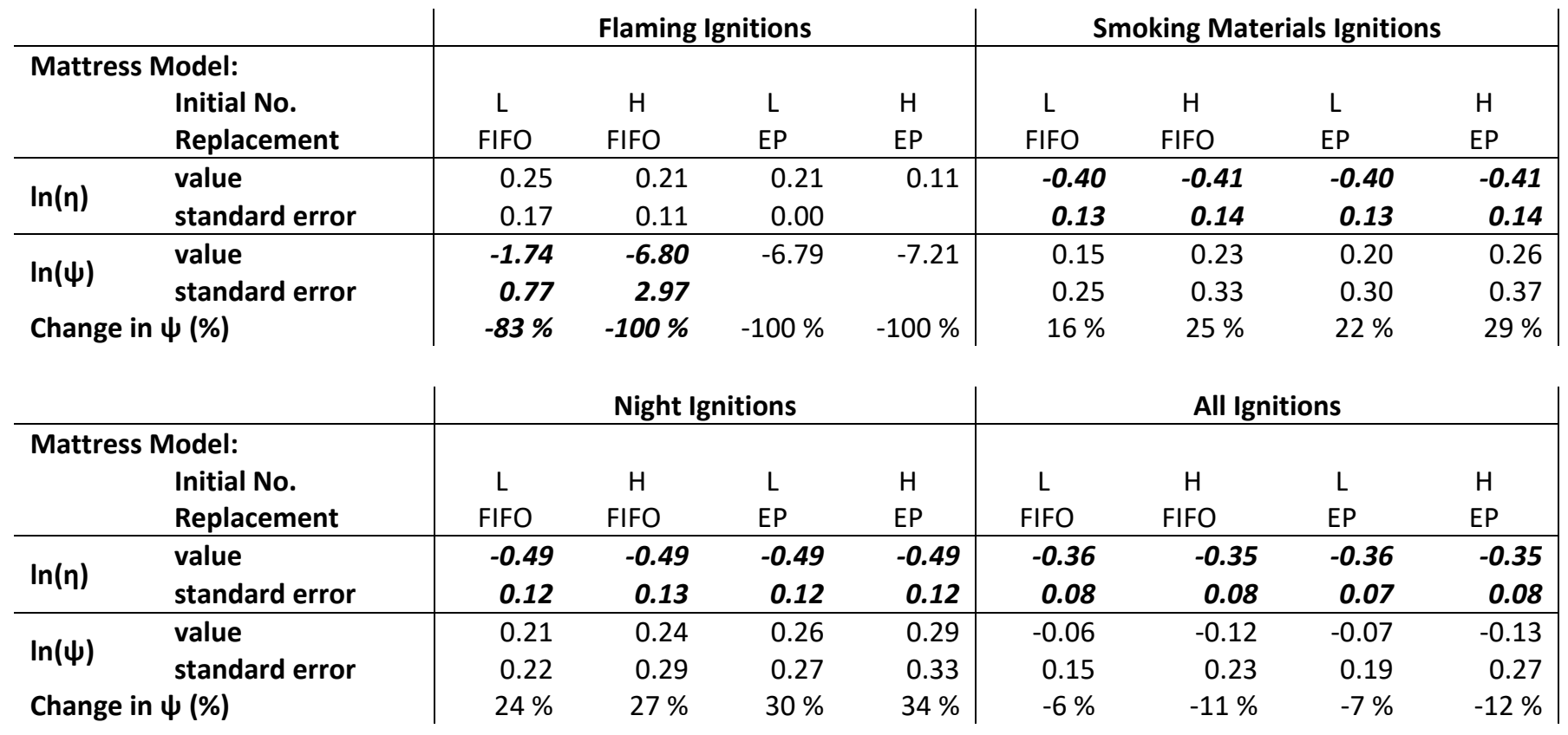


Before identifying patterns in the tabulated results, it is appropriate to gain perspective on what magnitude of differences among the percent decreases in fires and fire outcomes are significant. In all five tables, the calculations for Columns 1 and 2 are identical except for the number of mattresses initially in use. Thus, the percent decreases in Column 1 should always be at least as large as those in Column 2. This is because the sales rates are the same, but there are more mattresses to replace in Column 2. If a value in Column 2 is significantly larger than a corresponding value in Column 1, then a further explanation is warranted. The same premise applies to comparing the bottom rows of Columns 3 and 4 .

For columns 1 and 3, the initial number of mattresses in use are the same, but the replacement rate in Column 1 is faster. This is because, in all but the first year, some of the replaced mattresses in the ER model will be post-Standard. Thus, the percent decreases in Column 1 should always be at least as large as those in Column 3. If a value in Column 3 is significantly larger than a corresponding value in Column 1 , then a further explanation is warranted. The same premise applies to comparing the bottom rows of Columns 2 and 4 .

In this set of five tables, nearly all the calculated percent increases, and thus the differences among them, are statistically insignificant or nearly so. The calculated $\ln (\psi)$ results show no significant effect of whether the pre-Standard mattresses were replaced using the FIFO or random replacement models nor on the initial number of mattresses.

The sole exceptions are:

- A nearly complete decrease in the number of fatalities from fires started by flaming ignition sources (Table 16). This is consistent with the results in Tables 1,2, and 3.

- An increase in the number of injuries from fires ignited by smoking materials (Table 15). This is consistent with the results in Tables 3 and 4 . The nature of the Standard is to reduce the severity of flaming fires. Apparently, some of the fires that began as smoldering fires did not grow beyond the bed (Table 13) to life-threatening, flaming fires, but were severe enough to result in reported injuries. 


\section{D.3 All-Fire-Controlled Models}

Tables 17 through 21 present the results of calculations of changes in fire outcome which result from including fire reports in which (a) the bed was identified as the item contributing most to fire spread (IC) and (b) whether bedding was identified as the item first ignited (IFI) and/or the item most contributing to fire spread. Nighttime fires (all ignitions) are also singled out, since this is when people are more likely to be in an ignited bed and thus are more at risk of injury or death. They are similar to Tables 6 through 10, except for the bed fires being referenced to all fires, rather than RUF fires.

Table 17: Effect of including bedding and the item contributing most to flame spread on the number of reported ignitions, estimated using the all-fires-controlled approach and the before-and-after method.

\begin{tabular}{|c|c|c|c|c|c|c|c|c|c|}
\hline & & \multicolumn{4}{|c|}{ Flaming ignitions } & \multicolumn{4}{|c|}{ Smoking Materials Ignitions } \\
\hline Mode & $\begin{array}{l}\text { Ades: } \\
\text { Mattress } \\
\text { Bedding }\end{array}$ & $\mathrm{IFI}$ & IFI, IC & $\begin{array}{l}\text { IFI } \\
\text { IFI }\end{array}$ & $\begin{array}{l}\text { IFI, IC } \\
\text { IFI, IC }\end{array}$ & $\mathrm{IFI}$ & IFI, IC & $\begin{array}{l}\text { IFI } \\
\text { IFI }\end{array}$ & $\begin{array}{l}\text { IFI, IC } \\
\text { IFI, IC }\end{array}$ \\
\hline \multirow{2}{*}{$\ln (n)$} & value & -3.73 & -3.54 & -2.87 & -2.76 & -2.80 & -2.72 & -2.22 & -2.18 \\
\hline & standard error & 0.03 & 0.02 & 0.02 & 0.02 & 0.03 & 0.03 & 0.03 & 0.02 \\
\hline \multirow{2}{*}{$\ln (\delta)$} & Value & -0.39 & -0.35 & -0.50 & -0.45 & -0.41 & -0.37 & -0.36 & -0.34 \\
\hline & standard error & 0.04 & 0.04 & 0.03 & 0.03 & 0.06 & 0.05 & 0.04 & 0.04 \\
\hline \multicolumn{2}{|c|}{ Change in $\delta(\%)$} & $-33 \%$ & $-30 \%$ & $-39 \%$ & $-36 \%$ & $-34 \%$ & $-31 \%$ & $-30 \%$ & $-29 \%$ \\
\hline
\end{tabular}

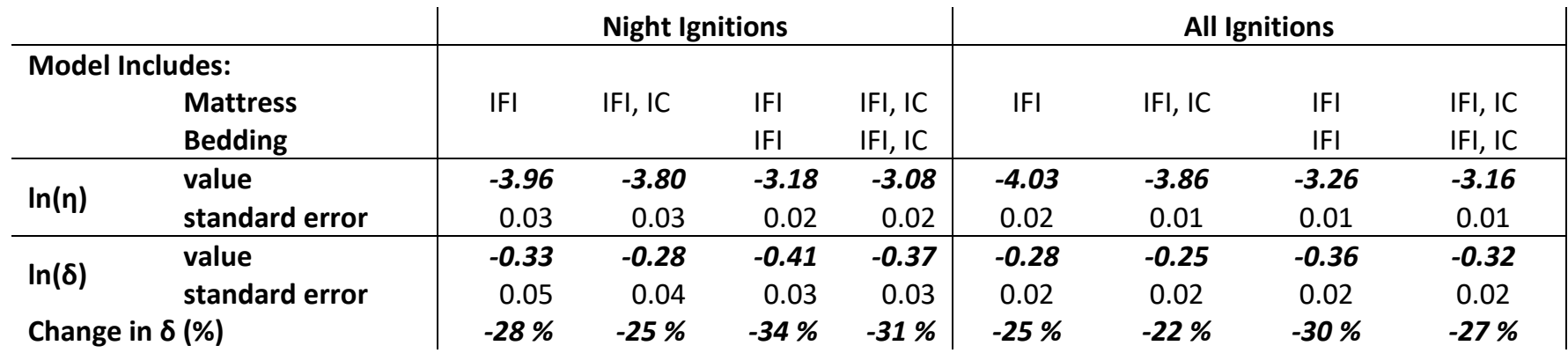


Table 18: Effect of including bedding and the item contributing most to flame spread on the number of fires that spread beyond the object of origin, estimated using the all-firescontrolled approach and the before-and-after method.

\begin{tabular}{|c|c|c|c|c|c|c|c|c|c|}
\hline & & \multicolumn{4}{|c|}{ Flaming Ignitions } & \multicolumn{4}{|c|}{ Smoking Materials Ignitions } \\
\hline Mode & $\begin{array}{l}\text { Ides: } \\
\text { Mattress } \\
\text { Bedding }\end{array}$ & IFI & IFI, IC & $\begin{array}{l}\mathrm{IFI} \\
\mathrm{IFI}\end{array}$ & $\begin{array}{l}\text { IFI, IC } \\
\text { IFI, IC }\end{array}$ & IFI & IFI, IC & $\begin{array}{l}\text { IFI } \\
\text { IFI }\end{array}$ & $\begin{array}{l}\text { IFI, IC } \\
\text { IFI, IC }\end{array}$ \\
\hline \multirow{2}{*}{$\ln (n)$} & value & -3.76 & -3.71 & -3.22 & -3.19 & -2.67 & -2.65 & -2.17 & -2.16 \\
\hline & standard error & 0.06 & 0.06 & 0.05 & 0.05 & 0.07 & 0.06 & 0.05 & 0.05 \\
\hline \multirow{2}{*}{$\ln (\delta)$} & value & -0.12 & -0.16 & -0.15 & -0.18 & -0.06 & -0.09 & -0.13 & -0.15 \\
\hline & standard error & 0.10 & 0.10 & 0.08 & 0.08 & 0.12 & 0.12 & 0.09 & 0.09 \\
\hline \multicolumn{2}{|c|}{ Change in $\delta(\%)$} & $-11 \%$ & $-15 \%$ & $-14 \%$ & $-16 \%$ & $-6 \%$ & $-8 \%$ & $-13 \%$ & $-13 \%$ \\
\hline
\end{tabular}

\begin{tabular}{|c|c|c|c|c|c|c|c|c|c|}
\hline \multirow{2}{*}{\multicolumn{2}{|c|}{ Model Includes: }} & \multicolumn{4}{|c|}{ Night Ignitions } & \multicolumn{4}{|c|}{ All Ignitions } \\
\hline & & & & & & & & & \\
\hline & Mattress & $\mathrm{IFI}$ & IFI, IC & $\mathrm{IFI}$ & $\mathrm{IFI}, \mathrm{IC}$ & IFI & IFI, IC & IFI & $\mathrm{IFI}, \mathrm{IC}$ \\
\hline & Bedding & & & $\mathrm{IFI}$ & IFI, IC & & & IFI & IFI, IC \\
\hline \multirow{2}{*}{$\ln (n)$} & value & -3.59 & -3.57 & -3.02 & -3.01 & -3.89 & -3.86 & -3.32 & -3.30 \\
\hline & standard error & 0.06 & 0.06 & 0.05 & 0.05 & 0.03 & 0.03 & 0.05 & 0.05 \\
\hline \multirow{2}{*}{$\ln (\delta)$} & value & -0.04 & -0.07 & -0.14 & -0.15 & -0.01 & -0.04 & -0.05 & -0.07 \\
\hline & standard error & 0.10 & 0.10 & 0.08 & 0.08 & 0.05 & 0.05 & 0.04 & 0.04 \\
\hline \multicolumn{2}{|c|}{ Change in $\delta(\%)$} & $-4 \%$ & $-7 \%$ & $-13 \%$ & $-14 \%$ & $-1 \%$ & $-4 \%$ & $-5 \%$ & $-6 \%$ \\
\hline
\end{tabular}

Table 19: Effect of including bedding and the item contributing most to flame spread on the number of fires that spread beyond the room of origin, estimated using the all-firescontrolled approach and the before-and-after method.

\begin{tabular}{|c|c|c|c|c|c|c|c|c|c|}
\hline & \multicolumn{4}{|c|}{ Flaming Ignitions } & \multicolumn{4}{|c|}{ Smoking Materials Ignitions } \\
\hline Mode & $\begin{array}{l}\text { Ides: } \\
\text { Mattress } \\
\text { Bedding }\end{array}$ & IFI & IFI, IC & $\begin{array}{l}\text { IFI } \\
\text { IFI }\end{array}$ & $\begin{array}{l}\text { IFI, IC } \\
\text { IFI, IC }\end{array}$ & IFI & IFI, IC & $\begin{array}{l}\text { IFI } \\
\text { IFI }\end{array}$ & $\begin{array}{l}\text { IFI, IC } \\
\text { IFI, IC }\end{array}$ \\
\hline \multirow{2}{*}{$\ln (n)$} & value & -3.62 & -3.42 & -2.82 & -2.71 & -2.72 & -2.64 & -2.15 & -2.11 \\
\hline & standard error & 0.04 & 0.03 & 0.02 & 0.02 & 0.04 & 0.04 & 0.03 & 0.03 \\
\hline \multirow{2}{*}{$\ln (\delta)$} & value & -0.25 & -0.25 & -0.35 & -0.33 & -0.21 & -0.20 & -0.21 & -0.18 \\
\hline & standard error & 0.054 & 0.049 & 0.038 & 0.036 & 0.068 & 0.066 & 0.052 & 0.051 \\
\hline \multirow{2}{*}{\multicolumn{2}{|c|}{ Change in $\delta(\%)$}} & $-22 \%$ & $-22 \%$ & $-29 \%$ & $-28 \%$ & $-19 \%$ & $-18 \%$ & $-19 \%$ & $-17 \%$ \\
\hline & & \multicolumn{4}{|c|}{ Night Ignitions } & \multicolumn{4}{|c|}{ All Ignitions } \\
\hline \multicolumn{2}{|c|}{ Model Includes: } & \multirow{3}{*}{$\mathrm{IFI}$} & \multirow{3}{*}{ IFI, IC } & & & \multirow{3}{*}{ IFI } & \multirow{3}{*}{ IFI, IC } & & \\
\hline & Mattress & & & IFI & IFI, IC & & & IFI & IFI, IC \\
\hline & Bedding & & & IFI & IFI, IC & & & IFI & IFI, IC \\
\hline \multirow{2}{*}{$\ln (n)$} & value & -3.62 & -3.46 & -2.90 & -2.79 & -3.85 & -3.69 & -3.14 & -3.03 \\
\hline & standard error & 0.04 & 0.04 & 0.03 & 0.03 & 0.02 & 0.02 & 0.01 & 0.01 \\
\hline \multirow{2}{*}{$\ln (\delta)$} & value & -0.17 & -0.16 & -0.24 & -0.22 & -0.14 & -0.13 & -0.20 & -0.17 \\
\hline & standard error & 0.06 & 0.06 & 0.04 & 0.04 & 0.03 & 0.03 & 0.02 & 0.02 \\
\hline \multicolumn{2}{|c|}{ Change in $\delta(\%)$} & $-16 \%$ & $-15 \%$ & $-21 \%$ & $-20 \%$ & $-13 \%$ & $-12 \%$ & $-18 \%$ & $-16 \%$ \\
\hline
\end{tabular}


Table 20: Effect of including bedding and the item contributing most to flame spread on the number of injuries, estimated using the all-fires-controlled approach and the before-andafter method.

\begin{tabular}{|c|c|c|c|c|c|c|c|c|c|}
\hline & & \multicolumn{4}{|c|}{ flame } & \multicolumn{4}{|c|}{ smoke } \\
\hline \multicolumn{10}{|c|}{ Model Includes: } \\
\hline & Mattress & IFI & IFI, IC & IFI & IFI, IC & IFI & IFI, IC & IFI & IFI, IC \\
\hline & Bedding & & & $\mathrm{IFI}$ & IFI, IC & & & IFI & IFI, IC \\
\hline \multirow{2}{*}{$\ln (n)$} & value & -2.86 & -2.66 & -2.01 & -1.87 & -2.36 & -2.23 & -1.53 & -1.45 \\
\hline & standard error & 0.09 & 0.07 & 0.05 & 0.05 & 0.09 & 0.08 & 0.06 & 0.06 \\
\hline \multirow{2}{*}{$\ln (\delta)$} & value & -0.61 & -0.53 & -0.54 & -0.47 & -0.14 & -0.06 & -0.06 & -0.05 \\
\hline & standard error & 0.14 & 0.13 & 0.09 & 0.09 & 0.15 & 0.14 & 0.10 & 0.10 \\
\hline \multicolumn{2}{|c|}{ Change in $\delta(\%)$} & $-46 \%$ & $-41 \%$ & $-42 \%$ & $-38 \%$ & $-13 \%$ & $-5 \%$ & $-6 \%$ & $-5 \%$ \\
\hline
\end{tabular}

\begin{tabular}{|c|c|c|c|c|c|c|c|c|c|}
\hline \multirow{2}{*}{\multicolumn{2}{|c|}{ Model Includes: }} & \multicolumn{4}{|c|}{ night } & \multicolumn{4}{|c|}{ all } \\
\hline & & \multirow{3}{*}{$|F|$} & \multirow{3}{*}{ IFI, IC } & \multirow{3}{*}{$\begin{array}{l}\mathrm{IFI} \\
\mathrm{IFI}\end{array}$} & \multirow{3}{*}{$\begin{array}{l}\text { IFI, IC } \\
\text { IFI, IC }\end{array}$} & \multirow{3}{*}{ IFI } & \multirow{3}{*}{$\mathrm{IFI}, \mathrm{IC}$} & \multirow{3}{*}{$\begin{array}{l}\text { IFI } \\
\text { IFI }\end{array}$} & \multirow{3}{*}{$\begin{array}{l}\text { IFI, IC } \\
\text { IFI, IC }\end{array}$} \\
\hline & Mattress & & & & & & & & \\
\hline & Bedding & & & & & & & & \\
\hline \multirow{2}{*}{$\ln (n)$} & value & -3.35 & -3.12 & -2.36 & -2.22 & -3.33 & -3.09 & -2.44 & -2.29 \\
\hline & standard error & 0.08 & 0.07 & 0.050 & 0.05 & 0.05 & 0.04 & 0.03 & 0.03 \\
\hline \multirow{2}{*}{$\ln (\delta)$} & value & -0.27 & -0.14 & -0.57 & -0.46 & -0.28 & -0.24 & -0.37 & -0.33 \\
\hline & standard error & 0.12 & 0.11 & 0.08 & 0.08 & 0.07 & 0.06 & 0.05 & 0.05 \\
\hline \multicolumn{2}{|c|}{ Change in $\delta(\%)$} & $-24 \%$ & $-13 \%$ & $-43 \%$ & $-37 \%$ & $-24 \%$ & $-21 \%$ & $-31 \%$ & $-28 \%$ \\
\hline
\end{tabular}

Table 21: Effect of including bedding and the item contributing most to flame spread on the number of fatalities, estimated using the all-fires-controlled approach and the before-andafter method.

\begin{tabular}{|c|c|c|c|c|c|c|c|c|c|}
\hline & & \multicolumn{4}{|c|}{ Flaming Ignitions } & \multicolumn{4}{|c|}{ Smoking Materials Ignitions } \\
\hline \multicolumn{2}{|c|}{ Model Includes: } & \multirow{3}{*}{ IFI } & \multirow{3}{*}{ IFI, IC } & \multirow{3}{*}{$\begin{array}{l}\text { IFI } \\
\text { IFI }\end{array}$} & \multirow{3}{*}{$\begin{array}{l}\text { IFI, IC } \\
\text { IFI, IC }\end{array}$} & \multirow{3}{*}{ IFI } & \multirow{3}{*}{ IFI, IC } & & \\
\hline & Mattress & & & & & & & $\mathrm{IFI}$ & IFI, IC \\
\hline & Bedding & & & & & & & $\mathrm{IFI}$ & IFI, IC \\
\hline \multirow{2}{*}{$\ln (\eta)$} & value & -3.52 & -3.43 & -2.39 & -2.27 & -2.17 & -2.07 & -1.47 & -1.41 \\
\hline & standard error & 0.32 & 0.31 & 0.19 & 0.18 & 0.18 & 0.17 & 0.13 & 0.13 \\
\hline \multirow{2}{*}{$\ln (\delta)$} & value & -2.10 & -2.20 & -1.85 & -1.57 & -0.89 & -0.66 & -0.05 & -0.02 \\
\hline & standard error & 1.06 & 1.052 & 0.54 & 0.45 & 0.37 & 0.32 & 0.21 & 0.20 \\
\hline \multicolumn{2}{|c|}{ Change in $\delta(\%)$} & $-88 \%$ & $-89 \%$ & $-84 \%$ & $-79 \%$ & $-59 \%$ & $-48 \%$ & $-5 \%$ & $-2 \%$ \\
\hline
\end{tabular}

\begin{tabular}{|c|c|c|c|c|c|c|c|c|c|}
\hline & & \multicolumn{4}{|c|}{ Night Ignitions } & \multicolumn{4}{|c|}{ All Ignitions } \\
\hline \multicolumn{2}{|c|}{ Model Includes: } & \multirow{3}{*}{ IFI } & \multirow{3}{*}{ IFI, IC } & & & \multirow{3}{*}{ IFI } & \multirow{3}{*}{ IFI, IC } & & \\
\hline & Mattress & & & IFI & IFI, IC & & & IFI & IFI, IC \\
\hline & Bedding & & & IFI & IFI, IC & & & IFI & IFI, IC \\
\hline \multirow{2}{*}{$\ln (\eta)$} & value & -3.49 & -3.37 & -2.64 & -2.53 & -3.48 & -3.29 & -2.52 & -2.42 \\
\hline & standard error & 0.18 & 0.17 & 0.12 & 0.11 & 0.12 & 0.11 & 0.08 & 0.08 \\
\hline \multirow{2}{*}{$\ln (\delta)$} & value & -0.65 & -0.24 & -0.61 & -0.42 & -0.70 & -0.45 & -0.56 & -0.45 \\
\hline & standard error & 0.29 & 0.25 & 0.19 & 0.17 & 0.21 & 0.18 & 0.13 & 0.12 \\
\hline \multicolumn{2}{|c|}{ Change in $\delta(\%)$} & $-48 \%$ & $-21 \%$ & $-46 \%$ & $-35 \%$ & $-50 \%$ & $-37 \%$ & $-43 \%$ & $-36 \%$ \\
\hline
\end{tabular}


It is possible that there are factors that affect both bed and RUF fires differently from all other types of fires. The calculated changes in the frequency of fires and fire outcomes in Tables 7 through 11 and the corresponding results in Table 17 through 21 would be uniform if no such effects existed. However, this is not the case in general - there is evidence for additional factors affecting subsets of the fire outcomes.

- The per-RUF-fire results in Tables 7 through 11 generally indicate no change in fires and fire spread compared to the significant decreases seen in the all-fire-controlled results in Tables 17 through 21. (As will be seen, the same is true when comparing the results between Tables 10 through 16 with those in Tables 22 through 26.)

- The fatalities for all ignitions showed no significant change for bed fires relative to RUF fires (Table 11), but significant decreases relative to all fires Table 16). Both sets of tables show remaining fire deaths from flaming ignitions that are not statistically distinguishable from zero (cf. Table 1). Thus, this is not a test of whether a factor is affecting the different reference sets of fires (RUF vs. all).

- The nighttime injuries and deaths decreased significantly relative to all fires, but showed no such change relative to RUF fires. We note that when indexed to all fires, the bed fires led to a very substantial decrease in injuries from fires coded as mattress or bedding as the ignited combustible (Table 15). When indexed to RUF fires, the bed fires led to an equally substantial increase in fires coded as mattress only (Table 10).

There are also some findings within Table 21.

- The values of $\ln (\eta)$ show that bedding and mattress fires constitute a small fraction of all reported fires. The standard errors in the calculations are also smaller relative to the $\ln (\eta)$ values. Thus, all of the $\ln (\eta)$ values are statistically significant. There is a similar effect of the indexing on all fires on $\ln (\delta)$, although the effect is generally smaller.

- Regardless of whether mattresses, bedding, or both were the combustibles coded as the first item ignited or the item most contributing to fire spread, the Standard led to dominant reductions in fire fatalities from flaming ignition and from nighttime fires. There were also major reductions in fatalities from mattresses, but not bedding, ignited by smoking materials. 
Tables 22 through 26 present the results of calculations of changes in fire outcome. Nighttime fires (all ignitions) are also singled out, since this is when people are more likely to be in an ignited bed and thus are more at risk of injury or death. They are similar to Tables 12 through 16, except for the bed fires being referenced to all fires, rather than RUF fires. In all cases, $\mathrm{H}$ is the upper estimate of the total number of mattresses in use at the time of the implementation of the Standard, 304 million; L is the lower estimate, 237 million; FIFO is the first-in-first-out mattress replacement model; and $\mathrm{EP}$ is the random mattress replacement model.

Table 22: Effect of varying the calculation method for the replacement rate of pre-Standard mattresses on the number of reported ignitions, estimated using the all-fires-controlled approach.

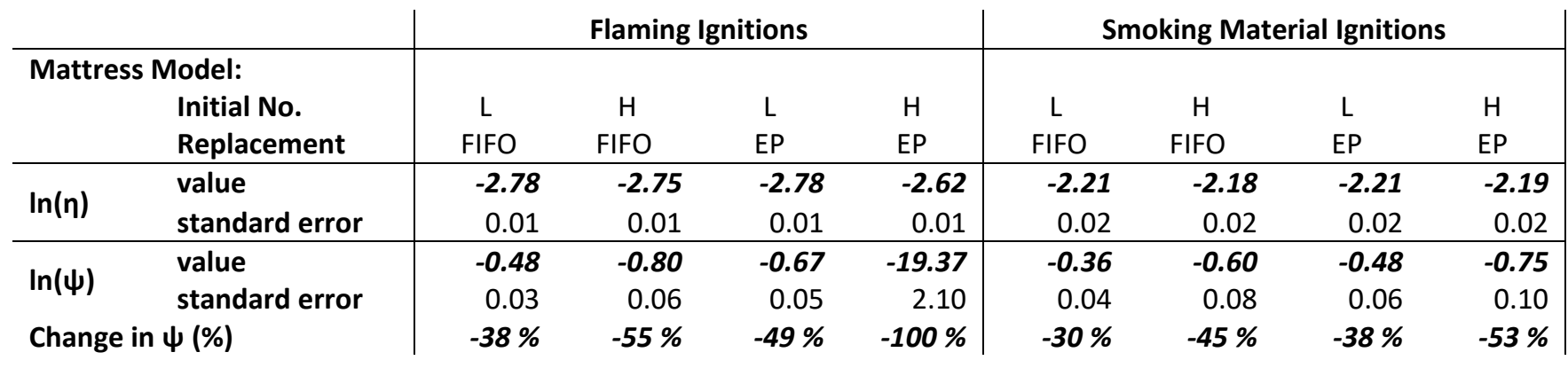

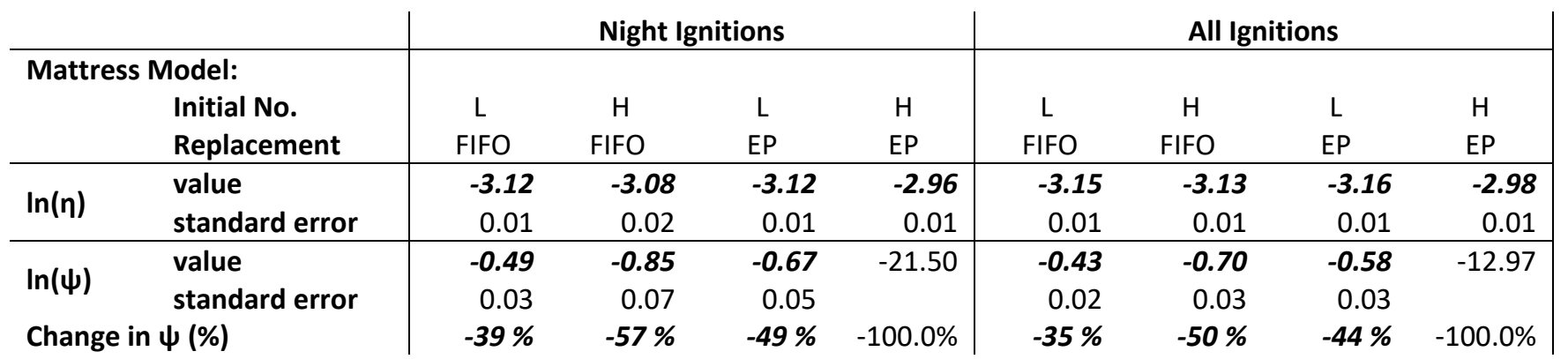


Table 23: Effect of varying the calculation method for the replacement rate of pre-Standard mattresses on the fires that spread beyond the object of fire origin, estimated using the allfires-controlled approach.

\begin{tabular}{|c|c|c|c|c|c|c|c|c|c|}
\hline & & \multicolumn{4}{|c|}{ Flaming Ignitions } & \multicolumn{4}{|c|}{ Smoking Material Ignitions } \\
\hline \multicolumn{10}{|c|}{ Mattress Model } \\
\hline & Initial No. & L & $\mathrm{H}$ & $\mathrm{L}$ & $\mathrm{H}$ & L & $\mathrm{H}$ & L & $\mathrm{H}$ \\
\hline & Replacement & FIFO & FIFO & EP & EP & FIFO & FIFO & EP & EP \\
\hline \multirow{2}{*}{$\ln (n)$} & value & -3.18 & -2.82 & -2.83 & -2.90 & -2.14 & -2.12 & -2.15 & -2.13 \\
\hline & standard error & 0.04 & 0.02 & & & 0.04 & 0.04 & 0.04 & 0.04 \\
\hline \multirow{2}{*}{$\ln (\psi)$} & value & -0.08 & -15.97 & -16.87 & -14.88 & -0.24 & -0.39 & -0.32 & -0.47 \\
\hline & standard error & 0.08 & & & & 0.10 & 0.16 & 0.13 & 0.20 \\
\hline \multicolumn{2}{|c|}{ Change in $\Psi(\%)$} & $-8 \%$ & $-100.0 \%$ & $-100.0 \%$ & $-100.0 \%$ & $-22 \%$ & $-33 \%$ & $-27 \%$ & $-38 \%$ \\
\hline
\end{tabular}

\begin{tabular}{|c|c|c|c|c|c|c|c|c|c|}
\hline \multirow{2}{*}{\multicolumn{2}{|c|}{ Mattress Model }} & \multicolumn{4}{|c|}{ Night Ignitions } & \multicolumn{4}{|c|}{ All Ignitions } \\
\hline & & & & & & & & & \\
\hline & Initial No. & $\mathrm{L}$ & $\mathrm{H}$ & $\mathrm{L}$ & $\mathrm{H}$ & $\mathrm{L}$ & $\mathrm{H}$ & L & $\mathrm{H}$ \\
\hline & Replacement & FIFO & FIFO & EP & EP & FIFO & FIFO & EP & EP \\
\hline \multirow{2}{*}{$\ln (n)$} & value & -2.95 & -2.67 & -2.95 & -2.75 & -3.25 & -3.25 & -3.25 & -3.25 \\
\hline & standard error & 0.035 & 0.000 & 0.035 & & 0.019 & 0.021 & 0.019 & 0.021 \\
\hline \multirow{2}{*}{$\ln (\psi)$} & value & -0.29 & -9.70 & -0.39 & -9.31 & -0.11 & -0.16 & -0.15 & -0.19 \\
\hline & standard error & 0.08 & & 0.12 & & 0.04 & 0.06 & 0.06 & 0.08 \\
\hline \multicolumn{2}{|c|}{ Change in $\psi(\%)$} & $-25 \%$ & $-100 \%$ & $-32 \%$ & $-100 \%$ & $-11 \%$ & $-15 \%$ & $-14 \%$ & $-18 \%$ \\
\hline
\end{tabular}

Table 24: Effect of varying the calculation method for the replacement rate of pre-Standard mattresses on the fires that spread beyond the room of fire origin, estimated using the allfires-controlled approach.

\begin{tabular}{|c|c|c|c|c|c|c|c|c|c|}
\hline & & \multicolumn{4}{|c|}{ Flaming Ignitions } & \multicolumn{4}{|c|}{ Smoking Material Ignitions } \\
\hline \multicolumn{10}{|c|}{ Mattress Model: } \\
\hline & Initial No. & $\mathrm{L}$ & $\mathrm{H}$ & $\mathrm{L}$ & $\mathrm{H}$ & $\mathrm{L}$ & $\mathrm{H}$ & L & $\mathrm{H}$ \\
\hline & Replacement & FIFO & FIFO & EP & EP & FIFO & FIFO & EP & EP \\
\hline \multirow{2}{*}{$\ln (\eta)$} & value & -2.72 & -2.70 & -2.73 & -2.71 & -2.11 & -2.09 & -2.11 & -2.10 \\
\hline & standard error & 0.02 & 0.02 & 0.02 & 0.02 & 0.03 & 0.03 & 0.03 & 0.03 \\
\hline \multirow{2}{*}{$\ln (\Psi)$} & value & -0.33 & -0.54 & -0.45 & -0.66 & -0.20 & -0.31 & -0.26 & -0.38 \\
\hline & standard error & 0.04 & 0.07 & 0.05 & 0.09 & 0.05 & 0.09 & 0.07 & 0.11 \\
\hline \multicolumn{2}{|c|}{ Change in $\Psi(\%)$} & $-28 \%$ & $-41 \%$ & $-36 \%$ & $-49 \%$ & $-18 \%$ & $-27 \%$ & $-23 \%$ & $-31 \%$ \\
\hline
\end{tabular}

\begin{tabular}{|c|c|c|c|c|c|c|c|c|c|}
\hline \multirow{2}{*}{\multicolumn{2}{|c|}{ Mattress Model: }} & \multicolumn{4}{|c|}{ Night Ignitions } & \multicolumn{4}{|c|}{ All Ignitions } \\
\hline & & & & & & & & & \\
\hline & Initial No. & L & $\mathrm{H}$ & L & $\mathrm{H}$ & L & $\mathrm{H}$ & L & $\mathrm{H}$ \\
\hline & Replacement & FIFO & FIFO & EP & EP & FIFO & FIFO & EP & EP \\
\hline \multirow{2}{*}{$\ln (\eta)$} & value & -2.80 & -2.77 & -2.80 & -2.78 & -3.01 & -2.99 & -3.01 & -3.00 \\
\hline & standard error & 0.02 & 0.02 & 0.02 & 0.02 & 0.01 & 0.01 & 0.01 & 0.01 \\
\hline \multirow{2}{*}{$\ln (\psi)$} & value & -0.32 & -0.52 & -0.43 & -0.64 & -0.26 & -0.40 & -0.34 & -0.49 \\
\hline & standard error & 0.04 & 0.07 & 0.06 & 0.10 & 0.02 & 0.04 & 0.03 & 0.05 \\
\hline \multicolumn{2}{|c|}{ Change in $\Psi$ (\%) } & $-27 \%$ & $-41 \%$ & $-35 \%$ & $-47 \%$ & $-23 \%$ & $-33 \%$ & $-29 \%$ & $-39 \%$ \\
\hline
\end{tabular}


Table 25: Effect of varying the calculation method for the replacement rate of pre-Standard mattresses on the number of injuries, estimated using the all-fires-controlled approach.

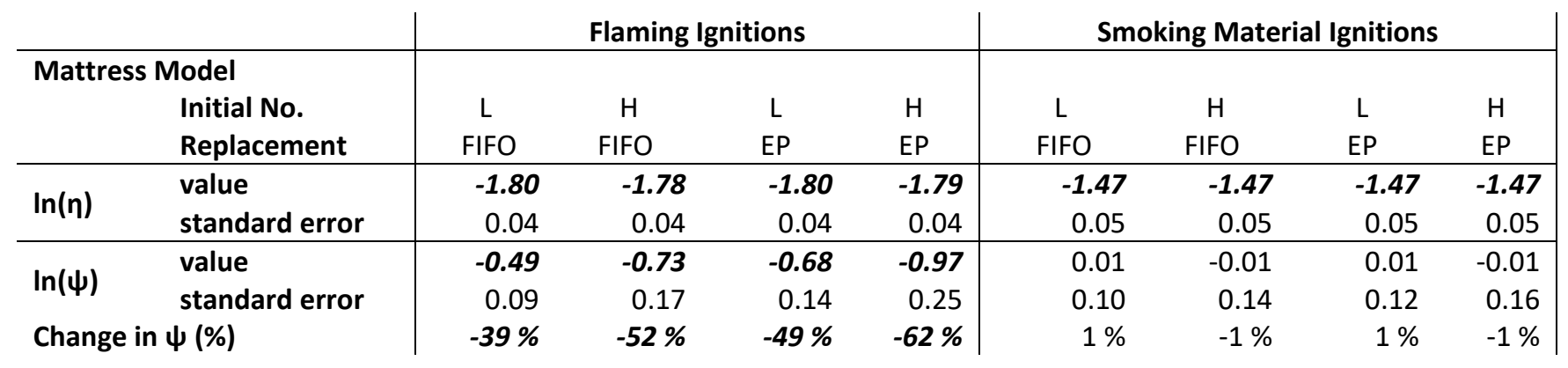

\begin{tabular}{|c|c|c|c|c|c|c|c|c|c|}
\hline & & \multicolumn{4}{|c|}{ Night Ignitions } & \multicolumn{4}{|c|}{ All Ignitions } \\
\hline \multicolumn{10}{|c|}{ Mattress Model } \\
\hline & Initial No. & $\mathrm{L}$ & $\mathrm{H}$ & $\mathrm{L}$ & $\mathrm{H}$ & $\mathrm{L}$ & $\mathrm{H}$ & $\mathrm{L}$ & $\mathrm{H}$ \\
\hline & Replacement & FIFO & FIFO & EP & EP & FIFO & FIFO & EP & EP \\
\hline \multirow{2}{*}{$\ln (n)$} & value & -2.20 & -2.16 & -2.21 & -2.17 & -2.27 & -2.25 & -2.27 & -2.25 \\
\hline & standard error & 0.03 & 0.04 & 0.03 & 0.04 & 0.02 & 0.02 & 0.02 & 0.02 \\
\hline \multirow{2}{*}{$\ln (\psi)$} & value & -0.64 & -1.16 & -0.91 & -1.64 & -0.44 & -0.72 & -0.60 & -0.92 \\
\hline & standard error & 0.09 & 0.20 & 0.14 & 0.38 & 0.05 & 0.09 & 0.07 & 0.13 \\
\hline \multicolumn{2}{|c|}{ Change in $\Psi(\%)$} & $-47 \%$ & $-69 \%$ & $-60 \%$ & $-815 \%$ & $-36 \%$ & $-51 \%$ & $-45 \%$ & $-60 \%$ \\
\hline
\end{tabular}

Table 26: Effect of varying the calculation method for the replacement rate of pre-Standard mattresses on the number of fatalities, estimated using the all-fires-controlled approach.

\begin{tabular}{|c|c|c|c|c|c|c|c|c|c|}
\hline & & \multicolumn{4}{|c|}{ Flame Ignitions } & \multicolumn{4}{|c|}{ Smoking Material Ignitions } \\
\hline \multicolumn{10}{|c|}{ Mattress Model } \\
\hline & Initial No. & $\mathrm{L}$ & $\mathrm{H}$ & $\mathrm{L}$ & $\mathrm{H}$ & $\mathrm{L}$ & $\mathrm{H}$ & L & $\mathrm{H}$ \\
\hline & Replacement & FIFO & FIFO & EP & EP & FIFO & FIFO & EP & EP \\
\hline \multirow{2}{*}{$\ln (\eta)$} & value & -2.13 & -2.09 & -2.13 & -2.17 & -1.45 & -1.45 & -1.46 & -1.45 \\
\hline & standard error & 0.13 & 0.08 & 0.13 & 0.00 & 0.11 & 0.12 & 0.10 & 0.11 \\
\hline \multirow{2}{*}{$\ln (\Psi)$} & value & -1.21 & -4.07 & -2.41 & -5.82 & 0.02 & 0.01 & 0.04 & 0.02 \\
\hline & standard error & 0.48 & & 2.03 & & 0.21 & 0.30 & 0.26 & 0.35 \\
\hline \multicolumn{2}{|c|}{ Change in $\Psi(\%)$} & $-70 \%$ & $-98 \%$ & $-91 \%$ & $-100 \%$ & $2 \%$ & $1 \%$ & $4 \%$ & $2 \%$ \\
\hline
\end{tabular}

\begin{tabular}{|c|c|c|c|c|c|c|c|c|c|}
\hline \multicolumn{2}{|c|}{ 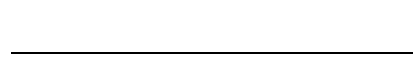 } & \multicolumn{4}{|c|}{ Night Ignitions } & \multicolumn{4}{|c|}{ All Ignitions } \\
\hline \multicolumn{10}{|c|}{ Mattress Model } \\
\hline & Initial No. & $\mathrm{L}$ & $\mathrm{H}$ & $\mathrm{L}$ & $\mathrm{H}$ & $\mathrm{L}$ & $\mathrm{H}$ & $\mathrm{L}$ & $\mathrm{H}$ \\
\hline & Replacement & FIFO & FIFO & EP & EP & FIFO & FIFO & EP & EP \\
\hline \multirow{2}{*}{$\ln (n)$} & value & -2.60 & -2.56 & -2.61 & -2.57 & -2.48 & -2.25 & -2.49 & -2.45 \\
\hline & standard error & 0.08 & 0.09 & 0.08 & 0.09 & 0.05 & & 0.05 & 0.06 \\
\hline \multirow{2}{*}{$\ln (\Psi)$} & value & -0.58 & -1.09 & -0.82 & -1.49 & -0.56 & -10.01 & -0.77 & -1.36 \\
\hline & standard error & 0.19 & 0.44 & 0.31 & 0.79 & 0.13 & & 0.20 & 0.47 \\
\hline \multicolumn{2}{|c|}{ Change in $\Psi(\%)$} & $-44 \%$ & $-66 \%$ & $-56 \%$ & $-77 \%$ & $-43 \%$ & $-100 \%$ & $-54 \%$ & $-74 \%$ \\
\hline
\end{tabular}


The discussion on Tables 12 through 16 provides perspective on what magnitude of differences among the percent decreases in fires and fire outcomes are significant. The percent decreases in Column 1 should always be at least as large as those in Column 2 because there ae more mattresses to replace in Column 2. The same premise applies to comparing the bottom rows of Columns 3 and 4 . The percent decreases in Column 1 should always be at least as large as those in Column 3 because, in all but the first year, some of the replaced mattresses will be postStandard. The same premise applies to comparing the bottom rows of Columns 2 and 4 .

The values of $\ln (\eta)$ show that bed fires constitute a small fraction of all reported fires. The standard errors in the calculations are also small relative to the $\ln (\eta)$ and $\ln (\delta)$ values than in Tables 12 through 16 . Thus, nearly all of the $\ln (\psi)$ values in Tables 22 through 26 are statistically significant.

There is evidence that the Standard is reducing the casualties from fires. There is also evidence that other factors are affecting the extent of the reduction.

- There are sizable decreases in the number of fires and fire outcomes in Tables 22 through 26. These decreases are generally larger than those in Tables 12 through 16. (This is similar to the findings in the discussion of Tables 16 through 21.) This points to one or more additional factors that decrease the number of other fires more than bed and RUF fires.

- Contrary to the expectations above, the decrease in the number of reported fires increases with the lower mattress replacement rates for all ignition categories (Table 22).

- The spread of fires beyond the initially ignited item increases more with the lower mattress replacement rates (Tables 23 and 24). (Flaming ignitions that lead to fire spread beyond the initially ignited item appear to be virtually eliminated. However, the remaining fires are too few to assess a pattern as a function of replacement rates.)

- Injuries and fatalities decreased substantially for all ignition groups except smoking materials, where the change was negligible. 


\section{D.4 Variable Fire Department Models}

Tables 27 through 31 present the results of calculations of changes in fire outcome which result from including fire reports in which (a) the bed was identified as the item contributing most to fire spread (IC) and (b) whether bedding was identified as the item first ignited (IFI) and/or the item most contributing to fire spread. As such, the modeling behind these tables is nearly identical to that in Tables 7 through 11. The difference is that in Tables 7 through 11, the model assumed that all fire departments reported the same ratio of bed fires to control fires prior to the Standard (single value of $\eta$ ). In Tables 27 through 31, each department has an individual value of $\eta$.

Table 27: Effect of including bedding and the item contributing most to flame spread on the number of reported ignitions, estimated using the variable fire department approach and the before-and-after method.

\begin{tabular}{|c|c|c|c|c|c|c|c|c|c|}
\hline & & \multicolumn{4}{|c|}{ Flame Ignitions } & \multicolumn{4}{|c|}{ Smoking Material Ignitions } \\
\hline \multicolumn{10}{|c|}{ Model Includes: } \\
\hline & Mattress/RUF & IFI & IFI, IC & IFI & IFI, IC & $\mathrm{IFI}$ & IFI, IC & $\mathrm{IFI}$ & IFI, IC \\
\hline & Bedding & & & IFI & IFI, IC & & & $\mathrm{IFI}$ & IFI, IC \\
\hline \multirow{2}{*}{$\ln (\eta)$} & value & 0.09 & 0.04 & 0.98 & 0.86 & -0.26 & -0.27 & 0.28 & 0.24 \\
\hline & standard error & 0.05 & 0.04 & 0.04 & 0.04 & 0.05 & 0.05 & 0.04 & 0.04 \\
\hline \multirow{2}{*}{$\ln (\delta)$} & value & 0.01 & -0.02 & -0.12 & -0.13 & -0.03 & -0.01 & 0.02 & 0.02 \\
\hline & standard error & 0.06 & 0.06 & 0.06 & 0.05 & 0.07 & 0.07 & 0.06 & 0.06 \\
\hline \multicolumn{2}{|c|}{ Change in $\delta(\%)$} & $1 \%$ & $-2 \%$ & $-11 \%$ & $-13 \%$ & $-3 \%$ & $-1 \%$ & $2 \%$ & $2 \%$ \\
\hline
\end{tabular}

\begin{tabular}{|c|c|c|c|c|c|c|c|c|c|}
\hline & & \multicolumn{4}{|c|}{ Night Ignitions } & \multicolumn{4}{|c|}{ All Ignitions } \\
\hline \multicolumn{10}{|c|}{ Model Includes: } \\
\hline & Mattress/RUF & IFI & IFI, IC & IFI & IFI, IC & IFI & IFI, IC & IFI & IFI, IC \\
\hline & Bedding & & & $\mathrm{IFI}$ & IFI, IC & & & $\mathrm{IFI}$ & IFI, IC \\
\hline \multirow{2}{*}{$\ln (n)$} & value & -0.40 & -0.43 & 0.38 & 0.31 & -0.33 & -0.36 & 0.50 & 0.39 \\
\hline & standard error & 0.05 & 0.04 & 0.04 & 0.04 & 0.03 & 0.02 & 0.02 & 0.02 \\
\hline \multirow{2}{*}{$\ln (\delta)$} & value & 0.07 & 0.11 & 0.02 & 0.05 & 0.06 & 0.07 & -0.02 & 0.00 \\
\hline & standard error & 0.06 & 0.06 & 0.05 & 0.05 & 0.03 & 0.03 & 0.03 & 0.03 \\
\hline \multicolumn{2}{|c|}{ Change in $\delta(\%)$} & $7 \%$ & $12 \%$ & $2 \%$ & $5 \%$ & $6 \%$ & $7 \%$ & $-2 \%$ & $-0 \%$ \\
\hline
\end{tabular}


Table 28: Effect of including bedding and the item contributing most to flame spread on the number of fires that spread beyond the object of origin, estimated using the variable fire department approach and the before-and-after method.

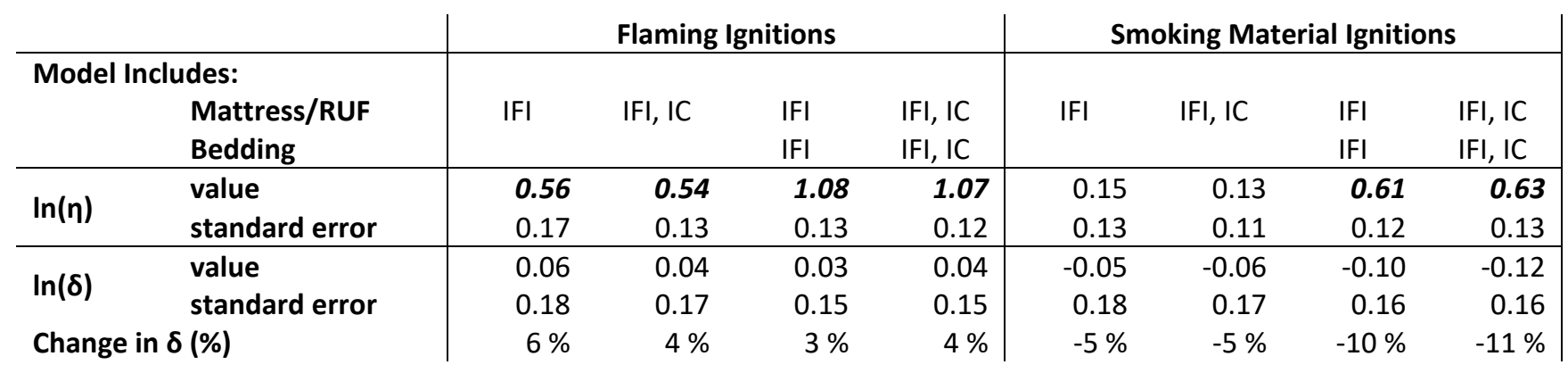

\begin{tabular}{|c|c|c|c|c|c|c|c|c|c|}
\hline \multirow{2}{*}{\multicolumn{2}{|c|}{ Model Includes: }} & \multicolumn{4}{|c|}{ Night Ignitions } & \multicolumn{4}{|c|}{ All Ignitions } \\
\hline & & & & & & & & & \\
\hline & Mattress/RUF & $\mathrm{IFI}$ & IFI, IC & IFI & IFI, IC & IFI & $\mathrm{IFI}, \mathrm{IC}$ & $\mathrm{IFI}$ & $\mathrm{IFI}, \mathrm{IC}$ \\
\hline & Bedding & & & IFI & IFI, IC & & & $\mathrm{IFI}$ & $\mathrm{IFI}, \mathrm{IC}$ \\
\hline \multirow{2}{*}{$\ln (n)$} & value & -0.03 & -0.05 & 0.57 & 0.52 & 0.08 & 0.08 & 0.66 & 0.66 \\
\hline & standard error & 0.12 & 0.11 & 0.12 & 0.11 & 0.06 & 0.06 & 0.05 & 0.05 \\
\hline \multirow{2}{*}{$\ln (\delta)$} & value & 0.11 & 0.11 & 0.01 & 0.05 & 0.04 & 0.02 & 0.00 & 0.01 \\
\hline & standard error & 0.16 & 0.16 & 0.14 & 0.14 & 0.08 & 0.08 & 0.07 & 0.07 \\
\hline \multicolumn{2}{|c|}{ Change in $\delta(\%)$} & $11 \%$ & $11 \%$ & $1 \%$ & $5 \%$ & $4 \%$ & $2 \%$ & $0 \%$ & $2 \%$ \\
\hline
\end{tabular}

Table 29: Effect of including bedding and the item contributing most to flame spread on the number of fires that spread beyond the room of origin, estimated using the variable fire department approach and the before-and-after method.

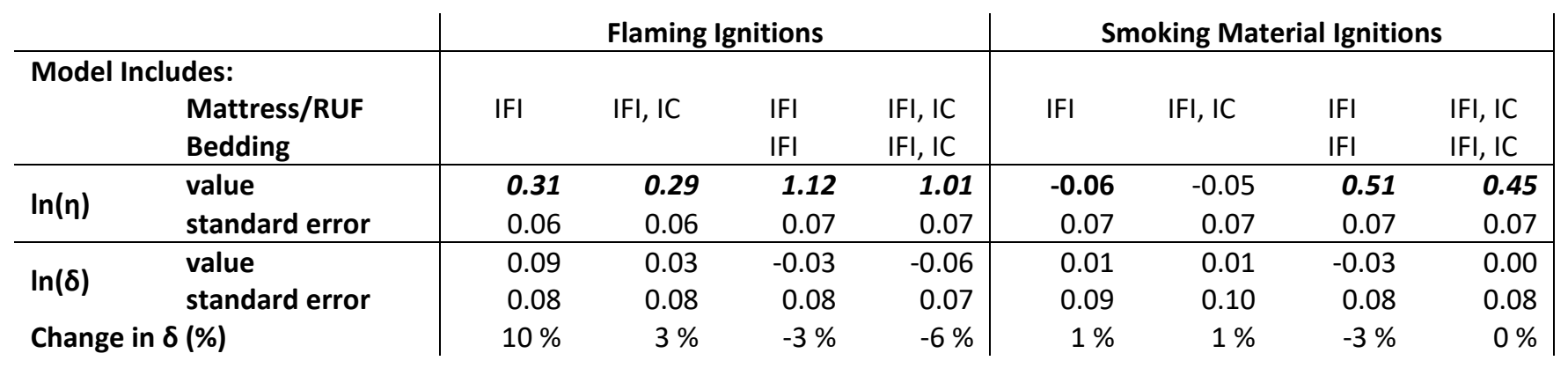

\begin{tabular}{|c|c|c|c|c|c|c|c|c|c|}
\hline \multirow{2}{*}{\multicolumn{2}{|c|}{ Model Includes: }} & \multicolumn{4}{|c|}{ Night Ignitions } & \multicolumn{4}{|c|}{ All Ignitions } \\
\hline & & & & & & & & & \\
\hline & Mattress/RUF & IFI & IFI, IC & IFI & IFI, IC & IFI & IFI, IC & IFI & IFI, IC \\
\hline & Bedding & & & $\mathrm{IFI}$ & IFI, IC & & & IFI & $\mathrm{IFI}, \mathrm{IC}$ \\
\hline \multirow{2}{*}{$\ln (\eta)$} & value & -0.19 & -0.18 & 0.57 & 0.51 & -0.10 & -0.10 & 0.67 & 0.60 \\
\hline & standard error & 0.06 & 0.06 & 0.06 & 0.05 & 0.03 & 0.03 & 0.03 & 0.03 \\
\hline \multirow[b]{2}{*}{$\ln (\delta)$} & value & 0.08 & 0.10 & 0.01 & 0.04 & 0.10 & 0.10 & 0.02 & 0.04 \\
\hline & standard error & 0.08 & 0.07 & 0.07 & 0.07 & 0.04 & 0.04 & 0.04 & 0.04 \\
\hline \multicolumn{2}{|c|}{ Change in $\delta(\%)$} & $9 \%$ & $10 \%$ & $1 \%$ & $4 \%$ & $11 \%$ & $11 \%$ & $2 \%$ & $4 \%$ \\
\hline
\end{tabular}


Table 30: Effect of including bedding and the item contributing most to flame spread on the number of injuries, estimated using the variable fire department approach and the before-and-after method.

\begin{tabular}{|c|c|c|c|c|c|c|c|c|c|}
\hline & & \multicolumn{4}{|c|}{ Flaming Ignitions } & \multicolumn{4}{|c|}{ Smoking Material Ignitions } \\
\hline \multicolumn{10}{|c|}{ Model Includes: } \\
\hline & Mattress/RUF & IFI & IFI, IC & IFI & IFI, IC & IFI & IFI, IC & IFI & IFI, IC \\
\hline & Bedding & & & IFI & IFI, IC & & & IFI & IFI, IC \\
\hline \multirow{2}{*}{$\ln (\eta)$} & value & 0.94 & 0.92 & 2.48 & 2.34 & -0.11 & -0.07 & 1.31 & 1.11 \\
\hline & standard error & 0.28 & 0.25 & 0.34 & 0.30 & 0.25 & 0.24 & 0.36 & 0.28 \\
\hline \multirow{2}{*}{$\ln (\delta)$} & value & -0.72 & -0.87 & -0.85 & -0.93 & 0.23 & 0.24 & 0.24 & 0.23 \\
\hline & standard error & 0.31 & 0.26 & 0.28 & 0.24 & 0.24 & 0.23 & 0.22 & 0.20 \\
\hline \multicolumn{2}{|c|}{ Change in $\delta(\%)$} & $-51 \%$ & $-58 \%$ & $-57 \%$ & $-60 \%$ & $26 \%$ & $27 \%$ & $27 \%$ & $26 \%$ \\
\hline
\end{tabular}

\begin{tabular}{|c|c|c|c|c|c|c|c|c|c|}
\hline \multirow{2}{*}{\multicolumn{2}{|c|}{ Model Includes: }} & \multicolumn{4}{|c|}{ Night Ignitions } & \multicolumn{4}{|c|}{ All Ignitions } \\
\hline & & & & & & & & & \\
\hline & Mattress/RUF & IFI & IFI, IC & IFI & IFI, IC & IFI & IFI, IC & IFI & IFI, IC \\
\hline & Bedding & & & $\mathrm{IFI}$ & IFI, IC & & & $\mathrm{IFI}$ & $\mathrm{IFI}, \mathrm{IC}$ \\
\hline \multirow{2}{*}{$\ln (n)$} & value & -0.19 & 0.00 & 1.60 & 1.47 & 0.06 & 0.02 & 1.15 & 0.92 \\
\hline & standard error & 0.22 & 0.23 & 0.24 & 0.21 & 0.13 & 0.11 & 0.11 & 0.10 \\
\hline \multirow{2}{*}{$\ln (\delta)$} & value & 0.00 & 0.17 & -0.39 & -0.17 & 0.07 & 0.03 & -0.11 & -0.12 \\
\hline & standard error & 0.22 & 0.20 & 0.20 & 0.18 & 0.13 & 0.11 & 0.10 & 0.09 \\
\hline \multicolumn{2}{|c|}{ Change in $\delta(\%)$} & $0 \%$ & $18 \%$ & $-32 \%$ & $-15 \%$ & $7 \%$ & $3 \%$ & $-10 \%$ & $-11 \%$ \\
\hline
\end{tabular}

Table 31: Effect of including bedding and the item contributing most to flame spread on the number of fatalities, estimated using the variable fire department approach and the before-and-after method.

\begin{tabular}{|c|c|c|c|c|c|c|c|c|c|}
\hline & & \multicolumn{4}{|c|}{ Flaming Ignitions } & \multicolumn{4}{|c|}{ Smoking Material Ignitions } \\
\hline \multicolumn{10}{|c|}{ Model Includes: } \\
\hline & Mattress/RUF & IFI & IFI, IC & IFI & IFI, IC & IFI & IFI, IC & $\mathrm{IFI}$ & IFI, IC \\
\hline & Bedding & & & $\mathrm{IFI}$ & IFI, IC & & & $\mathrm{IFI}$ & IFI, IC \\
\hline \multirow{2}{*}{$\ln (\eta)$} & value & -0.53 & -0.54 & 0.54 & 0.52 & -0.57 & -0.47 & 0.50 & 0.37 \\
\hline & standard error & 0.47 & 0.42 & 0.41 & 0.37 & 0.26 & 0.29 & 0.40 & 0.31 \\
\hline \multirow{2}{*}{$\ln (\delta)$} & value & -2.52 & -2.86 & -2.59 & -2.45 & -0.97 & -0.86 & -0.22 & -0.22 \\
\hline & standard error & 0.98 & 0.92 & 0.73 & 0.61 & 0.42 & 0.40 & 0.36 & 0.35 \\
\hline \multicolumn{2}{|c|}{ Change in $\delta(\%)$} & $-92 \%$ & $-94 \%$ & $-93 \%$ & $-91 \%$ & $-62 \%$ & $-58 \%$ & $-19 \%$ & $-19 \%$ \\
\hline
\end{tabular}

\begin{tabular}{|c|c|c|c|c|c|c|c|c|c|}
\hline & & \multicolumn{4}{|c|}{ Night Ignitions } & \multicolumn{4}{|c|}{ All Ignitions } \\
\hline \multicolumn{2}{|c|}{ Model Includes: } & \multirow{3}{*}{ IFI } & \multirow{3}{*}{ IFI, IC } & & & \multirow{3}{*}{ IFI } & \multirow{3}{*}{ IFI, IC } & & \\
\hline & Mattress/RUF & & & IFI & IFI, IC & & & IFI & IFI, IC \\
\hline & Bedding & & & $\mathrm{IFI}$ & IFI, IC & & & IFI & IFI, IC \\
\hline \multirow{2}{*}{$\ln (n)$} & value & -0.77 & -0.71 & 0.22 & 0.21 & -0.80 & -0.71 & 0.34 & 0.30 \\
\hline & standard error & 0.30 & 0.23 & 0.27 & 0.29 & 0.20 & 0.23 & 0.23 & 0.20 \\
\hline \multirow{2}{*}{$\ln (\delta)$} & value & -0.30 & 0.06 & -0.30 & -0.02 & -0.37 & -0.32 & -0.36 & -0.35 \\
\hline & standard error & 0.39 & 0.32 & 0.32 & 0.31 & 0.26 & 0.24 & 0.22 & 0.20 \\
\hline \multicolumn{2}{|c|}{ Change in $\delta(\%)$} & $-27 \%$ & $6 \%$ & $-26 \%$ & $-2 \%$ & $-31 \%$ & $-27 \%$ & $-30 \%$ & $-30 \%$ \\
\hline
\end{tabular}


Allowing for variability in the incident reporting on the roles of the combustible by individual fire department vs. aggregating the results showed no significant effect of the calculated numbers of fires and fires that spread beyond the item or room of origin. Most of the decreases were statistically insignificant or within approximately 10 percent of each other. These results mirror the results in Tables 7 through 9.

For injuries (Table 30), flaming ignitions were the only ignition group for which there are statistically significant decreases, and these were unaffected by the roles of the combustibles. This mirrors the results in Table 10. Table 10 also shows a large increase in the number of night ignitions leading to injuries. This does not appear in Table 30, where the result is well within statistical uncertainty.

Both Table 31 and Table 11 indicate that the Standard eliminated nearly all fatalities resulting from flaming ignitions, regardless of the roles of the combustibles. Both tables also showed a sizable reduction in fatalities from smoldering ignitions of bed fires, but not bedding fires. The results in both tables for fatalities from night fires were statistically insignificant. 
Tables 32 through 36 present the results of calculations of changes in fire outcome for four different ways of including the rate at which post-Standard mattresses replaced pre-Standard mattresses. As such, the modeling behind these tables is nearly identical to that in Tables 12 through 16. The difference is that in Tables 11 through 15, the model assumed that all fire departments reported the same ratio of bed fires to control fires prior to the Standard (single value of $\eta$ ). In Tables 27 through 31, each department has an individual value of $\eta$. In all cases, $\mathrm{H}$ is the upper estimate of the total number of mattresses in use at the time of the implementation of the Standard, 304 million; L is the lower estimate, 237 million; FIFO is the first-in-first-out mattress replacement model; and EP is the random mattress replacement model.

Table 32: Effect of varying the calculation method for the replacement rate of preStandard mattresses on the number of reported ignitions, estimated using the variable-fire department approach.

\begin{tabular}{|c|c|c|c|c|c|c|c|c|c|}
\hline \multirow{2}{*}{\multicolumn{2}{|c|}{ Mattress Model: }} & \multicolumn{4}{|c|}{ Flaming Ignitions } & \multicolumn{4}{|c|}{ Smoking Material Ignitions } \\
\hline & & & & & & & & & \\
\hline & Initial No. & $\mathrm{L}$ & $\mathrm{H}$ & L & $\mathrm{H}$ & $\mathrm{L}$ & $\mathrm{H}$ & L & $\mathrm{H}$ \\
\hline & Replacement & FIFO & FIFO & EP & EP & FIFO & FIFO & EP & EP \\
\hline \multirow{2}{*}{$\ln (\eta)$} & value & 0.83 & 0.87 & 0.83 & 0.82 & 0.21 & 0.21 & 0.21 & 0.21 \\
\hline & standard error & 0.03 & 0.14 & 0.03 & 0.03 & 0.04 & 0.04 & 0.04 & 0.04 \\
\hline \multirow{2}{*}{$\ln (\psi)$} & value & -0.07 & -31.60 & -0.10 & -0.11 & 0.04 & 0.04 & 0.05 & 0.05 \\
\hline & standard error & 0.05 & & 0.07 & 0.09 & 0.06 & 0.09 & 0.08 & 0.11 \\
\hline \multicolumn{2}{|c|}{ Change in $\Psi(\%)$} & $-7 \%$ & $-100 \%$ & $-10 \%$ & $-11 \%$ & $4 \%$ & $4 \%$ & $5 \%$ & $5 \%$ \\
\hline
\end{tabular}

\begin{tabular}{|c|c|c|c|c|c|c|c|c|c|}
\hline \multirow{2}{*}{\multicolumn{2}{|c|}{ Mattress Model: }} & \multicolumn{4}{|c|}{ Night Ignitions } & \multicolumn{4}{|c|}{ All Ignitions } \\
\hline & & & & & & & & & \\
\hline & Initial No. & $\mathrm{L}$ & $\mathrm{H}$ & L & $\mathrm{H}$ & $\mathrm{L}$ & $\mathrm{H}$ & $\mathrm{L}$ & $\mathrm{H}$ \\
\hline & Replacement & FIFO & FIFO & EP & EP & FIFO & FIFO & EP & EP \\
\hline \multirow{2}{*}{$\ln (n)$} & value & 0.20 & 0.20 & 0.20 & 0.21 & 0.35 & 0.39 & 0.34 & 0.34 \\
\hline & standard error & 0.03 & 0.03 & 0.03 & 0.03 & 0.02 & 0.15 & 0.02 & 0.02 \\
\hline \multirow{2}{*}{$\ln (\psi)$} & value & 0.09 & 0.11 & 0.11 & 0.12 & 0.02 & -31.76 & 0.03 & 0.04 \\
\hline & standard error & 0.05 & 0.07 & 0.06 & 0.08 & 0.03 & & 0.03 & 0.04 \\
\hline \multicolumn{2}{|c|}{ Change in $\Psi(\%)$} & $10 \%$ & $12 \%$ & $12 \%$ & $13 \%$ & $2 \%$ & $-100 \%$ & $3 \%$ & $4 \%$ \\
\hline
\end{tabular}


Table 33: Effect of varying the calculation method for the replacement rate of preStandard mattresses on the number of fires that spread beyond the object of origin, estimated using the variable-fire-department approach.

\begin{tabular}{|c|c|c|c|c|c|c|c|c|c|}
\hline \multicolumn{2}{|c|}{ Mattress Model: } & \multicolumn{4}{|c|}{ Flaming Ignitions } & \multicolumn{4}{|c|}{ Smoking Material Ignitions } \\
\hline Mattr & $\begin{array}{l}\text { lodel: } \\
\text { Initial No. } \\
\text { Replacement }\end{array}$ & $\begin{array}{c}\mathrm{L} \\
\text { FIFO }\end{array}$ & $\begin{array}{c}\mathrm{H} \\
\text { FIFO }\end{array}$ & $\begin{array}{c}\mathrm{L} \\
\mathrm{EP}\end{array}$ & $\begin{array}{l}\mathrm{H} \\
\mathrm{EP}\end{array}$ & $\begin{array}{c}\mathrm{L} \\
\text { FIFO }\end{array}$ & $\begin{array}{c}\mathrm{H} \\
\text { FIFO }\end{array}$ & $\begin{array}{c}\mathrm{L} \\
\mathrm{EP}\end{array}$ & $\begin{array}{l}\mathrm{H} \\
\mathrm{EP}\end{array}$ \\
\hline \multirow{2}{*}{$\ln (n)$} & value & 1.02 & 1.02 & 1.03 & 1.02 & 0.45 & 0.47 & 0.45 & 0.47 \\
\hline & standard error & 0.09 & 0.08 & 0.08 & 0.09 & 0.07 & 0.09 & 0.08 & 0.08 \\
\hline \multirow{2}{*}{$\ln (\psi)$} & value & 0.06 & 0.07 & 0.05 & 0.05 & -0.14 & -0.31 & -0.20 & -0.36 \\
\hline & standard error & 0.15 & 0.21 & 0.19 & 0.25 & 0.15 & 0.24 & 0.20 & 0.31 \\
\hline \multicolumn{2}{|c|}{ Change in $\Psi(\%)$} & $6 \%$ & $7 \%$ & $5 \%$ & $5 \%$ & $-13 \%$ & $-26 \%$ & $-19 \%$ & $-30 \%$ \\
\hline
\end{tabular}

\begin{tabular}{|c|c|c|c|c|c|c|c|c|c|}
\hline \multirow{2}{*}{\multicolumn{2}{|c|}{ Mattress Model: }} & \multicolumn{4}{|c|}{ Night Ignitions } & \multicolumn{4}{|c|}{ All Ignitions } \\
\hline & & & & & & & & & \\
\hline & Initial No. & $\mathrm{L}$ & $\mathrm{H}$ & L & $\mathrm{H}$ & $\mathrm{L}$ & $\mathrm{H}$ & $\mathrm{L}$ & $\mathrm{H}$ \\
\hline \multirow{2}{*}{$\ln (\eta)$} & value & 0.40 & 0.40 & 0.39 & 0.40 & 0.61 & 0.61 & 0.61 & 0.61 \\
\hline & standard error & 0.06 & 0.07 & 0.06 & 0.08 & 0.04 & 0.04 & 0.04 & 0.04 \\
\hline $\ln (\psi)$ & value & -0.01 & -0.02 & 0.02 & -0.04 & 0.01 & 0.02 & 0.01 & 0.01 \\
\hline \multicolumn{2}{|c|}{ Change in $\Psi(\%)$} & $-1 \%$ & $-2 \%$ & $2 \%$ & $-4 \%$ & $1 \%$ & $2 \%$ & $1 \%$ & $1 \%$ \\
\hline
\end{tabular}

Table 34: Effect of varying the calculation method for the replacement rate of preStandard mattresses on the number of fires that spread beyond the room of origin, estimated using the variable-fire-department approach.

\begin{tabular}{|c|c|c|c|c|c|c|c|c|c|}
\hline & \multicolumn{4}{|c|}{ Flaming Ignitions } & \multicolumn{4}{|c|}{ Smoking Material Ignitions } \\
\hline \multicolumn{10}{|c|}{ Mattress Model } \\
\hline & Initial No. & $\mathrm{L}$ & $\mathrm{H}$ & L & $\mathrm{H}$ & $\mathrm{L}$ & $\mathrm{H}$ & L & $\mathrm{H}$ \\
\hline & Replacement & FIFO & FIFO & EP & EP & FIFO & FIFO & EP & EP \\
\hline \multirow{2}{*}{$\ln (n)$} & value & 1.02 & 1.01 & 1.02 & 1.10 & 0.38 & 0.38 & 0.38 & 0.38 \\
\hline & standard error & 0.04 & 0.04 & 0.04 & 0.14 & 0.04 & 0.05 & 0.05 & 0.05 \\
\hline \multirow{2}{*}{$\ln (\Psi)$} & value & -0.01 & -0.01 & -0.03 & -33.82 & -0.01 & -0.03 & -0.02 & -0.04 \\
\hline & standard error & 0.07 & 0.10 & 0.09 & & 0.08 & 0.12 & 0.10 & 0.14 \\
\hline \multicolumn{2}{|c|}{ Change in $\Psi(\%)$} & $-1 \%$ & $-1 \%$ & $-3 \%$ & $-100 \%$ & $-1 \%$ & $-2 \%$ & $-1 \%$ & $-4 \%$ \\
\hline
\end{tabular}

\begin{tabular}{|c|c|c|c|c|c|c|c|c|c|}
\hline & & \multicolumn{4}{|c|}{ Night Ignitions } & \multicolumn{4}{|c|}{ All Ignitions } \\
\hline \multicolumn{2}{|c|}{ Mattress Model } & & & & & & & & \\
\hline & Initial No. & L & $\mathrm{H}$ & $\mathrm{L}$ & $\mathrm{H}$ & L & $\mathrm{H}$ & $\mathrm{L}$ & $\mathrm{H}$ \\
\hline & Replacement & FIFO & FIFO & EP & EP & FIFO & FIFO & EP & EP \\
\hline \multirow{2}{*}{$\ln (\eta)$} & value & 0.41 & 0.40 & 0.40 & 0.40 & 0.55 & 0.55 & 0.55 & 0.55 \\
\hline & standard error & 0.04 & 0.04 & 0.04 & 0.04 & 0.02 & 0.02 & 0.02 & 0.02 \\
\hline \multirow{2}{*}{$\ln (\Psi)$} & value & 0.07 & 0.09 & 0.10 & 0.11 & 0.06 & 0.09 & 0.08 & 0.10 \\
\hline & standard error & 0.07 & 0.09 & 0.08 & 0.11 & 0.04 & 0.05 & 0.05 & 0.06 \\
\hline \multicolumn{2}{|c|}{ Change in $\psi(\%)$} & $7 \%$ & $9 \%$ & $10 \%$ & $11 \%$ & $6 \%$ & $9 \%$ & $8 \%$ & $11 \%$ \\
\hline
\end{tabular}


Table 35: Effect of varying the calculation method for the replacement rate of preStandard mattresses on the number of injuries, estimated using the variable-firedepartment approach.

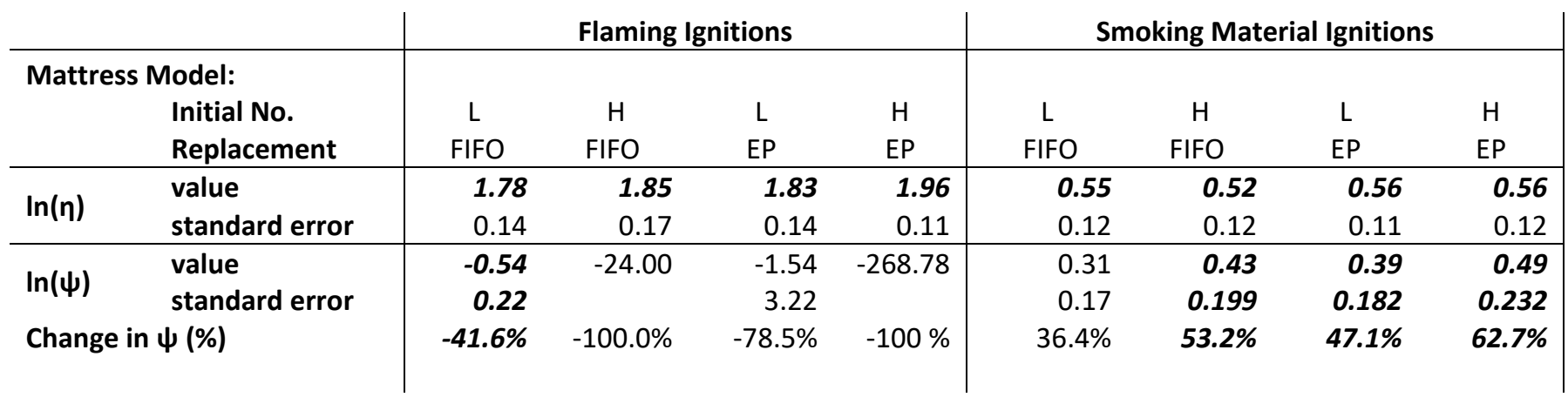

\begin{tabular}{|c|c|c|c|c|c|c|c|c|c|}
\hline \multirow{2}{*}{\multicolumn{2}{|c|}{ Mattress Model: }} & \multicolumn{4}{|c|}{ Night Ignitions } & \multicolumn{4}{|c|}{ All Ignitions } \\
\hline & & & & & & & & & \\
\hline & Initial No. & $\mathrm{L}$ & $\mathrm{H}$ & $\mathrm{L}$ & $\mathrm{H}$ & $\mathrm{L}$ & $\mathrm{H}$ & $\mathrm{L}$ & $\mathrm{H}$ \\
\hline & Replacement & FIFO & FIFO & EP & EP & FIFO & FIFO & EP & EP \\
\hline \multirow{2}{*}{$\ln (n)$} & value & 0.83 & 0.79 & 0.84 & 0.81 & 0.60 & 0.59 & 0.60 & 0.58 \\
\hline & standard error & 0.11 & 0.11 & 0.11 & 0.11 & 0.06 & 0.06 & 0.05 & 0.06 \\
\hline \multirow{2}{*}{$\ln (\psi)$} & value & 0.03 & 0.09 & 0.02 & 0.08 & -0.04 & -0.01 & -0.05 & -0.01 \\
\hline & standard error & 0.15 & 0.21 & 0.20 & 0.25 & 0.08 & 0.12 & 0.11 & 0.14 \\
\hline \multicolumn{2}{|c|}{ Change in $\Psi(\%)$} & $3.1 \%$ & $9.3 \%$ & $2.2 \%$ & $8.4 \%$ & $-3.5 \%$ & $-0.9 \%$ & $-4.9 \%$ & $-1.3 \%$ \\
\hline
\end{tabular}

Table 36: Effect of varying the calculation method for the replacement rate of preStandard mattresses on the number of fatalities, estimated using the variable-firedepartment approach.

\begin{tabular}{|c|c|c|c|c|c|c|c|c|c|}
\hline \multirow{2}{*}{\multicolumn{2}{|c|}{ Mattress Model: }} & \multicolumn{4}{|c|}{ Flaming Ignitions } & \multicolumn{4}{|c|}{ Smoking Materials Ignitions } \\
\hline & & & & & & & & & \\
\hline & Initial No. & $\mathrm{L}$ & $\mathrm{H}$ & $\mathrm{L}$ & $\mathrm{H}$ & $\mathrm{L}$ & $\mathrm{H}$ & $\mathrm{L}$ & $\mathrm{H}$ \\
\hline & Replacement & FIFO & FIFO & EP & EP & FIFO & FIFO & EP & EP \\
\hline \multirow{2}{*}{$\ln (\eta)$} & Value & 0.50 & 0.26 & 0.26 & 0.14 & 0.12 & 0.45 & 0.16 & 0.41 \\
\hline & Standard error & 0.21 & 0.15 & 0.16 & 0.18 & 0.22 & 0.24 & 0.28 & 0.15 \\
\hline $\ln (\Psi)$ & value & -321 & -319 & -309 & -302 & -0.09 & -240 & -92 & -279 \\
\hline \multicolumn{2}{|c|}{ Change in $\Psi(\%)$} & $-100 \%$ & $-100 \%$ & $-100 \%$ & $-100 \%$ & $-9 \%$ & $-100 \%$ & $-100 \%$ & $-100 \%$ \\
\hline
\end{tabular}

\begin{tabular}{|c|c|c|c|c|c|c|c|c|c|}
\hline \multicolumn{2}{|c|}{ Mattress Model: } & \multicolumn{4}{|c|}{ Night Ignitions } & \multicolumn{4}{|c|}{ All Ignitions } \\
\hline Mattr & $\begin{array}{l}\text { lodel: } \\
\text { Initial No. } \\
\text { Replacement }\end{array}$ & $\begin{array}{l}\text { L } \\
\text { FIFO }\end{array}$ & $\begin{array}{c}\mathrm{H} \\
\text { FIFO }\end{array}$ & $\begin{array}{c}\mathrm{L} \\
\mathrm{EP}\end{array}$ & $\begin{array}{l}\mathrm{H} \\
\mathrm{EP}\end{array}$ & $\begin{array}{l}\text { L } \\
\text { FIFO }\end{array}$ & $\begin{array}{c}\mathrm{H} \\
\text { FIFO }\end{array}$ & $\begin{array}{c}\mathrm{L} \\
\mathrm{EP}\end{array}$ & $\begin{array}{l}\mathrm{H} \\
\mathrm{EP}\end{array}$ \\
\hline \multirow{2}{*}{$\ln (n)$} & value & 0.04 & 0.30 & 0.05 & 0.29 & -0.01 & 0.17 & 0.02 & 0.21 \\
\hline & standard error & 0.19 & 0.20 & 0.20 & 0.13 & 0.12 & 0.19 & 0.15 & 0.09 \\
\hline $\ln (\psi)$ & $\begin{array}{l}\text { value } \\
\text { standard error }\end{array}$ & $\begin{array}{r}-0.19 \\
0.30\end{array}$ & -160 & -29 & -302 & $\begin{array}{r}-0.36 \\
0.20\end{array}$ & -119 & -31 & -301 \\
\hline \multicolumn{2}{|c|}{ Change in $\Psi(\%)$} & $-17 \%$ & $-100 \%$ & $-100 \%$ & $-100 \%$ & $-30 \%$ & $-100 \%$ & $-100 \%$ & $-100 \%$ \\
\hline
\end{tabular}


For the effect of the mattress replacement rate on the number of reported fires, there are no statistically significant decreases in either Table 12 or Table 321 . The same is true for fires that spread beyond the item of origin (Tables 13 and 33) and fires that spread beyond the room of fire origin (Tables 14 and 34).

There are large increases in fire injuries for smoking material ignitions in Tables 15 and 35. These increases are the largest for the mattress replacement models that are the slowest. This indicates that there are additional factors that decrease the number of other fires more than bed and RUF fires. There are no other statistically significant decreases in Table 15 and only one in Table 35. This shows a large decrease in injuries from flaming ignitions.

The results in Table 36 might suggest a virtual elimination of fatalities from all ignition sources, but the individual values are all statistically insignificant. At best, this provides support for the pair of near-total decreases in fatalities from flaming ignitions in Table 16. 


\section{D.5 Per-Bed-Fire Models}

Tables 37 and 38 present the results of calculations of numbers of fire outcomes normalized to the number of bed fires. Thus, the results indicate the degree of change in the severity of bed fires in which (a) the mattress was identified as the item contributing most to fire spread (IC) and (b) whether bedding was identified as the item first ignited (IFI) and/or the item most contributing to fire spread.

Table 37: Effect of including bedding and the item contributing most to flame spread on the numbers of injuries per bed fire, estimated using the before-and-after method.

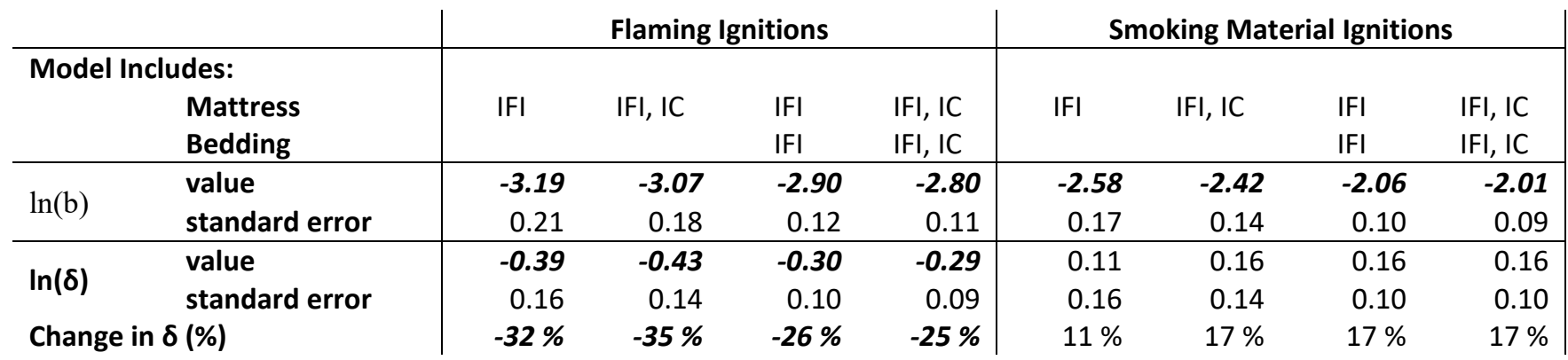

\begin{tabular}{|c|c|c|c|c|c|c|c|c|c|}
\hline & & \multicolumn{4}{|c|}{ Night Ignitions } & \multicolumn{4}{|c|}{ All Ignitions } \\
\hline Mode & $\begin{array}{l}\text { Ides: } \\
\text { Mattress } \\
\text { Bedding }\end{array}$ & IFI & IFI, IC & $\begin{array}{l}\text { IFI } \\
\text { IFI }\end{array}$ & $\begin{array}{l}\text { IFI, IC } \\
\text { IFI, IC }\end{array}$ & IFI & IFI, IC & $\begin{array}{l}\text { IFI } \\
\text { IFI }\end{array}$ & $\begin{array}{l}\text { IFI, IC } \\
\text { IFI, IC }\end{array}$ \\
\hline \multirow{2}{*}{$\ln (b)$} & value & -2.88 & -2.11 & -2.46 & -2.40 & -2.95 & -2.83 & -2.64 & -2.56 \\
\hline & standard error & 0.18 & 0.09 & 0.10 & 0.09 & 0.10 & 0.09 & 0.06 & 0.06 \\
\hline \multirow{2}{*}{$\ln (\delta)$} & value & 0.15 & 0.19 & -0.11 & -0.04 & 0.05 & 0.04 & 0.01 & 0.02 \\
\hline & standard error & 0.14 & 0.12 & 0.09 & 0.08 & 0.08 & 0.07 & 0.05 & 0.05 \\
\hline \multicolumn{2}{|c|}{ Change in $\delta(\%)$} & $16 \%$ & $21 \%$ & $-10 \%$ & $-4 \%$ & $5 \%$ & $4 \%$ & $1 \%$ & $2 \%$ \\
\hline
\end{tabular}


Table 38: Effect of including bedding and the item contributing most to flame spread on the numbers of fatalities per bed fire, estimated using the before-and-after method.

\begin{tabular}{|c|c|c|c|c|c|c|c|c|c|}
\hline & & \multicolumn{4}{|c|}{ Flaming Ignitions } & \multicolumn{4}{|c|}{ Smoking Material Ignitions } \\
\hline \multicolumn{2}{|c|}{ Model Includes: } & \multirow{3}{*}{ IFI } & \multirow{3}{*}{ IFI, IC } & \multirow{3}{*}{$\begin{array}{l}\mathrm{IFI} \\
\mathrm{IFI}\end{array}$} & \multirow{3}{*}{$\begin{array}{l}\text { IFI, IC } \\
\text { IFI, IC }\end{array}$} & \multirow{3}{*}{ IFI } & \multirow{3}{*}{ IFI, IC } & \multirow{3}{*}{$\begin{array}{l}\text { IFI } \\
\text { IFI }\end{array}$} & \multirow{3}{*}{$\begin{array}{l}\text { IFI, IC } \\
\text { IFI, IC }\end{array}$} \\
\hline & Mattress/RUF & & & & & & & & \\
\hline & Bedding & & & & & & & & \\
\hline \multirow{2}{*}{$\ln (\mathrm{b})$} & value & -11.09 & -11.04 & -9.82 & -4.77 & -4.70 & -4.60 & -4.43 & -4.34 \\
\hline & standard error & 1.47 & 1.38 & 0.79 & 0.19 & 0.52 & 0.46 & 0.32 & 0.29 \\
\hline \multirow{2}{*}{$\ln (\delta)$} & value & -0.92 & -1.36 & -1.20 & -1.12 & -0.58 & -0.39 & 0.20 & 0.21 \\
\hline & standard error & 1.19 & 1.13 & 0.63 & 0.45 & 0.40 & 0.35 & 0.21 & 0.20 \\
\hline \multirow{2}{*}{\multicolumn{2}{|c|}{ Change in $\delta(\%)$}} & $-60 \%$ & $-74 \%$ & $-70 \%$ & $-67 \%$ & $-44 \%$ & $-32 \%$ & $22 \%$ & $23 \%$ \\
\hline & & \multicolumn{4}{|c|}{ Night Ignitions } & \multicolumn{4}{|c|}{ All Ignitions } \\
\hline \multicolumn{2}{|c|}{ Model Includes: } & \multirow{3}{*}{ IFI } & \multirow{3}{*}{ IFI, IC } & & & \multirow{3}{*}{ IFI } & \multirow{3}{*}{ IFI, IC } & & \\
\hline & Mattress/RUF & & & IFI & IFI, IC & & & IFI & IFI, IC \\
\hline & Bedding & & & IFI & IFI, IC & & & IFI & IFI, IC \\
\hline \multirow{2}{*}{$\ln (\mathrm{b})$} & value & -7.83 & -3.72 & -7.24 & -6.91 & -4.12 & -7.97 & -7.05 & -6.32 \\
\hline & standard error & 0.71 & 0.19 & 0.55 & 0.53 & 0.13 & 0.47 & 0.38 & 0.48 \\
\hline \multirow{2}{*}{$\ln (\delta)$} & value & -0.07 & 0.21 & 0.31 & 0.38 & -0.18 & -0.03 & 0.14 & 0.16 \\
\hline & standard error & 0.44 & 0.26 & 0.25 & 0.22 & 0.21 & 0.22 & 0.14 & 0.13 \\
\hline \multicolumn{2}{|c|}{ Change in $\delta(\%)$} & $-7 \%$ & $23 \%$ & $36 \%$ & $47 \%$ & $-16 \%$ & $-3 \%$ & $15 \%$ & $17 \%$ \\
\hline
\end{tabular}

The flaming ignition group is the only one that shows any statistically significant effect of the roles of mattresses and bedding on fire severity.

- Fires involving post-Standard mattresses were distinctly less likely to lead to injuries, compared to fires involving pre-Standard mattresses (Table 37). This is consistent with Tables 1 through 4.

- It appears that the effect of the participation of bedding being reported is not very important in the likelihood of injuries. Fires involving post-Standard mattresses, and having a reported role for bedding, were distinctly less likely to lead to fatalities, compared to fires involving pre-Standard mattresses. This is also consistent with Tables 1 through 4.

- The observation for fatalities may well extend to fires with no reported role of bedding, but there are too few incidents for the calculation to generate statistically significant results. 
Tables 39 and 40 present the results of calculations of numbers of fire outcomes normalized to the number of bed fires, in which the rate of mattress replacement is included in the calculations. $\mathrm{H}$ is the upper estimate of the total number of mattresses in use at the time of the implementation of the Standard, 304 million; L is the lower estimate, 237 million; FIFO is the first-in-first-out mattress replacement model; and EP is the random mattress replacement model.

Table 39: Effect of varying the calculation method for the replacement rate of preStandard mattresses on the number of injuries per bed fire, estimated using the per-bedfire approach.

\begin{tabular}{|c|c|c|c|c|c|c|c|c|c|}
\hline & & \multicolumn{4}{|c|}{ Flaming Ignitions } & \multicolumn{4}{|c|}{ Smoking Material Ignitions } \\
\hline \multicolumn{10}{|c|}{ Mattress Model } \\
\hline & Initial No. & $\mathrm{L}$ & $\mathrm{H}$ & $\mathrm{L}$ & $\mathrm{H}$ & L & $\mathrm{H}$ & $\mathrm{L}$ & $\mathrm{H}$ \\
\hline & Replacement & FIFO & FIFO & EP & EP & FIFO & FIFO & EP & EP \\
\hline \multirow{2}{*}{$\ln (b)$} & value & -1.86 & -1.86 & -1.87 & -1.87 & -1.65 & -1.65 & -1.67 & -1.67 \\
\hline & standard error & 0.04 & 0.04 & 0.04 & 0.04 & 0.05 & 0.05 & 0.05 & 0.05 \\
\hline \multirow{2}{*}{$\ln (\Psi)$} & value & -0.27 & -0.37 & -0.31 & -0.42 & 0.18 & 0.22 & 0.27 & 0.30 \\
\hline & standard error & 0.08 & 0.12 & 0.13 & 0.17 & 0.09 & 0.11 & 0.11 & 0.13 \\
\hline \multicolumn{2}{|c|}{ Change in $\Psi(\%)$} & $-24 \%$ & $-31 \%$ & $-27 \%$ & $-34 \%$ & $19 \%$ & $25 \%$ & $31 \%$ & $36 \%$ \\
\hline
\end{tabular}

\begin{tabular}{|c|c|c|c|c|c|c|c|c|c|}
\hline \multicolumn{2}{|c|}{ 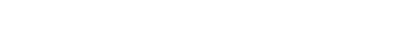 } & \multicolumn{4}{|c|}{ Night Ignitions } & \multicolumn{4}{|c|}{ All Ignitions } \\
\hline \multicolumn{10}{|c|}{ Mattress Model } \\
\hline & Initial No. & $\mathrm{L}$ & $\mathrm{H}$ & $\mathrm{L}$ & $\mathrm{H}$ & $\mathrm{L}$ & $\mathrm{H}$ & $\mathrm{L}$ & $\mathrm{H}$ \\
\hline & Replacement & FIFO & FIFO & EP & EP & FIFO & FIFO & EP & EP \\
\hline \multirow{2}{*}{$\ln (\mathrm{b})$} & value & -1.59 & -1.59 & -1.59 & -1.59 & -1.93 & -1.93 & -1.95 & -1.94 \\
\hline & standard error & 0.04 & 0.04 & 0.04 & 0.04 & 0.02 & 0.02 & 0.02 & 0.02 \\
\hline \multirow{2}{*}{$\ln (\psi)$} & value & -0.21 & -0.28 & -0.26 & -0.34 & -0.05 & -0.07 & -0.03 & -0.05 \\
\hline & standard error & 0.08 & 0.11 & 0.12 & 0.15 & 0.05 & 0.06 & 0.06 & 0.08 \\
\hline \multicolumn{2}{|c|}{ Change in $\Psi(\%)$} & $-19 \%$ & $-24 \%$ & $-23 \%$ & $-29 \%$ & $-4.8 \%$ & $-6.4 \%$ & $-2.9 \%$ & $-5.0 \%$ \\
\hline
\end{tabular}


Table 40: Effect of varying the calculation method for the replacement rate of pre-Standard mattresses on the number of fatalities per bed fire, estimated using the per-bed-fire approach.

\begin{tabular}{|c|c|c|c|c|c|c|c|c|c|}
\hline & & \multicolumn{4}{|c|}{ Flaming Ignitions } & \multicolumn{4}{|c|}{ Smoking Material Ignitions } \\
\hline Mattr & $\begin{array}{l}\text { Model } \\
\text { Initial No. } \\
\text { Replacement }\end{array}$ & $\begin{array}{c}\mathrm{L} \\
\text { FIFO }\end{array}$ & $\begin{array}{c}\mathrm{H} \\
\text { FIFO }\end{array}$ & $\begin{array}{c}\mathrm{L} \\
\mathrm{EP}\end{array}$ & $\begin{array}{l}\mathrm{H} \\
\mathrm{EP}\end{array}$ & $\begin{array}{c}\mathrm{L} \\
\text { FIFO }\end{array}$ & $\begin{array}{c}\mathrm{H} \\
\text { FIFO }\end{array}$ & $\begin{array}{c}\mathrm{L} \\
\mathrm{EP}\end{array}$ & $\begin{array}{l}\mathrm{H} \\
\mathrm{EP}\end{array}$ \\
\hline \multirow{2}{*}{$\ln (\mathrm{b})$} & value & -4.54 & -4.53 & -4.53 & -4.53 & -3.24 & -3.25 & -3.26 & -3.25 \\
\hline & standard error & 0.13 & 0.13 & 0.14 & 0.13 & 0.10 & 0.10 & 0.11 & 0.11 \\
\hline \multirow{2}{*}{$\ln (\Psi)$} & value & -0.63 & -0.93 & -0.90 & -1.28 & 0.16 & 0.21 & 0.24 & 0.27 \\
\hline & standard error & 0.38 & 0.66 & 0.71 & 1.14 & 0.19 & 0.23 & 0.26 & 0.29 \\
\hline \multicolumn{2}{|c|}{ Change in $\Psi(\%)$} & $-46 \%$ & $-61 \%$ & $-59 \%$ & $-72 \%$ & $18 \%$ & $24 \%$ & $27 \%$ & $31 \%$ \\
\hline
\end{tabular}

\begin{tabular}{|c|c|c|c|c|c|c|c|c|c|}
\hline \multicolumn{2}{|c|}{ Mattress Model } & \multicolumn{4}{|c|}{ Night Ignitions } & \multicolumn{4}{|c|}{ All Ignitions } \\
\hline Mattr & $\begin{array}{l}\text { Model } \\
\text { Initial No. } \\
\text { Replacement }\end{array}$ & $\begin{array}{l}\mathrm{L} \\
\text { FIFO }\end{array}$ & $\begin{array}{c}\mathrm{H} \\
\text { FIFO }\end{array}$ & $\begin{array}{l}\mathrm{L} \\
\mathrm{EP}\end{array}$ & $\begin{array}{l}\mathrm{H} \\
\mathrm{EP}\end{array}$ & $\begin{array}{l}\mathrm{L} \\
\text { FIFO }\end{array}$ & $\begin{array}{c}\mathrm{H} \\
\text { FIFO }\end{array}$ & $\begin{array}{c}\mathrm{L} \\
\mathrm{EP}\end{array}$ & $\begin{array}{l}\mathrm{H} \\
\mathrm{EP}\end{array}$ \\
\hline \multirow{2}{*}{$\ln (\mathrm{b})$} & value & -3.51 & -3.51 & -3.51 & -3.51 & -3.99 & -3.99 & -3.99 & -3.99 \\
\hline & standard error & 0.09 & 0.09 & 0.10 & 0.10 & 0.06 & 0.06 & 0.07 & 0.06 \\
\hline \multirow{2}{*}{$\ln (\psi)$} & value & 0.09 & 0.12 & 0.11 & 0.13 & 0.04 & 0.05 & 0.04 & 0.05 \\
\hline & standard error & 0.17 & 0.22 & 0.24 & 0.28 & 0.12 & 0.15 & 0.17 & 0.19 \\
\hline \multicolumn{2}{|c|}{ Change in $\Psi(\%)$} & $10 \%$ & $12 \%$ & $11 \%$ & $14 \%$ & $4 \%$ & $5 \%$ & $4 \%$ & $5 \%$ \\
\hline
\end{tabular}

Fires involving flaming ignition of post-Standard mattresses were significantly less likely to lead to injuries, compared to fires involving pre-Standard mattresses. This is consistent with Tables 1 through 4. Nighttime ignitions were also less likely lead to fatalities. For both ignition categories, there was no significant dependence of the results on the mattress replacement model.

Fires involving ignition by smoking materials of post-Standard mattresses were significantly more likely to lead to injuries, compared to fires involving pre-Standard mattresses. The fastest replacement model (FIFO, L) appears to lead to the smallest increase in injuries.

An interesting observation is that the aggregated effect (All Ignitions) shows no significant change in overall fire severity. This points out the value in examining the subsets of the fire incidence data.

None of the calculations of the increase in fatalities yielded statistically significant results. The data subsets were just too small. This points out the limitation of trying to examine the fine structure of the database. 